\title{
Morphological phylogenetic analyses and taxonomic revi- sion of the Panorpa davidi group (Mecoptera: Panorpidae)
}

\author{
Ning Li ${ }^{1}$, Ji-Shen Wang ${ }^{1}$, Bao-Zhen Hua ${ }^{1}$ \\ 1 Entomological Museum, College of Plant Protection, Northwest A\&F University, Yangling, Shaanxi 712100, China; Ning Li [liningning@ \\ nwafu.edu.cn]; Ji-Shen Wang [wangjishen826@gmail.com]
}

http://zoobank.org/E4C130CF-221E-4C43-BC7B-D1083120CFD9

Corresponding author: Bao-Zhen Hua, College of Plant Protection, Northwest A\&F University, Yangling, Shaanxi 712100, China. Tel. +86-2987082430 (huabzh@nwafu.edu.cn)

$\begin{array}{ll}\text { Received } & 28 \text { February } 2021 \\ \text { Accepted } & 10 \text { June } 2021 \\ \text { Published } & 15 \text { July } 2021\end{array}$

Academic Editor Bradley Sinclair

Citation: Li N, Wang JS and Hua BZ (2021) Morphological phylogenetic analyses and taxonomic revision of the Panorpa davidi group (Mecoptera: Panorpidae). Arthropod Systematics \& Phylogeny 79: 309-342. https://doi.org/10.3897/asp.79.e65179

\begin{abstract}
The Chinese Panorpa species without anal horn are normally assigned to the Panorpa davidi group. Here, we taxonomically revise the $P$. davidi group, which currently includes 17 known species and four new species: $P$. gaokaii sp. nov., $P$. huayuani sp. nov., $P$. uncinata sp. nov. and P. yaoluopingensis sp. nov. Panorpa shanyangensis Chou \& Wang, 1981 and P. sexspinosa zhongnanensis Chou \& Ran, 1981 are treated as junior synonyms of $P$. sexspinosa Cheng, 1949. We describe for the first time the male of $P$. stigmosa Zhou, 2006, and the females of P. curva Carpenter, 1938, P. davidi Navás, 1908, P. difficilis Carpenter, 1938, P. fructa Cheng, 1949, and $P$. jinchuana Hua, Sun \& Li, 2001. A key to species of the group is provided. Phylogenetic analyses of maximum parsimony and maximum likelihood based on 79 morphological characters show that the newly defined $P$. davidi group is a well-supported monophyletic group and is sister to the genus Cerapanorpa Gao, Ma \& Hua, 2016.
\end{abstract}

\section{Key words}

Oriental Region, Panorpa, phylogeny, synonym, taxonomy

\section{Introduction}

Panorpidae, the largest family of Mecoptera, consist of approximately 500 extant species in eight genera (Gao and Hua 2019; Wang et al. 2019; Hu and Hua 2020). The genus Panorpa Linnaeus, 1758 is the largest taxon in Panorpidae, comprising approximately 270 extant species widely distributed in Asia, Europe, and North America (Esben-Petersen 1921; Wang et al. 2019). Panorpa has been confirmed to be paraphyletic based on molecular data (Whiting 2002; Hu et al. 2015; Miao et al. 2019) and morphological characters (Willmann 1989; Ma et al.
2012; Wang and Hua 2020), and needs continued taxonomic revision.

The species of Panorpa are divided into various species groups for local faunas based on different morphological criteria (Esben-Petersen 1921; Carpenter 1931, 1938; Issiki 1933; Cheng 1957; Willmann 1977; Byers 1993). The European species are divided into three groups (Willmann 1977). The North American species are categorized into three (Carpenter 1931) or four groups (Byers 1993). The Japanese-East Asiatic species are cat- 
egorized into four (Esben-Petersen 1921) or nine groups (Issiki 1933). Based on the number of anal horns on the posterior margin of tergum VI in males, the Chinese fauna is assigned to three species groups: the $P$. davidi group (without anal horn), the $P$. centralis group (with a single anal horn), and the $P$. diceras group (with two anal horns) (Carpenter 1938; Cheng 1957). The P. diceras and $P$. centralis groups have been raised to generic status as Dicerapanorpa Zhong \& Hua, 2013 and Cerapanorpa Gao, Ma \& Hua, 2016, respectively. Another genus, Sinopanorpa Cai \& Hua, 2008 is established for P. tincta Navás, 1931 and related species, former members of the P. davidi group (Cai et al. 2008).

The $P$. davidi group is considerably diverse in morphology (Ma et al. 2009, 2011, 2012; Jiang et al. 2019; Miao et al 2019). Their eggs differ mainly in the ridges of the extrachorion, protuberances within the cells and arranged pattern of the pole area (Ma et al. 2009). Male salivary glands are varied markedly in the number and shape of secretory tubes (Ma et al. 2011). The female genitalia vary distinctly in the developed degree of the main plate and axis; the relative length of the main plate and posterior arm; and the number, shape and position of the basal plates among species (Ma et al. 2012). The first-instar larvae exhibit prominent differences in chaetotaxy on the head and body (Cai and Hua 2009; Jiang and Hua 2013, 2016; Jiang et al. 2019). Morphological and molecular phylogenetic analyses suggest that the $P$. davidi group is paraphyletic (Ma et al. 2012; Hu et al. 2015; Miao et al. 2019). Therefore, a taxonomic revision is urgently needed.

In this study, we present a taxonomic revision of the $P$. davidi group, propose two new synonyms and describe for the first time the male of one species and females of five species. Four species are described as new to science. A key to species of the $P$. davidi group is provided. Phylogenetic analyses of the $P$. davidi group were conducted using maximum parsimony and maximum likelihood based on morphological characters.

\section{Material and methods}

\section{Taxonomy}

More than 1000 adult specimens in the $P$. davidi group were examined. The specimens are mainly stored in the Entomological Museum, Northwest A\&F University, China (NWAU), except $P$. jinchuana Hua, Sun \& Li, 2001 in the Tianjin Natural History Museum, China (TJNH). Specimens were dissected under a Nikon SMZ 1500 Stereoscopic Zoom microscope. Wings were measured with a vernier caliper. Male aedeagal complex and female medigynia were macerated in cold $5 \% \mathrm{NaOH}$ for 5 min. Pictures of adult habitus were taken with a Canon EOS 70D digital camera, and pictures of dissections were taken using an advanced Stereo Microscope System (Discovery V20, Zeiss; an auto-montage imaging system
Axio ICc5). Photographs were assembled and annotated with Adobe Photoshop CS6. Detailed illustrations are provided for new species, known species whose male or female are described for the first time, and P. sexspinosa with new synonyms.

Terminology follows Willmann (1989) and Wang and Hua (2020). The following acronyms are used in the main text: A1 -abdominal segment I (and so forth for other segments); T1 -tergum I (and so forth for other terga); FL - forewing length; FW - forewing width; HL hindwing length; HW - hindwing width. The following abbreviations are used in figures: ax - axis; bst - basal stalk; ce - cercus; $\mathbf{d p}$ - dorsal process; $\mathbf{d v}$ - dorsal valve; ep - epandrium; gcx - gonocoxite; gs - gonostylus; hv hypovalve; lbp - lateral basal plate; lp - lateral process; mp - main plate; no - notal organ; pa - posterior arm; pm - paramere; pno - postnotal organ; sgp - subgenital plate; stp - stalk of paramere; vv - ventral valve.

\section{Phylogenetic analyses}

Phylogenetic trees were reconstructed using maximum parsimony (MP) and maximum likelihood (ML). A total of 38 species were selected for character coding and phylogenetic analyses, including 21 species of the $P$. davi$d i$ group, five species of other Chinese Panorpa without anal horn, $P$. communis Linnaeus, 1758 (the type species of Panorpa) and its closely related species $P$. sibirica Esben-Petersen, 1915, ten species of other genera of Panorpidae. Panorpodes kuandianensis Zhong, Zhang \& Hua, 2011 in Panorpodidae was selected as outgroup. A data matrix containing 79 characters coded for 39 taxa was created using Mesquite v. 3.61 (Tables S1-S2) (Maddison and Maddison 2019).

All characters were equally weighted. Traditional search with 100 replications was conducted with TNT 1.1 (Goloboff et al. 2008). Bremer support values (BR) (Bremer 1994) and bootstrap support (MPBS) values (Felsenstein 1985) were calculated with TNT. The unambiguous characters were mapped on the most parsimonious tree and the strict consensus tree using WinClada version 1.00.08 (Nixon 2002). The ML analysis was performed with IQ-TREE (Nguyen et al. 2015) under Ultrafast bootstrap. Bootstrap support (MLBS) values were evaluated with 5000 replicates.

\section{Results}

\section{Panorpa davidi group Esben-Petersen, 1921}

Panorpa davidi group Esben-Petersen, 1921: 14; Carpenter, 1938: 268; Cheng, 1957: 5.

Emended diagnosis. The Panorpa davidi group can be differentiated from other groups of Panorpa by the following features: in males, (1) flat notal organ on posterior 


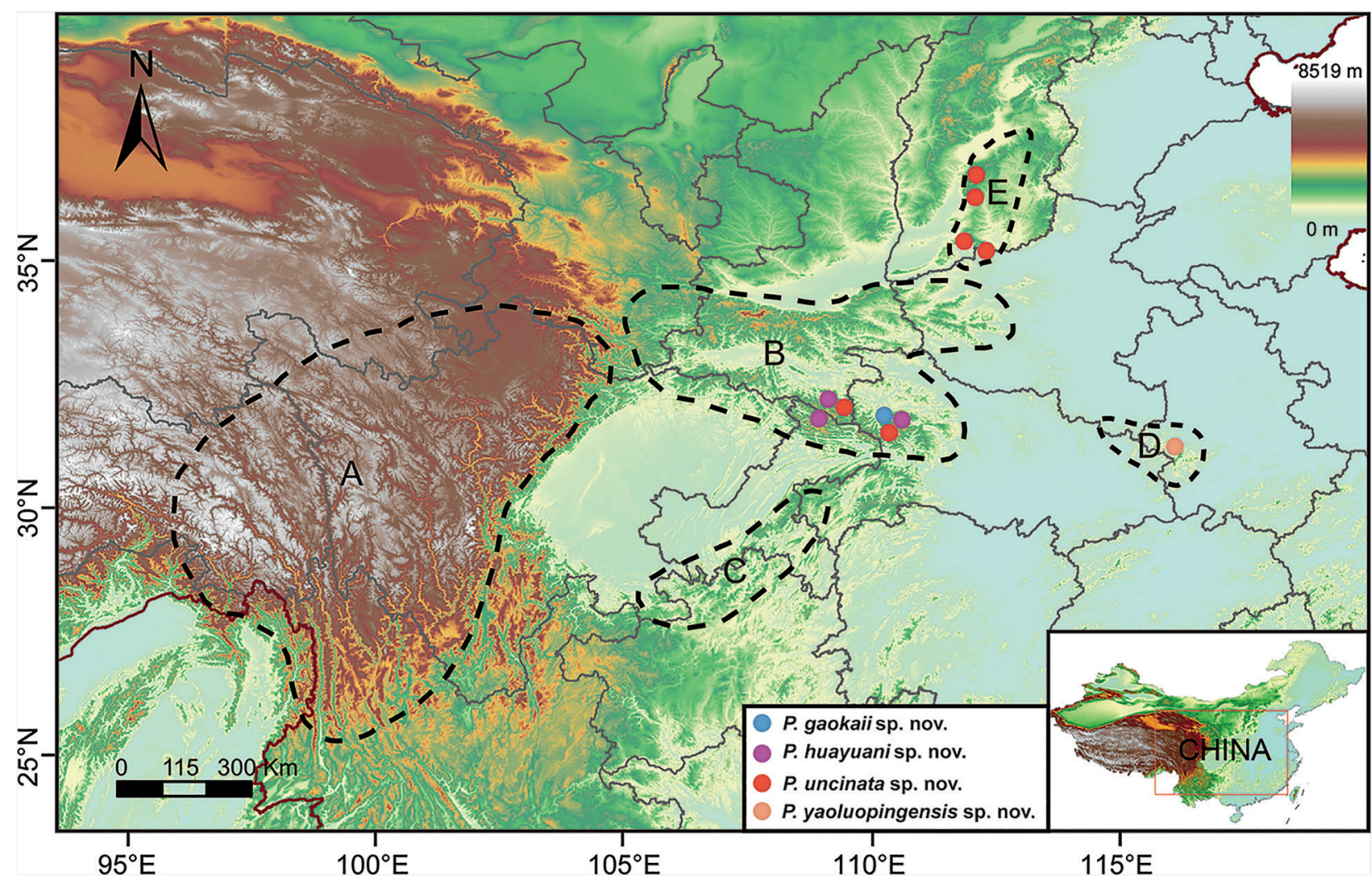

Figure 1. Main distribution range of the Panorpa davidi group. A. Hengduan Mountains. B. Qinling-Bashan Mountains. C. Dalou Mountains. D. Dabie Mountains. E. Taihang Mountains.

margin of T3 covering acute postnotal organ on anterior portion of T4; (2) A6 cylindrical, lacking anal horns, mostly projected and setose on dorsal apex; (3) gonostylus with obtuse triangular median tooth and large basal cup on inner margin, (4) elongated dorsal valves of aedeagus with enlarged dorsal processes; and (5) parameres simple, unfurcated, elongated, mostly twisted and crossed mesally; in females, (6) medigynium elongated, broad, with posterior arms distinctly shorter than main plate; and (7) paired lateral basal plates mostly well-developed.

Distribution. Species of the $P$. davidi group are distributed in the mountainous regions of China, mainly in the Hengduan, Qinling-Bashan, Dalou, Dabie and Taihang mountains (Fig. 1).
Remarks. The $P$. davidi group was proposed by Esben-Petersen (1921) to contain P. sibirica and $P$. davidi. Martynova (1957) later transferred $P$. sibirica to the P. communis group. According to Carpenter (1938) and Cheng (1957), this species group consisted of 19 Chinese species of Panorpa without anal horn on the posterior margin of T6 in males. Of these, Panorpa tincta Navás, 1931 was transferred to Sinopanorpa (Cai et al. 2008), and 12 species that differ remarkably from $P$. davidi are herein removed from this group. In this paper, 21 species are recognized in the newly defined $P$. davidi group, including 17 known species and four new species.

\section{Key to species of the Panorpa davidi group (males)}

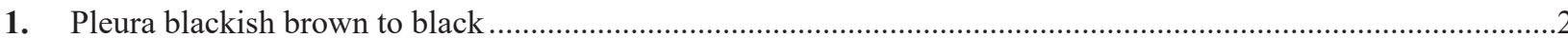

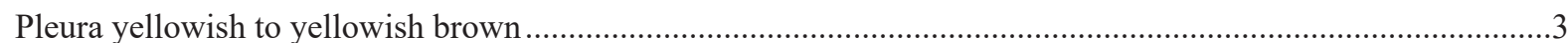

2. Forewings with apical band splitting into a series of small spots; pterostigmal band complete anteriorly, with discrete basal branch and faint apical branch posteriorly; basal band split into two spots; marginal spot prominent; basal spot greatly reduced (Figs 10B, 11A)....

P. fructa Cheng, 1949

- $\quad$ Forewings with pterostigmal band usually reduced, basal and apical branches absent; apical band indistinct and extremely reduced (Fig. 8B)

P. diqingensis Li \& Hua, 2020

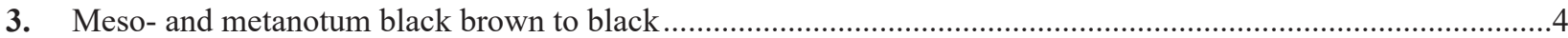

- $\quad$ Meso- and metanotum black with yellow mesal stripe or mostly yellow, only darker laterally ............................6

4. Wings without markings ......................................................................................... curvata Zhou, 2006

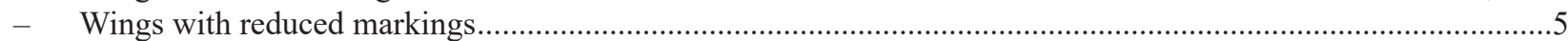

5. Gonocoxites bearing 3-5 long setae, with acute protuberance on inner apex (Fig. 21G) ...P. stigmosa Zhou, 2006 
- $\quad$ Gonocoxites with cluster of stout dark brown setae and 3-5 long setae along oblique inner apex ventrally; without acute protuberance (Fig. 9B)

6. Wing with $1 \mathrm{~A}$ ending before or at level of origin of Rs

Wing with $1 \mathrm{~A}$ ending beyond origin of Rs

7. Wing with $1 \mathrm{~A}$ ending before origin of Rs (Fig. 2C)

P. bashanicola Hua, Tao \& Hua, 2018

- Wing with $1 \mathrm{~A}$ ending at level of origin of Rs

8. Wings tinged with yellow, markings yellowish brown, reduced; parameres stout, extending nearly to apex of gonocoxites (Fig. 12B)......

P. fulvastra Chou, 1981

- Wing membrane hyaline, without markings; parameres slender, intensely curved, reaching middle of aedeagus (Fig. 3B)

9. Meso- and metanotum pale brown, with broad pale to pale yellow mesal stripe, extending to T3 (Figs 13B, 14A) ......................................................................................................................... gaokaii sp. nov. Meso- and metanotum blackish brown to black, with yellow mesal stripe only extending to scutellum.............10

10. Parameres greatly curved, hook-like on apical half, reaching two-thirds of gonocoxites ...................................11

- Parameres thick, nearly twisted in S-shape, exceeding or reaching apex of gonocoxites ...................................12

11. Meso- and metanotum with extremely broad yellow mesal stripe; basal spot large and conspicuous

P. yangi Chou, 1981

- $\quad$ Meso- and metanotum with narrow yellow mesal stripe; basal spots extremely reduced and faint (Fig. 22A)........

12. Gonocoxites with process on inner margin of ventral apex.

P. uncinata sp. nov.

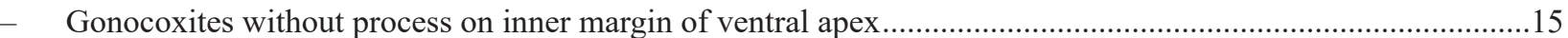

13. Gonocoxites with normal triangular process on inner apex, bearing 1 or 2 long setae on inner margin subapically P. qinlingensis Chou \& Ran, 1981

Gonocoxites with elongated process on inner apex, bearing short setae

14. Forewings with basal band split into two large spots; basal spot reduced (Fig. 5A) .................................................... Navâs, 1908

- $\quad$ Forewings with basal band complete; basal spot absent (Fig. 4A) .....................................P. curva Carpenter, 1938

15. Forewing with basal band reduced into middle spot, extending from $\mathrm{M}$ to anal margin (Fig. 23A) ......

P. yaoluopingensis sp. nov.

Forewing with broad basal band complete or split into two spots.

16. Dorsal valves of aedeagus slender and stalked, each with intensively enlarged circular dorsal process on apical portion (Fig. 7G)

P. difficilis Carpenter, 1938

- Dorsal process of aedeagus not extending to apical portion of dorsal valves.....................................................17

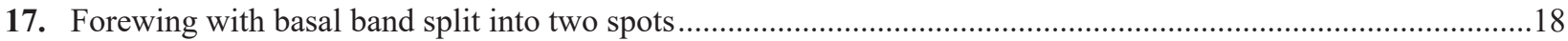

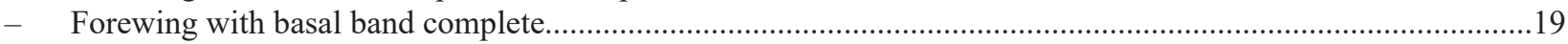

18. Hypovalves slightly broadened towards rounded apexes .........................................P. typicoides Cheng, 1949

- Hypovalves with apical third widest, then tapered towards apex (Fig. 17E)..... P. jinchuana Hua, Sun \& Li, 2001

19. Forewings without basal spot (Figs 18B, 19A) ........................................................ P. sexspinosa Cheng, 1949

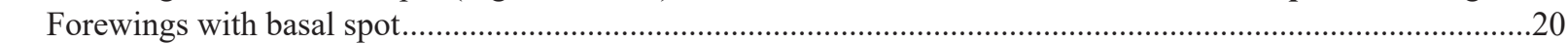

20. Gonocoxites bearing 4-5 setae on inner apex ventrally, with triangular emarginated subapical portion (Fig. 16G) P. huayuani sp. nov.

- $\quad$ Gonocoxites bearing 4-7 (usually 6) long setae along beveled inner apex ventrally, without triangular emarginated subapical portion. P. neospinosa Chou \& Wang, 1981

\section{Taxonomy}

\section{Panorpa bashanicola Hua, Tao \& Hua, 2018}

Fig. 2

Panorpa bashanicola Hua, Tao \& Hua, 2018: 111, figs 1-6. Type locality: Nangongshan, Bashan Mountains, Lan'gao County, Shaanxi, China.

Diagnosis. This species can be recognized by the following features: (1) occiput black, with two pale submedian stripes and two eye-shaped speckles on lateral regions;
(2) wing membrane hyaline, pterostigma prominent yellow, almost without markings (Fig. 2C-D); (3) $1 \mathrm{~A}$ ending before origin of Rs (Fig. 2C); (4) meso- and metanotum pale with yellowish brown laterally, and pale color extending to $\mathrm{T} 3$ in $\mathrm{V}$-shape (Fig. 2C); in males, (5) inner apex of gonocoxite bearing 3-6 long black bristles; (6) parameres crossed, twisted in S-shape, reaching apex of gonocoxites; in females, (7) medigynium with main plate twice as long as wide; a pair of small lateral basal plates near middle; axis extending beyond main plate one-third its length anteriorly. 


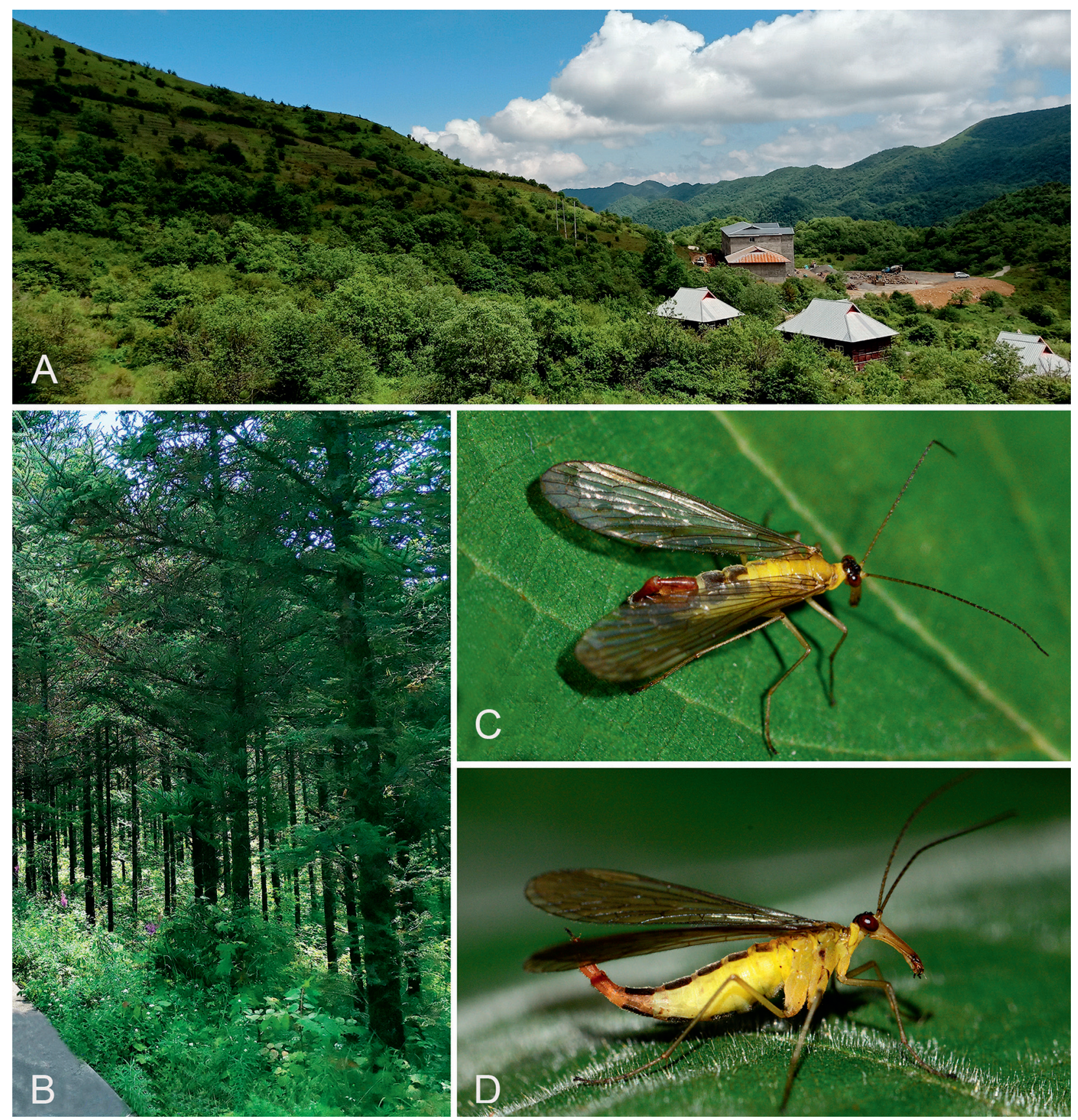

Figure 2. Live adult habitus and habitat of Panorpa bashanicola Hua, Tao \& Hua, 2018. A. Habitat in Huang'anba, Chengkou, Chongqing. B. Habitat in Hualongshan, Shaanxi. C. Male, dorsal view. D. Female, lateral view. Photos by Kai Gao (A, C, and D) and by Le-Le He (B).

Material examined. CHINA - Shaanxi Prov. • $1 \delta$ (Holotype); Lan'gao, Nangongshan; 1200-2025 m a.s.1.; 24-25 Jun. 2007; BaoZhen Hua \& Jiang-Li Tan leg. • 26ðð, $22 \circ 0$ (Paratypes); same data as

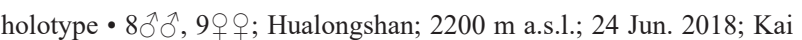
Gao \& Yuan Hua leg. - Chongqing • $8 \hat{\jmath} \delta, 9+q$; Chengkou, Shentian Alpine Shrub Meadow; 2400-2500 m a.s.1.; 22 Jun. 2018; Kai Gao,

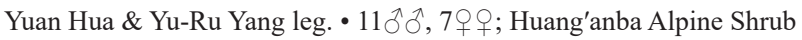
Meadow; 2400 m a.s.1.; 22 Jun. 2018; Kai Gao, Yuan Hua, \& Yu-Ru Yang leg. - Hubei Prov. • 2ðð; Shennongjia, Hongping; 28 Jun. 2007; Bao-Zhen Hua \& Jiang-Li Tan leg. $・ 1 \jmath$, 8 우; Yanziya; 1950 m a.s.1.;

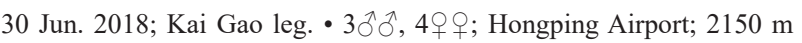
a.s.1.; 30 Jun. 2018; Kai Gao \& Yu-Ru Yang leg.
Measurements. Male: $\mathrm{FL}=11.1-12.1 \mathrm{~mm}, \mathrm{FW}=2.8-3.0$ $\mathrm{mm} ; \mathrm{HL}=10.0-11.1 \mathrm{~mm}, \mathrm{HW}=2.7-2.9 \mathrm{~mm}$. Female: $\mathrm{FL}=11.2-12.6 \mathrm{~mm}, \mathrm{FW}=2.8-3.1 \mathrm{~mm} ; \mathrm{HL}=10.2-11.6$ $\mathrm{mm}, \mathrm{HW}=2.7-3.0 \mathrm{~mm}$.

Distribution. China: Chongqing, Hubei, Shaanxi.

Remarks. This species resembles $P$. chengi in appearance, but can be differentiated from the latter by vein $1 \mathrm{~A}$ ending before (cf. at) the origin of Rs. 

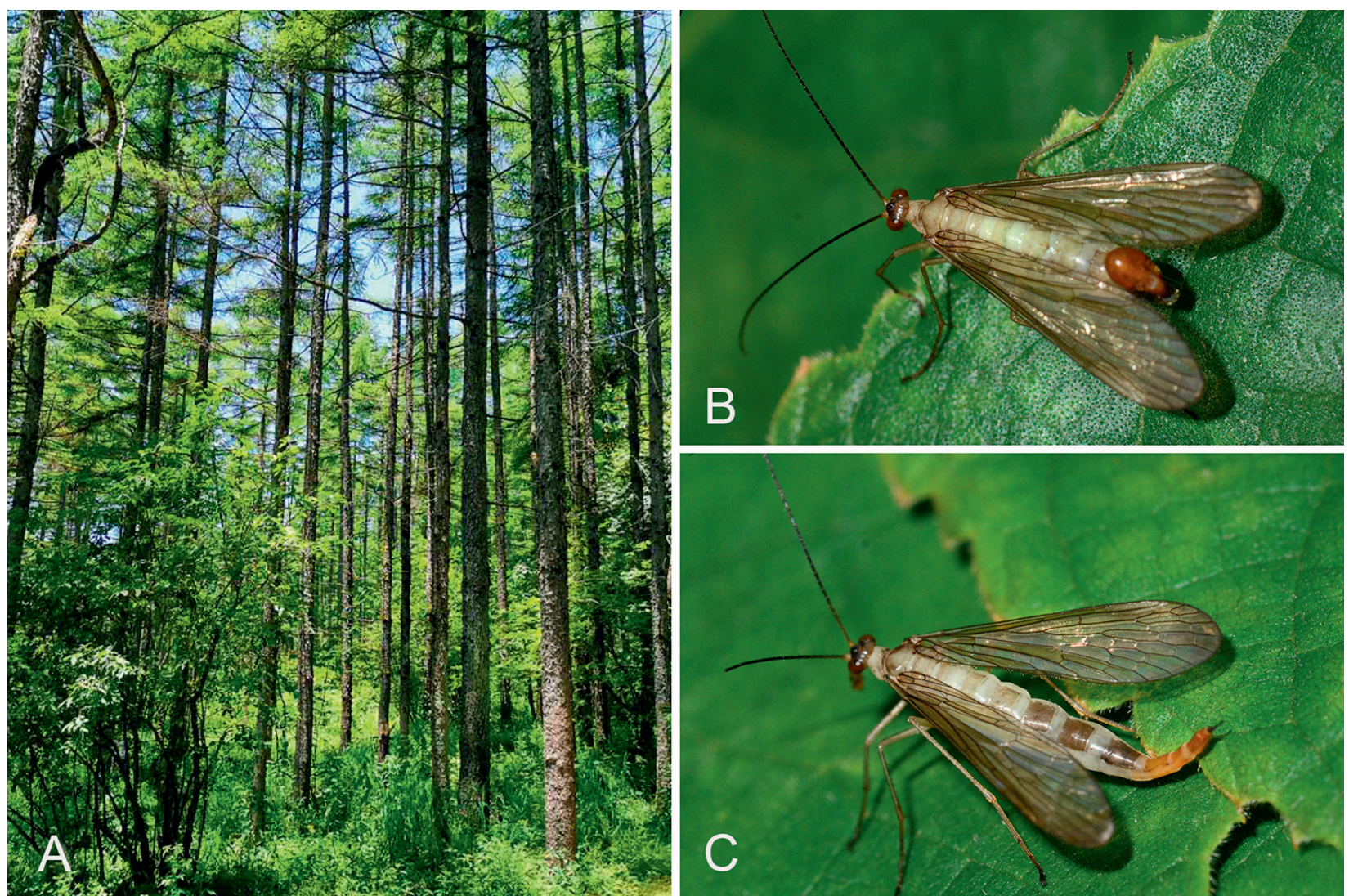

Figure 3. Live adult habitus and habitat of Panorpa chengi Chou, 1981. A. Habitat in Huoditang, Ningshan, Shaanxi. B. Male, dorsal view. C. Female, dorsal view. Photos by Xin Tong (A) and by Kai Gao (B-C).

\section{Panorpa chengi Chou, 1981}

Fig. 3

Panorpa chengi Chou in Chou et al., 1981: 16, figs 63-64. Type locality: Qinling, Shaanxi, China; Wang \& Hua, 2018: 315, figs 5-109$1-5-109-2$

Diagnosis. This species can be readily recognized by the following characters: (1) wings devoid of markings, pterostigma faint (Fig. 3B-C); (2) vein 1A ending at level of origin of Rs; (Fig. 3B-C) (3) pro-, meso-, and metanotum yellowish, darkened laterally (Fig. 3B-C); in males, (4) gonostylus with broad row of stout setae on inner margin; (5) gonocoxites bearing 4-6 short setae along beveled inner apex ventrally, with small protuberance below setae; (6) parameres slender, intensely curved, reaching half length of aedeagus; in females, (7) medigynium with main plate oblong; axis extending beyond main plate more than half its length anteriorly; lateral basal plates absent.

Material examined. CHINA - Shaanxi Prov. 1 1 (Holotype); Qinling; 13 Jul. 1951; Io Chou leg. • 1; Huashan; 30 Aug. 1983; XiaoLin Lu leg. $\bullet 1 \overbrace{}^{\top}$; Zhouzhi, Taibaishan, Tiejiashu; $1770 \mathrm{~m}$ a.s.1.; 17 Jul.

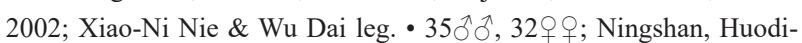
tang; 5 May-13 Jul. 2019; Xin Tong \& Peng-Yang Wang leg. $・ 2 \lesssim \widehat{\jmath}$, 2우; Zhuque National Forest Park; 2000 m a.s.1.; 23 Aug. 2008; BaoZhen Hua \& Qiang Fu leg. $・ 9 \widehat{\partial}, 12$, $ᄋ$; Hanyin, Fenghuangshan, Leigutai; 1800 m a.s.1.; 27 Jun. 2018; Kai Gao leg.
Measurements. Male: $\mathrm{FL}=11.3-12.6 \mathrm{~mm}, \mathrm{FW}=2.9-3.2$ $\mathrm{mm} ; \mathrm{HL}=10.3-11.6 \mathrm{~mm}, \mathrm{HW}=2.8-3.1 \mathrm{~mm}$. Female: $\mathrm{FL}=11.6-13.1 \mathrm{~mm}, \mathrm{FW}=3.1-3.3 \mathrm{~mm} ; \mathrm{HL}=10.8-12.0$ $\mathrm{mm}, \mathrm{HW}=2.8-3.3 \mathrm{~mm}$.

\section{Distribution. China: Shaanxi.}

Remarks. This species can be readily identified from other members of the $P$. davidi group by the gonostylus with a broad row of stout setae on inner margin.

\section{Panorpa curva Carpenter, 1938}

Fig. 4

Panorpa curva Carpenter, 1938: 269, figs $1 \& 8$. Type locality: "OEr, 26 miles of Li Fan" [now Lixian], "Szechwan" [now Sichuan], China; Cheng, 1957: 43, figs 52-53; Wang \& Hua, 2018: 323, figs $5-113-1-5-113-2$

Diagnosis. This species can be readily recognized by the following characters: (1) forewing apical band broad, with small hyaline spot posteriorly; pterostigmal band with basal branch broad and apical branch mostly absent; basal band complete, broad; marginal and basal spots absent (Fig. 4A-B); (2) meso- and metanotum black, with prominent pale yellow mesal stripe (Fig. 4A-B); in males, (3) gonocoxites with elongated process, bearing short stout setae on inner margin (Fig. 4E); (4) parameres 

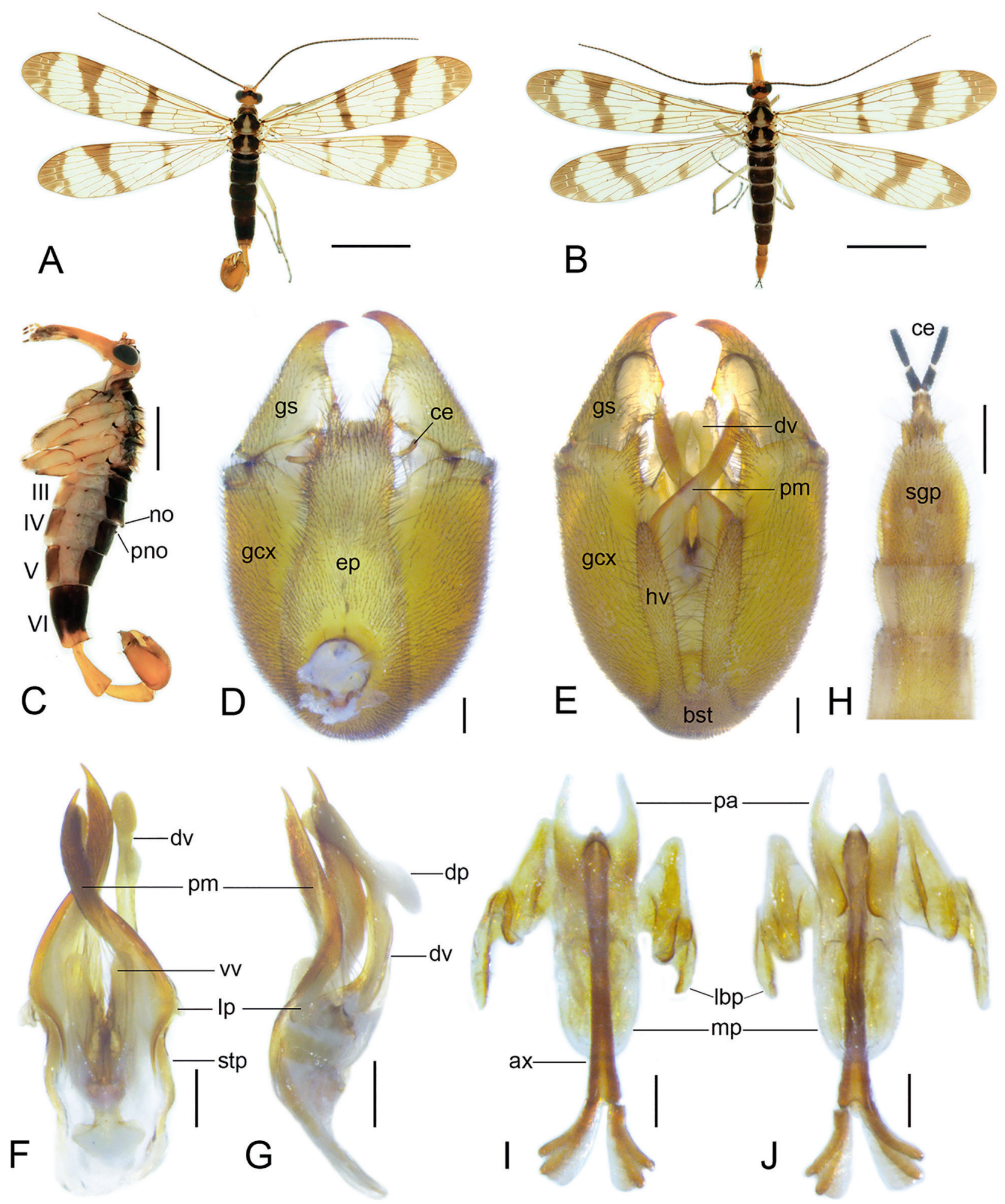

Figure 4. Panorpa curva Carpenter, 1938 from Wolong, Sichuan. A, C-G. Male. A. Habitus, dorsal view. C. Habitus, lateral view. D-E. Genital bulb, dorsal and ventral views. F-G. Aedeagal complex, ventral and lateral views. B, H-J. Female. B. Habitus, dorsal view. H. Terminalia, ventral view. I-J. Medigynium, dorsal and ventral views. Scale bars: A-B = $5 \mathrm{~mm} ; \mathrm{C}=2 \mathrm{~mm}$; D-G, I-J = $0.2 \mathrm{~mm} ; \mathrm{H}=0.5 \mathrm{~mm}$.

elongate, crossed mesally, and twisted in S-shape (Fig. $4 \mathrm{~F})$; and in females; (5) medigynium with main plate rectangular, three times as long as wide, with pair of large lateral basal plates near middle portion; axis extending beyond main plate for two-fifths its length anteriorly (Fig. 4I-J).

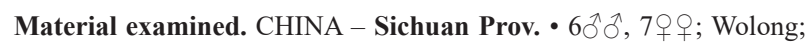
$31^{\circ} 02^{\prime} 12^{\prime \prime} \mathrm{N}, 103^{\circ} 12^{\prime} 35^{\prime \prime} \mathrm{E}$; 1940-2060 m a.s.1.; 9-10 Aug. 2018; Ning

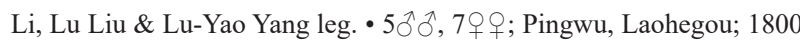
m a.s.1.; 25 May 2018; Kai Gao leg. • 10; Heishui, Dagubingchuan; 2700 m a.s.1.; 6 Jun. 2019; Kai Gao leg. $・ 1$; ; Lixian, Bipenggou; 2600 m a.s.l.; 6 Jun. 2019; Kai Gao leg. - Shaanxi Prov.•1ㅇ; Baoji, Fengx- 
ian, Tiantaishan Forest Park; 1 Jun. 2015; Ji-Shen Wang \& Lu Jiang

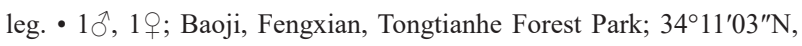

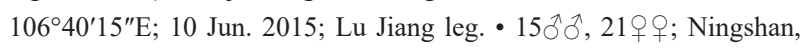
Huoditang; 5 May-13 Jul. 2019; Xin Tong \& Peng-Yang Wang leg.

Measurements. Male: $\mathrm{FL}=11.4-13.9 \mathrm{~mm}, \mathrm{FW}=2.9-3.5$ $\mathrm{mm}$; $\mathrm{HL}=10.3-12.0 \mathrm{~mm}, \mathrm{HW}=2.7-3.2 \mathrm{~mm}$. Female: $\mathrm{FL}=11.3-14.1 \mathrm{~mm}, \mathrm{FW}=3.0-3.6 \mathrm{~mm} ; \mathrm{HL}=10.3-12.1$ $\mathrm{mm}, \mathrm{HW}=2.9-3.3 \mathrm{~mm}$.

Description. Female: Head (Fig. 4B): Frons, vertex, and occiput yellowish brown. Black transverse band passing through ocellar triangle, extending to inner margins of compound eyes. Rostrum yellow, slender, with labrum dark brown. Maxillary and labial palps mostly pale brown, with distal segments dark brown. Antennal scape yellowish brown; pedicel dark yellowish brown; flagellum blackish brown, filiform. Thorax (Fig. 4B): Pronotum black, with 12-16 setae along anterior margin. Meso- and metanotum black, with pale yellow mesal stripe; scutella totally pale yellow. Pleura yellowish; legs yellowish brown, with distal tarsomere blackish. Wings (Fig. 4B): Wing membrane hyaline, with black brown markings. In forewing, broad apical band with small hyaline spot posteriorly; pterostigmal band with broad basal branch, apical branch absent; broad basal band complete; marginal and basal spots almost absent. Hindwing similar to forewing, with relatively reduced markings; basal band usually narrower and incomplete. Abdomen (Fig. 4B): T2-T6 black. A7-A10 brown. Genitalia (Fig. 4H-J): Subgenital plate ligulate, with V-shaped distal emargination, bearing long setae on distal quarter. Medigynium with rectangular main plate, three times as long as wide; pair of large wing-like lateral basal plates near middle portion; paired posterior arms forming broad U-shaped emargination; axis slightly extruded posteriorly, extending beyond main plate for two-fifths of its length anteriorly.

Distribution. China: Shaanxi, Sichuan.

Remarks. This species resembles $P$. davidi in appearance, but can be readily identified by complete basal band (cf. split into two spots) in forewing and elongated process on gonocoxites with the base 1.5 times (cf. twice) as wide as the apex.

\section{Panorpa curvata Zhou, 2006}

Panorpa curvata Zhou, 2006: 273, figs 1-3. Type locality: Chishui Suoluo National Nature Reserve, Guizhou, China.

Diagnosis. This species can be recognized by the following features: (1) frons, vertex, occiput, and ocellar triangle blackish brown; (2) wing membrane hyaline, without markings; (3) pro-, meso-, and metanotum black; (4) hypovalves slender with rounded apexes, almost extending to apex of gonocoxites; (5) row of setae on ventral apex of gonocoxites; (6) parameres slender, intensively curved, twisted in S-shape.

Female. Unknown.

Measurements. Male: $\mathrm{FL}=11 \mathrm{~mm}, \mathrm{FW}=2 \mathrm{~mm}$; $\mathrm{HL}=$ $10 \mathrm{~mm}, \mathrm{HW}=2 \mathrm{~mm}$.

Distribution. China: Guizhou.

\section{Panorpa davidi Navás, 1908}

Fig. 5

Panorpa davidi Navás, 1908: 415, fig. 19. Type locality: "Mou-Pin, Tibet" [now Baoxing, Sichuan], China; Esben-Petersen, 1921: 29, figs 21-23; Cheng, 1957: 25, fig. 57; Rust \& Byes, 1976: 84, fig. 156; Wang \& Hua, 2018: 325, figs 5-114-1-5-114-2.

Diagnosis. This species can be readily recognized by the following characters: (1) forewing markings well-developed, apical band broad and scattered posteriorly; pterostigmal band with basal branch complete and apical branch separated or absent; basal band split into two spots; basal spot greatly reduced (Fig. 5A-B); (2) mesoand metanotum black, with narrower pale yellow mesal stripe (Fig. 5A-C); in males, (3) gonocoxites with protruding process bearing short black setae on inner apex (Fig. 5E); (4) parameres elongate, crossed mesally, and twisted in S-shape (Fig. 5E); and in females (5) medigynium with main plate oblong, three times as long as wide; axis extending beyond main plate for half its length anteriorly (Fig. 5G).

Material examined. CHINA - Sichuan Prov. • 1 9 ; Baoxing, Qingyi River Source; 2500 m a.s.1.; 13 Aug. 2018; Ji-Shen Wang leg. $11 \hat{\jmath}, 2 \uparrow ᄋ$, collecting data missing.

Measurements. Male: $\mathrm{FL}=13.0 \mathrm{~mm}, \mathrm{FW}=3.0 \mathrm{~mm}$; HL $=11.5 \mathrm{~mm}, \mathrm{HW}=2.9 \mathrm{~mm}$. Female: $\mathrm{FL}=13.0-14.0 \mathrm{~mm}$, $\mathrm{FW}=3.0-3.2 \mathrm{~mm} ; \mathrm{HL}=11.6-12.5 \mathrm{~mm}, \mathrm{HW}=3.0-3.1$ $\mathrm{mm}$.

Description. Female: Head (Fig. 5B-C): Frons yellowish brown, occiput yellowish brown with two black spots laterally. Vertex with broad black transverse stripe passing through ocellar triangle and extending to inner margins of compound eyes. Rostrum yellow, slender. Maxillary and labial palps mostly pale brown, with distal segments black brown. Antennal scape yellowish brown; pedicel dark brown; flagellum black, filiform. Thorax (Fig. 5 B-C): Pronotum black, with 12-16 setae along anterior margin. Meso- and metanotum black, with narrower pale yellow mesal stripe; scutella totally pale yellow. Pleura and legs light yellowish brown, with distal tarsomere blackish. Wings (Fig. 5B): Wing membrane hyaline, with dark brown markings. In forewing, apical band broad and scattered posteriorly; pterostig- 


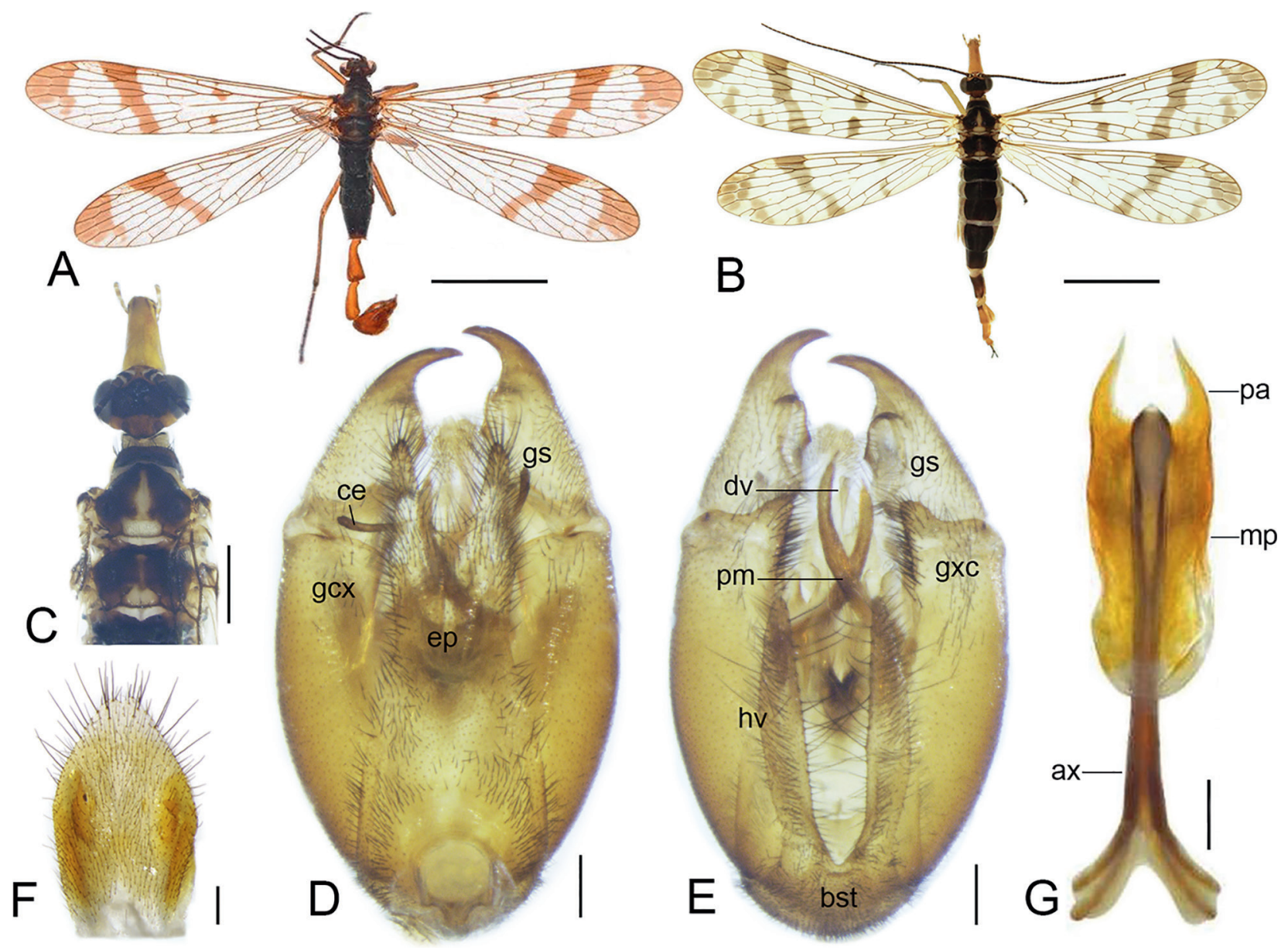

Figure 5. Panorpa davidi Navás, 1908 from Baoxing, Sichuan. A, D-E. Male. A. Habitus, dorsal view. D-E. Genital bulb, dorsal and ventral views. B-C, F-G. Female. B. Habitus, dorsal view. C. Dorsum, dorsal view. F. Subgenital plate, ventral view. G. Medigynium, ventral view. Scale bars: $\mathrm{A}-\mathrm{B}=5 \mathrm{~mm} ; \mathrm{C}=2 \mathrm{~mm} ; \mathrm{D}-\mathrm{G}=0.2 \mathrm{~mm}$.

mal band with broad basal branch, apical branch absent or reduced to small spot posteriorly; marginal spot absent or reduced to small spot; basal band split into two spots; basal spot greatly reduced on base of $\mathrm{CuA}$ and CuP. Hindwing similar to forewing, with relatively reduced markings; basal spot absent. Abdomen (Fig. 5B): T2-T6 black. A7-A10 brown. Genitalia (Fig. 5F-G): Subgenital plate elliptical, with V-shaped distal emargination, bearing long setae on distal part. Medigynium with oblong main plate, three times as long as wide, and lateral margin emarginate at basal one-third; paired posterior arms quarter as long as main plate, forming broad U-shaped emargination; axis slightly extruded posteriorly, extending beyond main plate for half of its length anteriorly.

Distribution. China: Sichuan.

Remarks. Only a single male (holotype) of $P$. davidi from Baoxing, Sichuan was known previously. A female specimen was erroneously treated as $P$. davidi by Navás (1908), but was later designated as the holotype of $P$. guttata Navás, 1908 (Esben-Petersen 1915). A female of $P$. davidi captured recently from the type locality can be differentiated from that of P. guttata by the well-developed (cf. greatly reduced) wing markings and by meso- and metanotum black (cf. yellowish brown), with a narrower (cf. broad) pale yellow mesal stripe.

\section{Panorpa difficilis Carpenter, 1938}

Figs 6-7

Panorpa difficilis Carpenter, 1938: 269, figs 4 \& 6. Type locality: "Chengtu, Szechwan" [now Chengdu, Sichuan], China; Cheng, 1957: 29, figs $42 \& 46$.

Diagnosis. This species can be readily recognized by the following characters: (1) wings with well-developed variable markings (Figs 6A-B, 7A-B); (2) meso- and metanotum black, with prominent pale yellow mesal stripe (Figs 6A-B, 7A-B); in males, (3) gonocoxites with a row of long setae along slightly beveled inner apex (Fig. 7E); (4) parameres crossed subapically, twisted in S-shape (Fig. 7G); (5) dorsal valves slender, stalked, each with an intensively enlarged dorsal process on apical portion dorsally (Fig. 7F-G); and in females, (6) medigynium bearing a pair of auricular lateral basal plates on middle portion (Fig. 7I-J). 

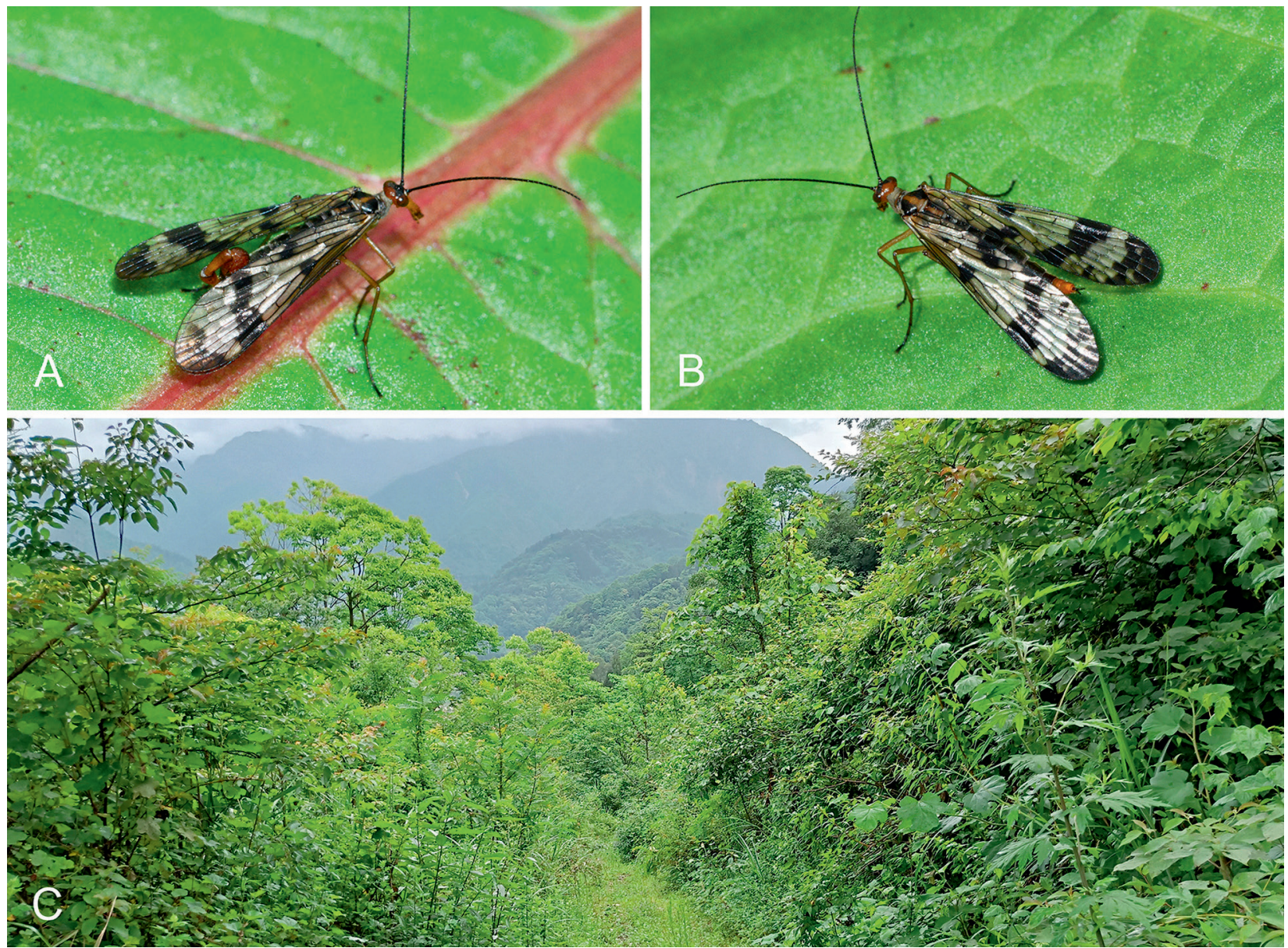

Figure 6. Live adult habitus and habitat of Panorpa difficilis Carpenter, 1938. A. Male, dorsal view. B. Female, dorsal view. C. Habitat in Maoxian, Tudiling, Sichuan. Photos by Kai Gao.

Material examined. CHINA - Chongqing • 1 ; ; Beibei, Longfengxi; 27 Oct. 1984; Xin Yue leg.; ・18 $\widehat{\jmath}, 21$ 우우 Beibei, Xiema, Damotan; 230 m a.s.l.; 5 Apr. 2013; Jian-Yue Qiu \& Hao Xu leg. -Shaanxi Prov. -2우; Nanzheng, Liping; 3254'09"N, 106³6'36"E; 1530 m a.s.1.; 11 Jul. 2019; Ying Miao \& Yue Pan leg. • $2 \delta^{3}$; Liping; 2018; Zheng Wei.

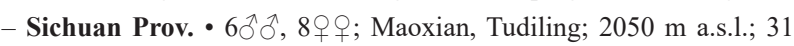
May 2019; Kai Gao.

Measurements. Male: $\mathrm{FL}=10.9-12.8 \mathrm{~mm}, \mathrm{FW}=2.9-3.1$ $\mathrm{mm} ; \mathrm{HL}=10.0-11.8 \mathrm{~mm}, \mathrm{HW}=2.7-3.0 \mathrm{~mm}$. Female: $\mathrm{FL}=11.3-12.9 \mathrm{~mm}, \mathrm{FW}=2.9-3.2 \mathrm{~mm} ; \mathrm{HL}=10.3-12.1$ $\mathrm{mm}, \mathrm{HW}=2.9-3.1 \mathrm{~mm}$.

Description. Female: Head (Figs 6B, 7B): Frons, vertex, and occiput yellowish brown. Broad black band passing through ocellar triangle to inner margins of compound eyes. Rostrum yellow, slender, with labrum dark brown. Maxillary and labial palps mostly pale brown with distal segments dark brown. Antennal scape dark brown; pedicel blackish brown; flagellum black, filiform. Thorax (Figs 6B, 7B): Pronotum black, with 10-16 setae along anterior margin. Meso- and metanotum black, with pale yellow mesal stripe; scutella totally pale yellow. Pleura and legs yellowish brown, with distal tarsomere blackish. Wings (Figs 6B, 7B): Wing membrane hyaline, with markings black brown. In forewing, broad apical band scattered on posterior margin, several small hyaline spots along apical crossveins; pterostigmal band with broad basal branch, apical branch usually detached and thin; marginal spot as one or two small spots; basal band generally split into two large spots, complete in a few individuals; basal spot prominent. Hindwing similar to forewing, with relatively reduced markings; marginal spot usually faint and basal spot absent. Abdomen (Figs 6B, 7B): T2-T6 black. A7-A10 yellowish brown. Genitalia (Fig. 7H-J): Subgenital plate ligulate, with $\mathrm{V}$-shaped distal emargination, bearing long setae on distal half. Medigynium with broad, long main plate, lateral margin emarginate medially, distal portion broader than base; pair of auricular lateral basal plates on middle part, each basal plate consisting of sclerotized middle structure enclosing very small one; axis slightly extruded posteriorly, extending beyond main plate for half of its length anteriorly.

Distribution. China: Chongqing, Shaanxi, Sichuan.

Remarks. Panorpa difficilis was previously known only by the male holotype. A series of male and female specimens were captured recently from Chongqing and Shaanxi. This species should be a bivoltine insect in Chongqing at low elevations. 


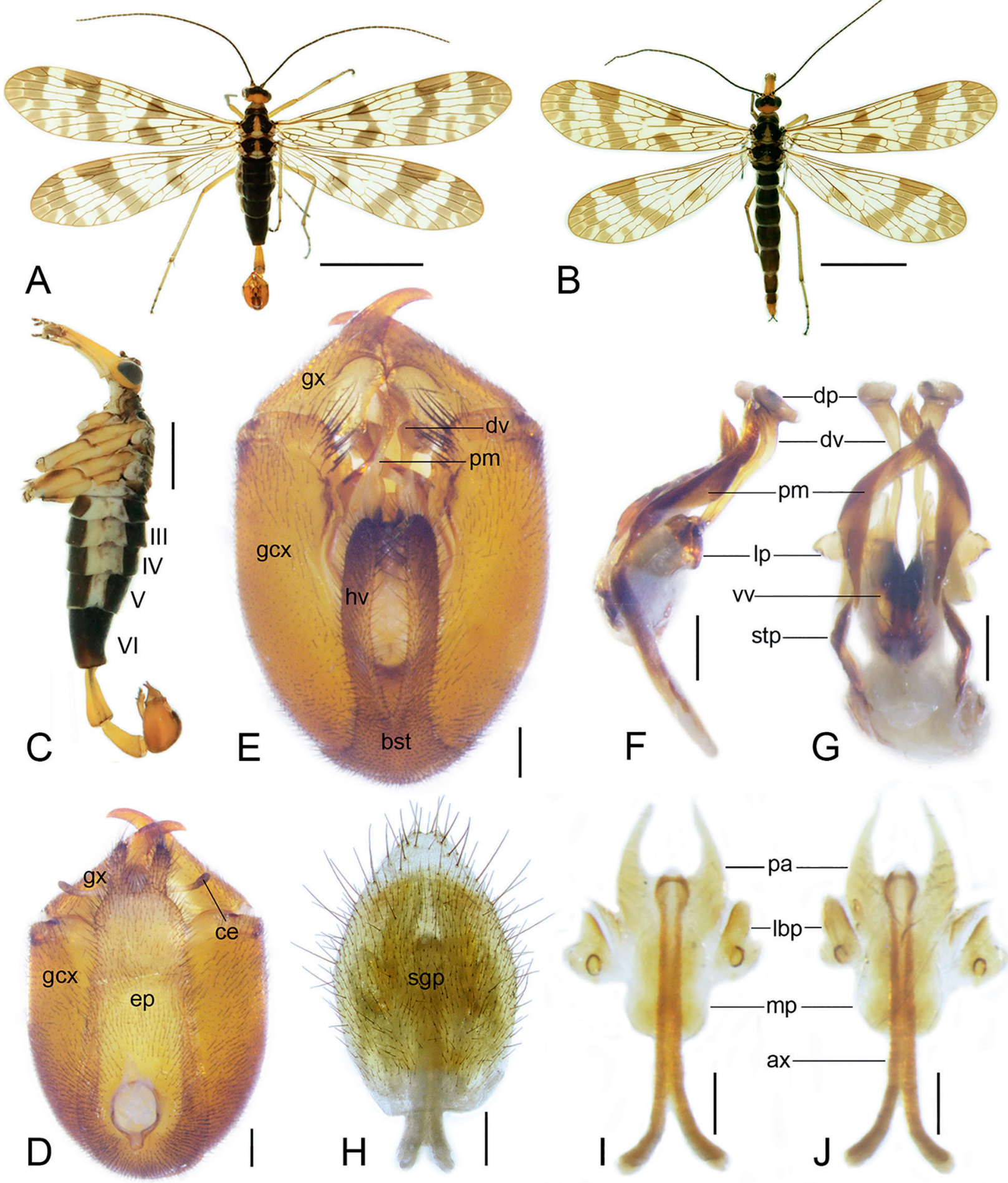

Figure 7. Panorpa difficilis Carpenter, 1938 from Maoxian, Sichuan. A, C-G. Male. A. Habitus, dorsal view. C. Habitus, lateral view. D-E. Genital bulb, dorsal and ventral views. F-G. Aedeagal complex, lateral and ventral views. B, H-J. Female. B. Habitus, dorsal view. H. Subgenital plate, ventral view. I-J. Medigynium, ventral and dorsal views. Scale bars: A-B = $5 \mathrm{~mm} ; \mathrm{C}=2 \mathrm{~mm}$; $\mathrm{D}-\mathrm{J}=0.2 \mathrm{~mm}$. 


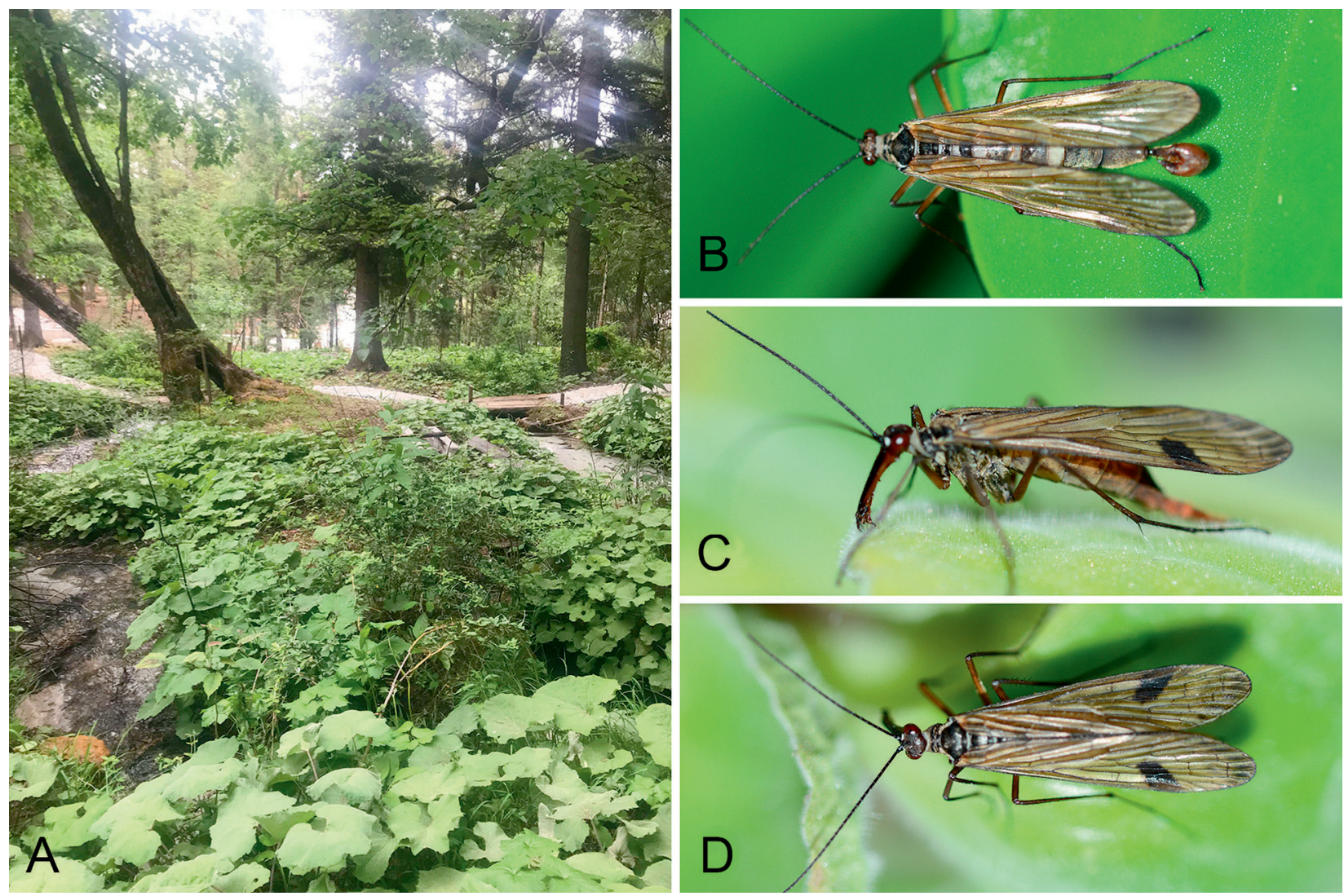

Figure 8. Live adult habitus and habitat of Panorpa diqingensis Li \& Hua, 2020. A. Habitat in Haba, Shangri-La, Yunnan. B. Male, dorsal view. C-D. Female, lateral and dorsal views. Photos by Ning Li (A) and by Xin Tong (B-D).

\section{Panorpa diqingensis Li \& Hua, 2020}

Fig. 8

Panorpa diqingensis Li \& Hua, 2020: 141, figs 2-4. Type locality: Diqing, Shangri-La, Yunnan, China.

Diagnosis. This species can be recognized by the following features: (1) pleura blackish brown to black (Fig. 8C); (2) wing with pterostigmal band usually reduced to anterior half in females, males with relatively reduced markings; apical band incomplete, scattered, faint (Fig. 8B-D); (3) pro-, meso- and metanotum blackish brown, scutella dark brown (Fig. 8B, D); in males, (4) gonocoxites with triangular process on inner apex ventrally, bearing tuft of long black setae; (5) parameres crossed and twisted in S-shape; and in females, (6) medigynium with main plate three times as long as wide; lateral basal plates absent; axis extending beyond main plate for a quarter length anteriorly.

Material examined. CHINA - Yunnan Prov. 11 (Holotype); Diqing, Shangri-La, Haba; 2600-2700 m a.s.1.; 20 Jun. 2014; Chao Gao \& Mei

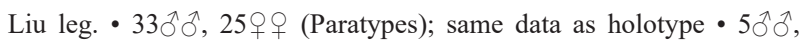
7우우 ; Shangri-La, Haba; $27^{\circ} 22^{\prime} 14^{\prime \prime} \mathrm{N}, 100^{\circ} 7^{\prime} 49^{\prime \prime} \mathrm{E} ; 2730$ m a.s.1.; $27-28$ May 2019; Ning Li \& Lu Liu leg.

Measurements. Male: $\mathrm{FL}=13.2-14.1 \mathrm{~mm}, \mathrm{FW}=3.0-3.2$ $\mathrm{mm} ; \mathrm{HL}=12.1-13.0 \mathrm{~mm}, \mathrm{HW}=3.0-3.1 \mathrm{~mm}$. Female: $\mathrm{FL}=13.6-14.6 \mathrm{~mm}, \mathrm{FW}=3.3-3.5 \mathrm{~mm} ; \mathrm{HL}=12.6-13.6$ $\mathrm{mm}, \mathrm{HW}=3.2-3.4 \mathrm{~mm}$.
Distribution. China: Yunnan.

Remarks. This species resembles $P$. fructa with its blackish brown pro-, meso- and metanotum; darker pleura; roof-like wings at repose, but can be differentiated from the latter by pterostigmal band reduced and not reaching $\mathrm{R}_{2+3}$ (cf. scattered); axis of female main plate extended beyond main plate for a quarter (cf. half) of its length.

\section{Panorpa dispergens Li \& Hua, 2020}

Fig. 9

Panorpa dispergens Li \& Hua, 2020: 142, figs 5-7. Type locality: Diqing, Shangri-La, Yunnan, China.

Diagnosis. This species can be recognized by the following features: (1) frons, vertex, ocellar triangle and occiput dark brown (Fig. 9B-C); (2) wing membrane hyaline; pterostigma prominent; apical band absent in a few specimens, nearly elliptical with small hyaline spot inside in most individuals (Fig. 9B-C); (3) nota blackish brown to black (Fig. 9B-C); in males, (4) gonocoxites with cluster of stout dark brown setae and 3-5 long setae along oblique inner apex ventrally; (5) parameres crossed mesally, twisted in S-shape; and in females, (6) medigynium with main plate oblong, middle part bearing pair of lateral basal plates; axis extending beyond main plate for half of its length anteriorly. 

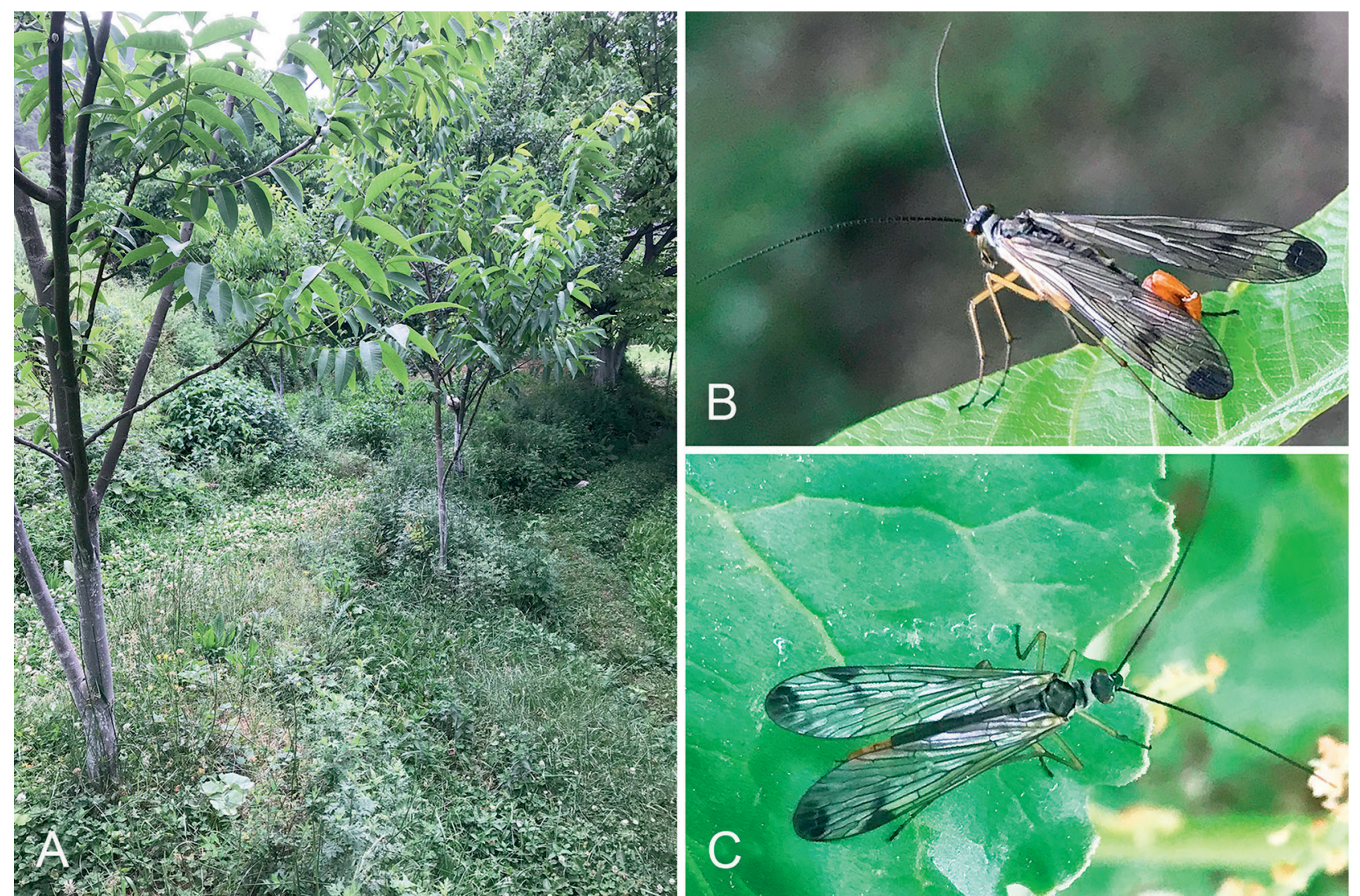

Figure 9. Live adult habitus and habitat of Panorpa dispergens Li \& Hua, 2020. A. Habitat in Baishuitai, Shangri-La, Yunnan. B. Male, dorsal view. C. Female, dorsal view. Photos by Ning Li (A) and by Lu Liu (B-C).

Material examined. CHINA - Yunnan Prov. $1 \delta^{\Uparrow}$ (Holotype); Diqing, Shangri-La, Haba; $27^{\circ} 22^{\prime} 12^{\prime \prime} \mathrm{N}, 100^{\circ} 7^{\prime} 48^{\prime \prime} \mathrm{E} ; 2700$ m a.s.1.; 2 Jun. 2016; Gui-Lin Hu \& Wei Du leg. • 1ठ, 3 우 (Paratypes); same data as ho-

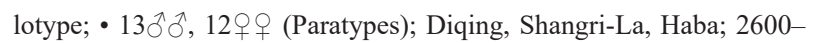

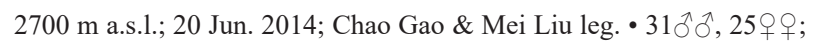
Diqing, Shangri-La, Baishuitai; $27^{\circ} 30^{\prime} 2^{\prime \prime} \mathrm{N}, 100^{\circ} 2^{\prime} 36^{\prime \prime} \mathrm{E} ; 2500 \mathrm{~m}$ a.s.1.; 28-29 May 2019; Ning Li \& Lu Liu leg.

Measurements. Male: $\mathrm{FL}=12.6-14.4 \mathrm{~mm}, \mathrm{FW}=3.1-3.5$ $\mathrm{mm} ; \mathrm{HL}=11.8-13.4 \mathrm{~mm}, \mathrm{HW}=3.0-3.4 \mathrm{~mm}$. Female: $\mathrm{FL}=13.7-14.5 \mathrm{~mm}, \mathrm{FW}=3.2-3.6 \mathrm{~mm} ; \mathrm{HL}=12.6-13.4$ $\mathrm{mm}, \mathrm{HW}=3.1-3.5 \mathrm{~mm}$.

\section{Distribution. China: Yunnan.}

Remarks. This species resembles $P$. curva in female medigynium, but can be differentiated from the latter by the black meso- and metanotum (cf. black, with prominent pale yellow mesal stripe); and reduced (cf. well-developed) wing markings.

\section{Panorpa fructa Cheng, 1949}

Figs 10-11

Panorpa fructa Cheng, 1949: 144, figs 5-7. Type locality: "Wakiakeng, 50 miles west of Tachienlu, Sikang" [now Kangding, Sichuan], China; Cheng, 1957: 30, figs 29, 35 \& 38; Wang \& Hua, 2018: 339, figs 5-121-1-5-121-2.
Diagnosis. This species can be readily recognized by the following characters: (1) pleura blackish brown to black (Figs 10B, 11C); (2) wing markings reduced into series of scattered dark brown spots (Fig 10B-C); (3) meso- and metanotum black, without pale mesal stripe (Fig 11A-B); (4) inner apex of gonocoxites projected inwards, bearing cluster of long black setae (Fig. 11E); (5) hypovalves gradually broadened towards rounded apexes, extending to apex of gonocoxites (Fig. 11F); and in females, (6) medigynium with main plate broad, long; pair of lateral basal plates subbasally extended to three-quarters length of main plate (Fig. 11J-K).

Material examined. CHINA - Sichuan, Garze • $1 ð$ (Holotype); "Wakiakeng, 50 miles west of Tachienlu" [now Kangding]; 9 Sep. 1939; Fung Ying Cheng, Io Chou \& Tein Ho Hei leg. • 1§; Kangding, Gongga Temple; 3650-4000 m a.s.1.; 3 Sep. 1982; Shu-Yong Wang leg. • 1ð̊; Yajiang Military Station; 3600 m a.s.1.; 28 Aug. 1982; Huai-Cheng Cai leg. • 1q; Yajiang Military Station; 3350 m a.s.1.; 25 Jul. 1982; Xue-Zhong Zhang leg. • 19; Yajiang Military Station; $3380 \mathrm{~m}$ a.s.1.; 6 Aug. 2018; Ning Li \& Lu Liu leg. • 2 9 \%; same data as previous; 3 Jul. 2019 • 2ððં; Luhuo, Zhuwo; 3 Jun. 2009; Jiang-Li Tan leg. •

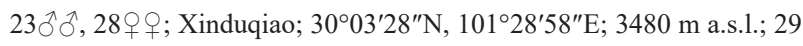

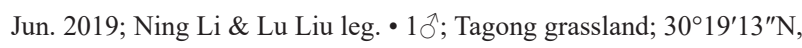
$101^{\circ} 28^{\prime} 58^{\prime \prime}$; 3760 m a.s.1.; 3 Aug. 2018; Lu-Yao Yang leg.

Measurements. Male: $\mathrm{FL}=11.3-12.2 \mathrm{~mm}, \mathrm{FW}=2.8-3.2$ $\mathrm{mm} ; \mathrm{HL}=10.2-11.0 \mathrm{~mm}, \mathrm{HW}=2.7-3.0 \mathrm{~mm}$. Female: $\mathrm{FL}=12.0-12.5 \mathrm{~mm}, \mathrm{FW}=2.9-3.2 \mathrm{~mm} ; \mathrm{HL}=10.4-11.3$ $\mathrm{mm}, \mathrm{HW}=2.9-3.2 \mathrm{~mm}$. 


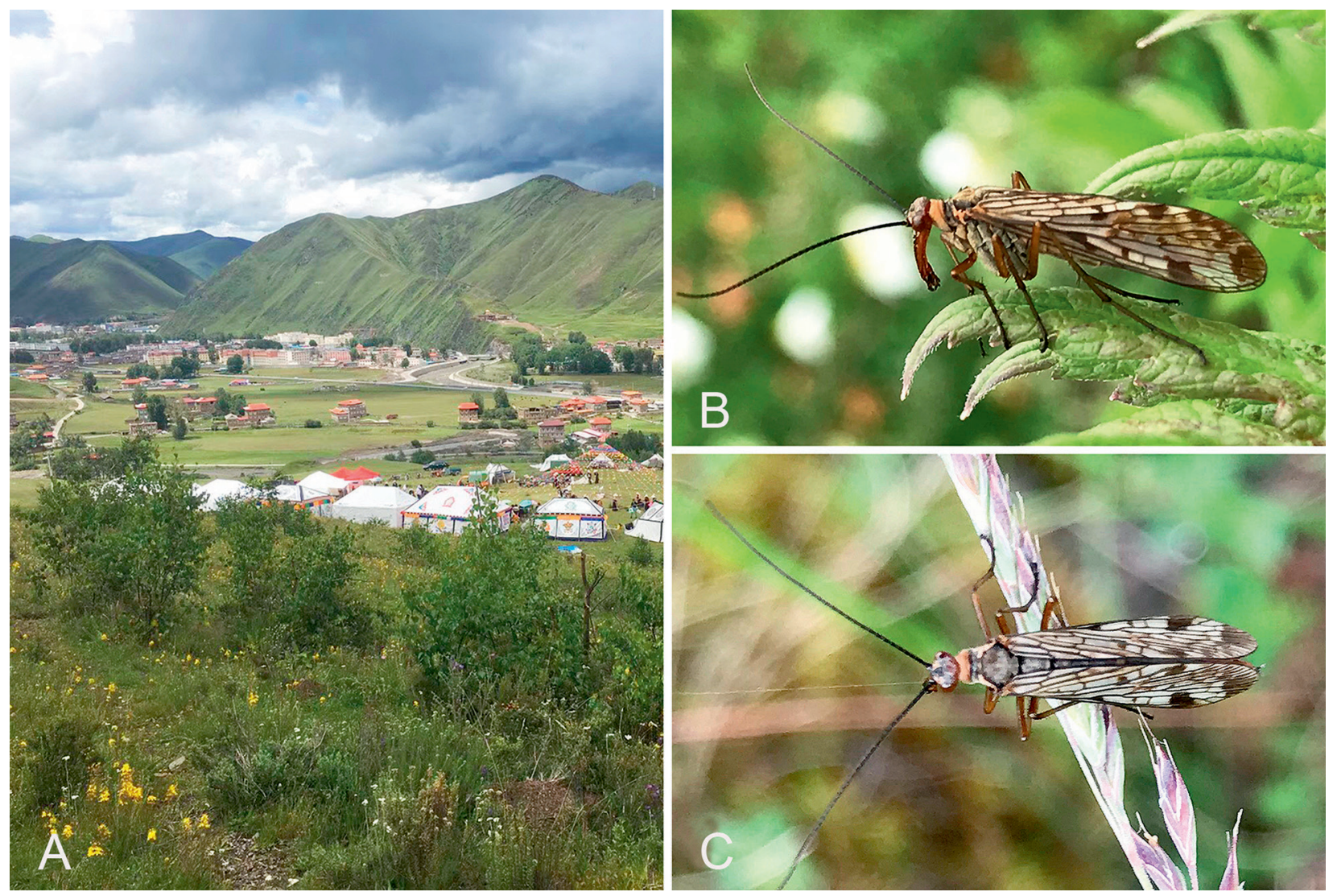

Figure 10. Live adult habitus and habitat of Panorpa fructa Cheng, 1949. A. Habitat in Xinduqiao, Sichuan. B. Male, lateral view. C. Female, dorsal view. Photos by Lu-Yao Yang (A) and by Ning Li (B-C).

Description. Female: Head (Figs 10C, 11B): Frons and occiput reddish brown. Vertex with broad black transverse band passing through ocellar triangle and extending to inner margins of compound eyes. Rostrum reddish brown, with two blackish brown submedian stripes. Labrum black brown. Maxillary and labial palps dark brown, with distal segments black. Antennal scape, pedicel black brown; flagellum black, filiform. Thorax (Figs 10C, 11B): Pronotum black, with 10-16 stout setae along anterior margin. Mesoand metanotum black, without pale mesal stripe; scutella black brown. Pleura black brown to black. Legs reddish brown, with distal tarsomere black. Wings (Figs 10C, 11B): Wing membrane hyaline, with dark brown markings. Forewing with broad apical band split into large spot anteriorly and series of small spots posteriorly; pterostigmal band complete anteriorly, with discrete basal branch and faint apical branch posteriorly; marginal spot prominent; basal band split into two spots; basal spot small and faint. Hindwing similar to forewing, but with relatively reduced markings; marginal spot and basal band extremely faint or absent; basal spot absent. Abdomen (Fig. 11B): T2-T6 black. A7-A10 reddish brown. Genitalia (Fig. 11I-K): Subgenital plate ligulate, with V-shaped distal emargination, bearing long setae in distal half. Medigynium with broad, long main plate, lateral margin concaved; each lateral basal plate subbasally consisting of three pieces of sclerotized structure, extended to three-quarters length of main plate. Posterior arms slender, one-third as long as main plate; axis slightly extruded posteriorly, extending beyond main plate for half of its length anteriorly.
Distribution. China: Sichuan.

Remarks. Panorpa fructa was originally described based on a single male specimen. Over two dozen female specimens from Kangding, the type locality, are determined here as members of this species. The specimens were collected at high-altitude from 3300 to $4000 \mathrm{~m}$ in alpine shrub meadow (Fig. 10A). The darker body may help absorb solar heating to adapt the cold environment. The adults hold wings roof-like at repose (Fig. 10B), which may be adapted to the strong wind environment in the alpine region.

\section{Panorpa fulvastra Chou, 1981}

Fig. 12

Panorpa fulvastra Chou in Chou et al., 1981: 4, figs 10-13. Type locality: Taibai Mountain, Shaanxi, China; Wang \& Hua, 2018: 343, figs 5-123-1-5-123-2.

Diagnosis. This species can be readily recognized by the following characters: (1) wing membrane tinged with yellow, reduced markings (Fig. 12B-C); (2) vein $1 \mathrm{~A}$ ending at level of origin of Rs (Fig. 12B-C); (3) mesoand metanotum black brown with yellowish mesal stripe (Fig. 12B-C); in males, (4) arcuate inner apex of ventral gonocoxites bearing cluster of extremely long setae; (5) parameres slender, twisted in S-shape, crossed once or 


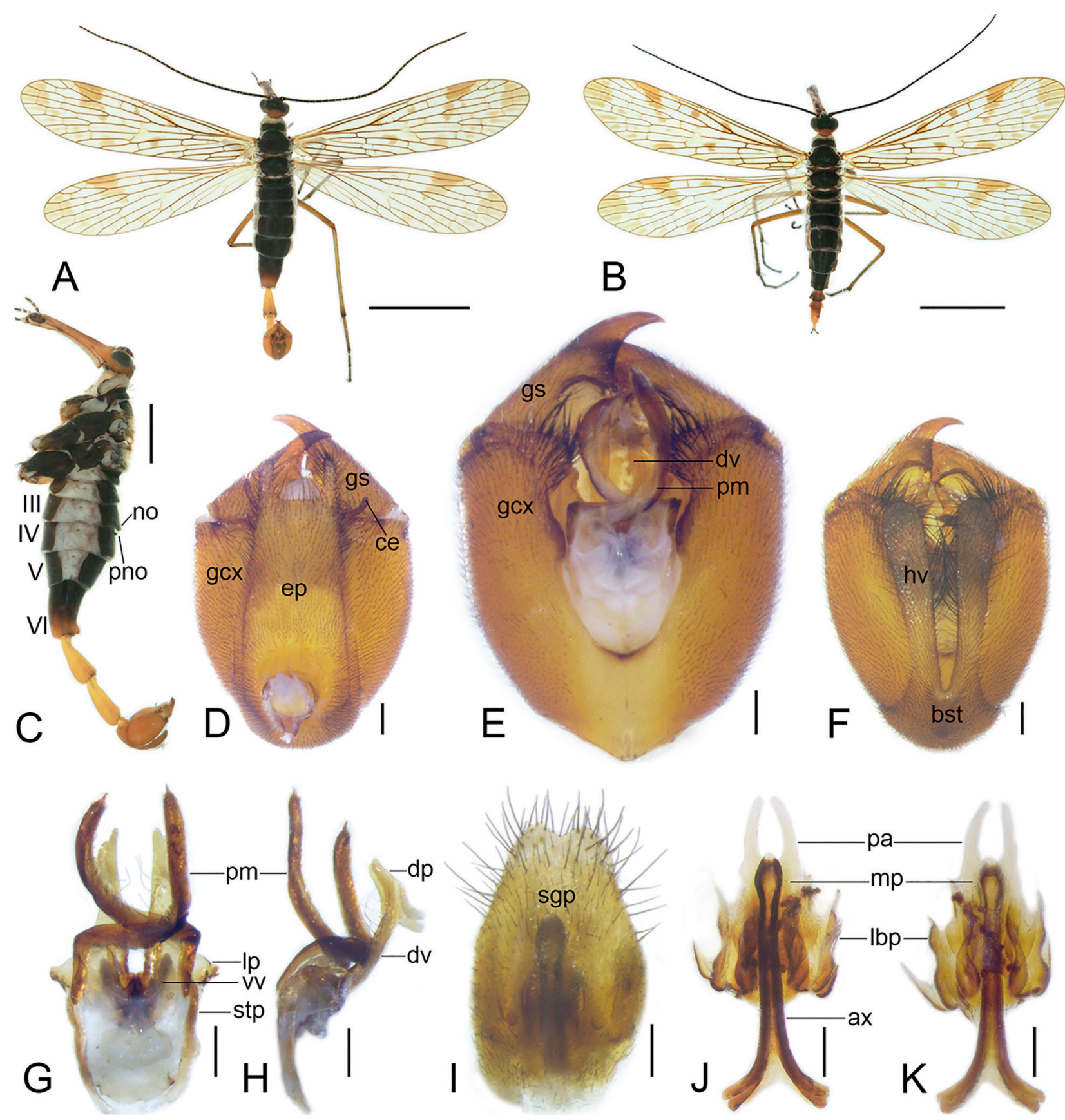

Figure 11. Panorpa fructa Cheng, 1949 from Xinduqiao, Sichuan. A, C-H. Male. A. Habitus, dorsal view. C. Habitus, lateral view. D-F. Genital bulb, dorsal, ventral (removing hypandrium), and ventral views. G-H. Aedeagal complex, ventral and lateral views. B, I-K. Female. B. Habitus, dorsal view. I. Subgenital plate, ventral view. J-K. Medigynium, ventral and dorsal views. Scale bars: A-B $=5 \mathrm{~mm} ; \mathrm{C}=2 \mathrm{~mm} ; \mathrm{D}-\mathrm{K}=0.2 \mathrm{~mm}$.

twice; in females, (6) main plate of medigynium broad; pair of large lateral basal plates extending from base to two-thirds of length of main plate; axis extended beyond main plate one-third of its length anteriorly.

Material examined. CHINA - Shaanxi Prov. $・ 1 \widehat{\jmath}$ (Holotype); Taibaishan; 22 Jul. 1956; Io Chou leg.; 4 서소, 5 우 (Paratypes); same

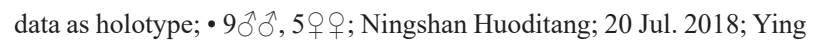
Miao \& Xiao-Yan Wang leg. $・ 5 \hat{\jmath} \widehat{\partial}$, 4 우우; Liuba; $1200-1600 \mathrm{~m}$ a.s.l.; 3

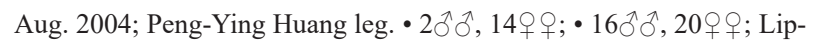
ing National Forest Park, Qixingge; $1500 \mathrm{~m}$ a.s.1.; 12 Jul. 2018; Zheng Wei leg. $\bullet 4 \hat{\jmath} \widehat{\partial}, 3$ 웅 Hanyin, Fenghuangshan, Leigutai, $1800 \mathrm{~m}$ a.s.1.;
27 Jun. 2018; Kai Gao leg. • 2o+ ; Zhouzhi, Houzhenzi; 2030 m a.s.l.; 24 Jul. 2019; Kai Gao leg. • 2 \%ㅇ; Foping, Liangfengya; 2200 m a.s.l.; 26 Jul. 2019; Kai Gao leg. $12 \hat{\jmath}$ ô, 16우; Qinling Railway Station; $34^{\circ} 14^{\prime} 13^{\prime \prime} \mathrm{N}, 106^{\circ} 55^{\prime} 08^{\prime \prime}$ E; 1440 m a.s.l.; 18 Aug. 2019; Ning Li \& Yue Pan leg.

Measurements. Male: $\mathrm{FL}=10.4-11.9 \mathrm{~mm}, \mathrm{FW}=2.9-3.1$ $\mathrm{mm} ; \mathrm{HL}=9.4-11.0 \mathrm{~mm}, \mathrm{HW}=2.7-3.1 \mathrm{~mm}$. Female: $\mathrm{FL}$ $=11.2-12.6 \mathrm{~mm}, \mathrm{FW}=3.0-3.3 \mathrm{~mm} ; \mathrm{HL}=10.1-11.5$ $\mathrm{mm}, \mathrm{HW}=2.9-3.2 \mathrm{~mm}$.

Distribution. China: Shaanxi. 

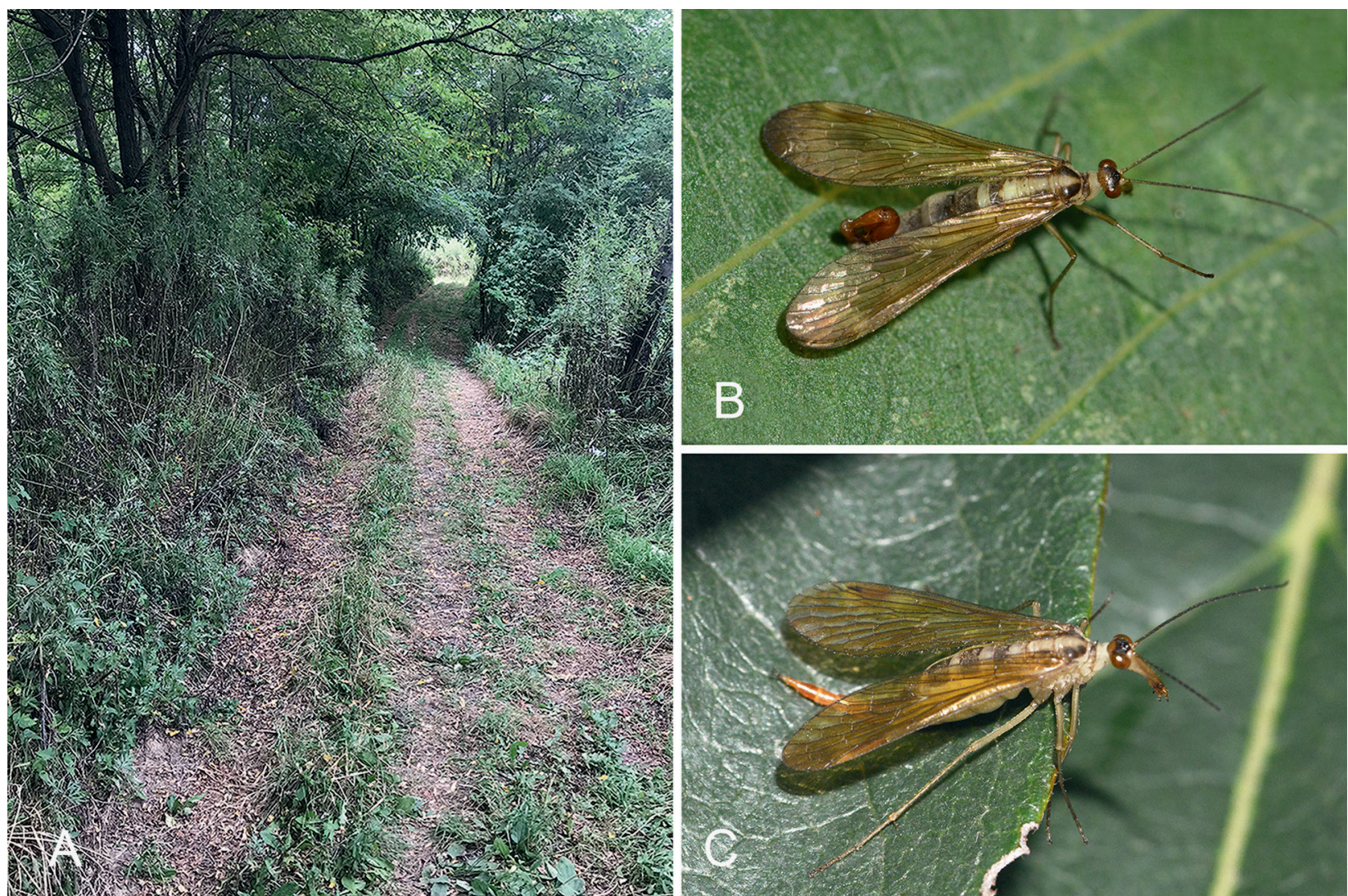

Figure 12. Live adult habitus and habitat of Panorpa fulvastra Chou, 1981. A. Habitat in Qinling Railway station, Fengxian, Shaanxi. B. Male, dorsal view. C. Female, dorso-lateral view. Photos by Ning Li (A) and by Kai Gao (B-C).

\section{Panorpa gaokaii sp. nov.}

Figs 13-14

Diagnosis. This species can be recognized by the following features: (1) frons and occiput yellowish brown (Fig. 14A-C); (2) vertex with broad black transverse band passing through ocellar triangle, extending to inner margins of compound eyes (Fig. 14A-C); (3) forewing with pterostigma brown; apical band indistinctly faint brown, greatly reduced; other bands and spots absent (Figs $13 \mathrm{~A}-\mathrm{B}, 14 \mathrm{~A}-\mathrm{B})$; in males, (4) meso- and metanotum pale brown, with broad pale yellow mesal stripe extending to T3 (Figs 13B, 14A); (5) A6 uniformly black, projected on dorsal apex with sparse long brown setae (Fig. 14D); (6) gonocoxites bearing cluster of black setae on inner apex (Fig. 14F-G); (7) parameres crossed, twisted in S-shape, reaching apex of gonocoxites (Fig. 14H); in females, (8) medigynium with main plate broad, long, twice as long as wide; a pair of large lateral basal plates reaching three-fourths of length of main plate; posterior arms half length of main plate; axis extended beyond main plate for half of its length anteriorly, extruded posteriorly (Fig. 14K-L).

Etymology. The specific epithet is dedicated to Kai Gao, the collector of the type specimens, for his support to this research.
Material examined. Holotype: CHINA- Hubei Prov. • $\jmath^{\dagger}$; Shennongjia National Nature Reserve; 1800 m a.s.1.; 1 Jul. 2018; Kai Gao leg. Paratypes: CHINA - Hubei Prov. 7 $\hat{\partial}, 10$ 우; same data as holotype.

Measurements. Male: $\mathrm{FL}=13.3-14.3 \mathrm{~mm}, \mathrm{FW}=$ $3.7-3.9 \mathrm{~mm}$; $\mathrm{HL}=12.0-13.0 \mathrm{~mm}, \mathrm{HW}=3.5-3.6 \mathrm{~mm}$. Female: $\mathrm{FL}=13.9-14.2 \mathrm{~mm}, \mathrm{FW}=3.7-3.8 \mathrm{~mm} ; \mathrm{HL}=$ $2.8-13.1 \mathrm{~mm}, \mathrm{HW}=3.4-3.5 \mathrm{~mm}$.

Description. Male: Head (Figs 13A-B, 14A, C): Frons and occiput yellowish brown; vertex with broad black transverse band passing through ocellar triangle and extending to inner margins of compound eyes. Rostrum yellow, with labrum brown; labial and maxillary palps yellowish brown basally, gradually darkening toward apex, with apical segment dark brown. Antennal scape ununiformly brownish black; pedicel and flagellum dark brown, filiform, with 35-39 flagellomeres. Thorax (Figs 13A-B, 14A, D): Pronotum unevenly pale brown, with two darkbrown transverse stripes, bearing 10-14 black setae along anterior margin; meso- and metanotum pale brown, with broad pale to pale yellow mesal stripe. Pleura pale yellow. Legs yellowish brown with tarsi darkened toward apices. Wings (Figs 13A-B, 14A): Membrane hyaline. Forewing with pterostigma reddish brown. Apical band indistinctly faint brown, greatly reduced, arranged between $\mathrm{R}_{2 \mathrm{al}}$ and $R_{5}$ or $M_{1}$. Hindwing similar to forewing, but slightly smaller with reduced markings. Abdomen (Figs 13A-B, 

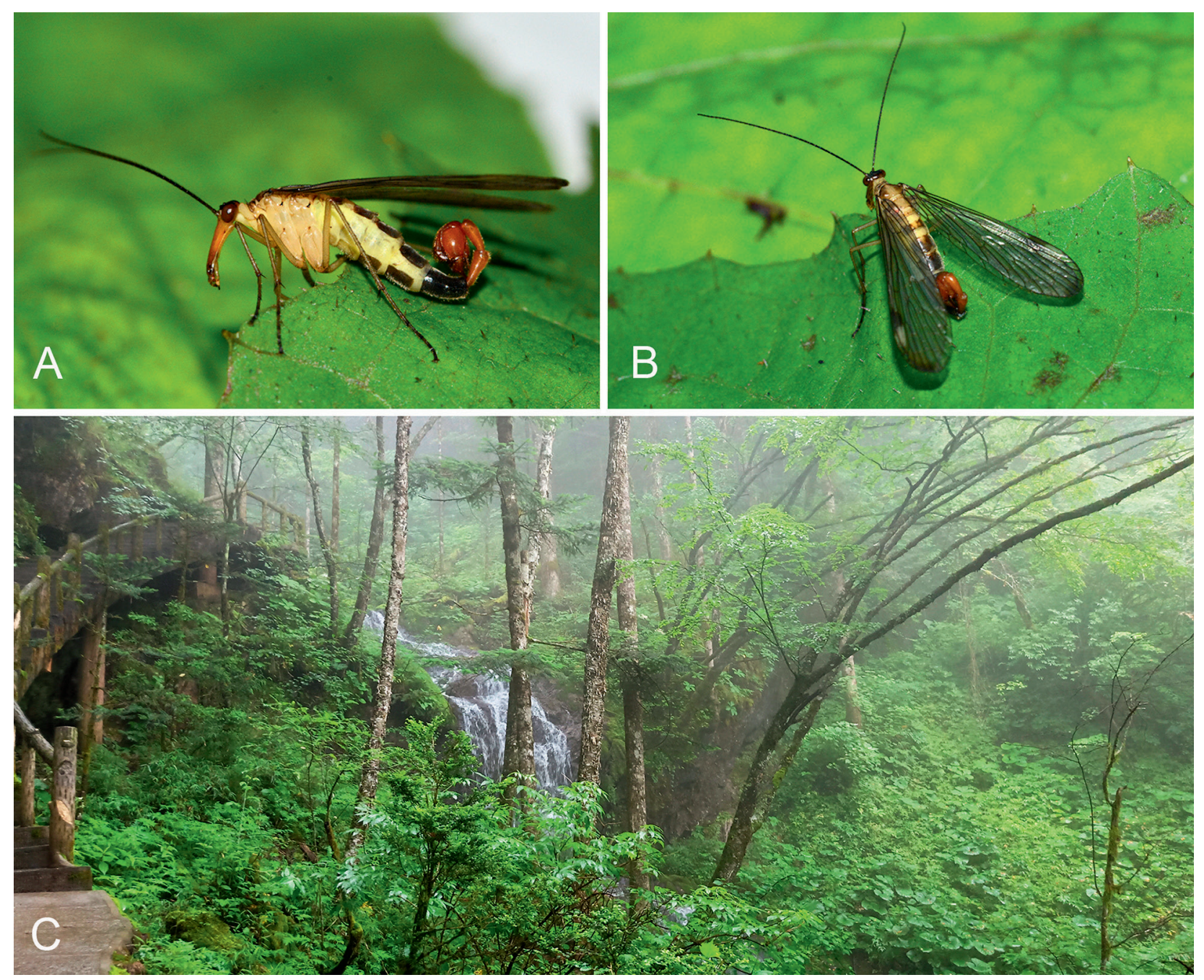

Figure 13. Live adult habitus and habitat of Panorpa gaokaii sp. nov. A-B Male, lateral and dorsal views. C. Habitat in Shennongjia, Hubei. Photos by Kai Gao.

14A, D): T2 and T3 unevenly pale with lateral and posterior margins dark brown. Notal organ of T3 flat rectangular, covering acute postnotal organ on anterior portion of T4. T4-T6 black brown. A6 projected on dorsal apex with long brown setae. A7 and A8 elongate, uniformly yellow, constricted basally. Genitalia (Fig. 14E-I): Genital bulb oval, yellow. Epandrium broad basally, bearing dense setae distally, with deep terminal emargination. Cercus long clavate, slightly expanded towards apex. Hypandrium with shortened basal stalk; hypovalves long and broad, reaching apex of gonocoxites; each hypovalve rounded at apex, bearing long dense setae along apical half and shorter setae along basal half on inner margin. Gonocoxites bearing cluster of stout black setae on inner apex. Gonostylus with large basal cup and obtuse triangular median tooth. Parameres twisted in S-shape, crossed mesally, bearing dense short spines on inner margin. Dorsal valves of aedeagus slender, strongly curved ventrally; with circular dorsal process on middle portion. Ventral valves shortened. Lateral process distinctly triangled. Female: Similar to male in body coloration except, T3 uniformly dark brown in most females and small portion pale in a few specimens. Wing markings similar to males (Fig. 14B). Genitalia (Fig. 14J-L): Subgenital plate broad subbasally, narrowing into subtriangular and indistinctly distal emarginate, bearing long setae on caudal and lateral margins. Medigynium with well-developed main plate, nearly rectangular, twice as long as wide; lateral basal plates broad, long, reaching three-fourths length of main plate, each basal plate formed by two pieces of sclerotized structures basally connected by membrane; posterior arms half length of main plate, forming deep U-shaped emargination; axis elongated, bifurcated anteriorly, extended beyond main plate for half of its length, with posterior slightly extruded.

\section{Distribution. China: Hubei.}

Remarks. This new species resembles $P$. bashanicola in appearance, but can be readily differentiated from the latter by the following characters: (1) wing with apical band narrow (cf. absence); (2) 1A ending beyond (cf. before) the origin of Rs; (3) forewing usually longer than $13 \mathrm{~mm}$ (cf. shorter than $13 \mathrm{~mm}$ ). 


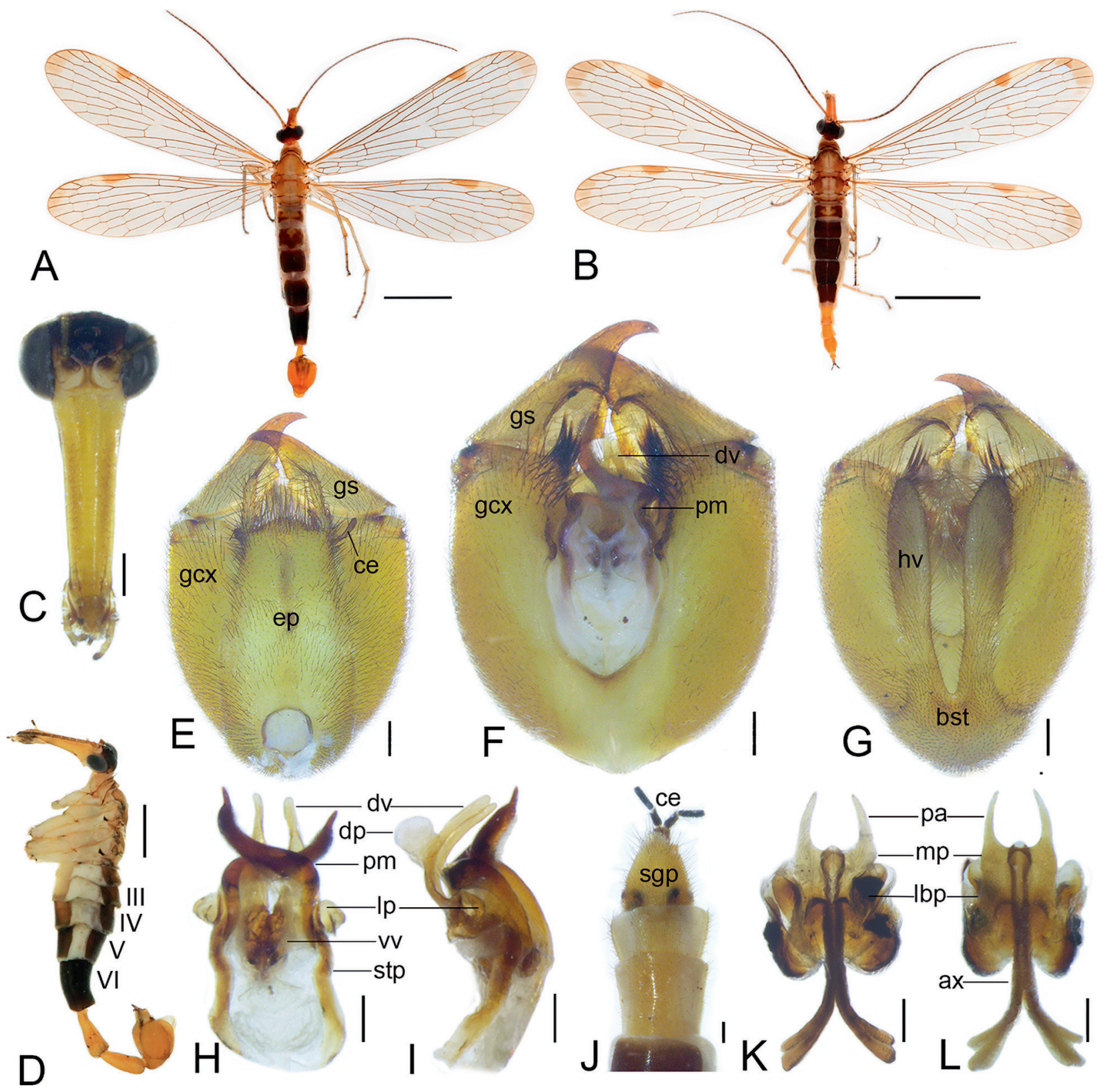

Figure 14. Panorpa gaokaii sp. nov from Shennongjia, Hubei. A, C-I. Male. A. Habitus, dorsal view. C. Head, frontal view. D. Habitus, lateral view. E-G. Genital bulb, dorsal, ventral (removing hypandrium), and ventral views. H-I. Aedeagal complex, ventral and lateral views, respectively. B, J-L. Female. B. Habitus, dorsal view. J. Terminalia, ventral view. K-L. Medigynium, ventral and dorsal views. Scale bars: $\mathrm{A}-\mathrm{B}=5 \mathrm{~mm} ; \mathrm{C}=0.5 \mathrm{~mm} ; \mathrm{D}=2 \mathrm{~mm}$; $\mathrm{E}-\mathrm{L}=0.2 \mathrm{~mm}$.

\section{Panorpa huayuani sp. nov.}

Figs $15-16$

Diagnosis. This species can be recognized by the following features: (1) forewing apical band broad with large hyaline spot posteriorly; pterostigmal band with broad basal branch and thin or incomplete apical branch; marginal spot conspicuous; basal band broad; basal spots greatly reduced, faint (Figs 15C-D, 16A-B); (2) mesoand metanotum black brown to black, with narrow or indistinct yellow mesal stripe (Figs 15C-D, 16A-B); in males, (3) gonocoxites with 4-5 stout setae on inner apex ventrally, and triangular notch on subapical portion (Fig. $16 \mathrm{G})$; (4) parameres crossed mesally, twisted in S-shape
(Fig. 16G, I); in females, (5) medigynium with main plate broad, elongate, twice as long as wide; a pair of lateral basal plates on middle part of main plate; axis extended beyond main plate for half of its length anteriorly (Fig. $16 \mathrm{~K}-\mathrm{L})$.

Etymology. The specific name is dedicated to Yuan Hua, the collector of the type specimens.

Material examined. Holotype: CHINA - Shaanxi - $\delta$; Ankang, Hualongshan; 2200 m a.s.1.; 24 Jul. 2018; Yuan Hua leg. Paratypes:

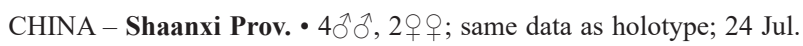
2018; Yuan Hua leg. ・ 1 $\widehat{\jmath}, 3$ 우; same data as holotype; 4 Aug. 2020;

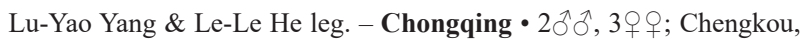
Huang'anba Alpine Shrub Meadow; 2400 m a.s.1.; 22 Jun. 2018; Yuan 

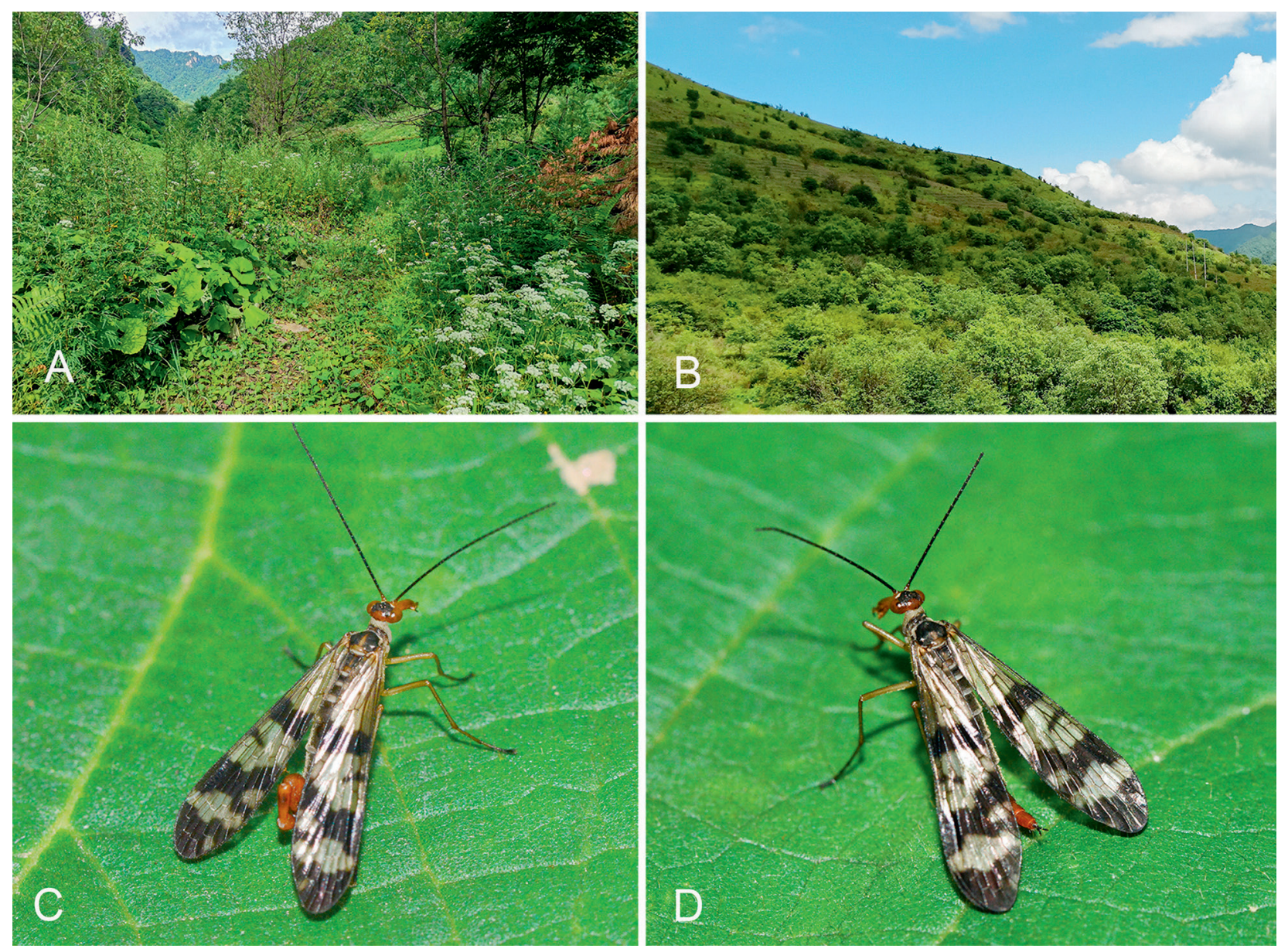

Figure 15. Live adult habitus and habitat of Panorpa huayuani sp. nov. A. Habitat in Hualongshan, Shaanxi. B. Habitat in Huang'anba, Chengkou, Chongqing. C. Male, dorsal view. D. Female, dorsal view. Photos by Le-Le He (A) and by Kai Gao (B-D).

Hua \& Kai Gao leg. - Hubei Prov. • 19; Shennongjia, Jiuhuping; 24 Jun. 2018; Yuan Hua leg.

Measurements. Male: $\mathrm{FL}=10.0-10.9 \mathrm{~mm}, \mathrm{FW}=2.7-$ $3.1 \mathrm{~mm}$; HL $=9.0-9.9 \mathrm{~mm}, \mathrm{HW}=2.6-2.9 \mathrm{~mm}$. Female: $\mathrm{FL}=10.9-11.3 \mathrm{~mm}, \mathrm{FW}=3.0-3.1 \mathrm{~mm} ; \mathrm{HL}=10.0-10.4$ $\mathrm{mm}, \mathrm{HW}=2.9-3.0 \mathrm{~mm}$.

Description. Male: Head (Figs 15C, 16A, C-D): Frons, vertex and occiput yellowish brown; broad black transverse band passing through ocellar triangle and extending to inner margins of compound eyes. Rostrum yellow, with labrum brown; labial and maxillary palps yellow basally and gradually darkened towards apex, with apical segment dark brown. Antennal scape unevenly yellowish brown; pedicel and flagellum dark brown, filiform, with 35-37 flagellomeres. Thorax (Figs 15C, 16A, D): Pronotum brownish black, bearing 10-12 black setae along anterior margin; meso- and metanotum unevenly black, bearing narrow yellow mesal stripe, with scutellum dark brown. Pleura and coxae pale. Legs yellowish, with tarsi darkened toward apices. Wings (Figs 15C, 16A): Forewing membrane hyaline, with wing markings dark brown. Apical band broad, with hyaline inner spot. Pterostigmal band complete, with basal branch approximately three times as wide as apical branch; basal band broad; marginal spot separated, thin, striped or absent; basal spot greatly reduced. Hindwing similar to forewing, but with relatively reduced markings and slightly smaller. Abdomen (Figs 15C, 16A, E): T2-T5 black. Notal organ of T3 flat triangular, covering acute postnotal organ on T4. A6 cylindrical, basal three-fourths brownish black, distal third yellowish brown, slightly projected on dorsal apex with sparse long dark brown setae. A7 and A8 elongate, usually yellow, constricted basally, gradually wider toward apices. Genitalia (Fig. 16F-I): Genital bulb long oval, yellow. Epandrium broad basally, narrowed towards apex, with U-shaped terminal emargination, bearing dense setae. Cercus long clavate, expanded apically, yellowish brown, with slightly darker apex. Hypandrium with reduced stalk and pair of slender hypovalves, extending two-thirds length of gonocoxites; hypovalve bearing separated long setae on inner margin. Gonocoxite bearing 4-5 stout setae on inner apex ventrally and triangular notch on subapical portion. Gonostylus with large basal cup and obtuse triangular median tooth on inner margin. Parameres twisted in S-shape, mesally crossed, bearing dense short spines on inner margin and whole distal portion; apex long, acute. Ventral valves greatly shortened. Dorsal valves of aedeagus elongated, bearing bundle of long hairs ventrally on base and enlarged dorsal process on subapical portion dorsally. Lateral process distinctly triangular. - Female: Similar to male except, relatively denser wing markings (Figs 15D, 16B). Genitalia (Fig. 


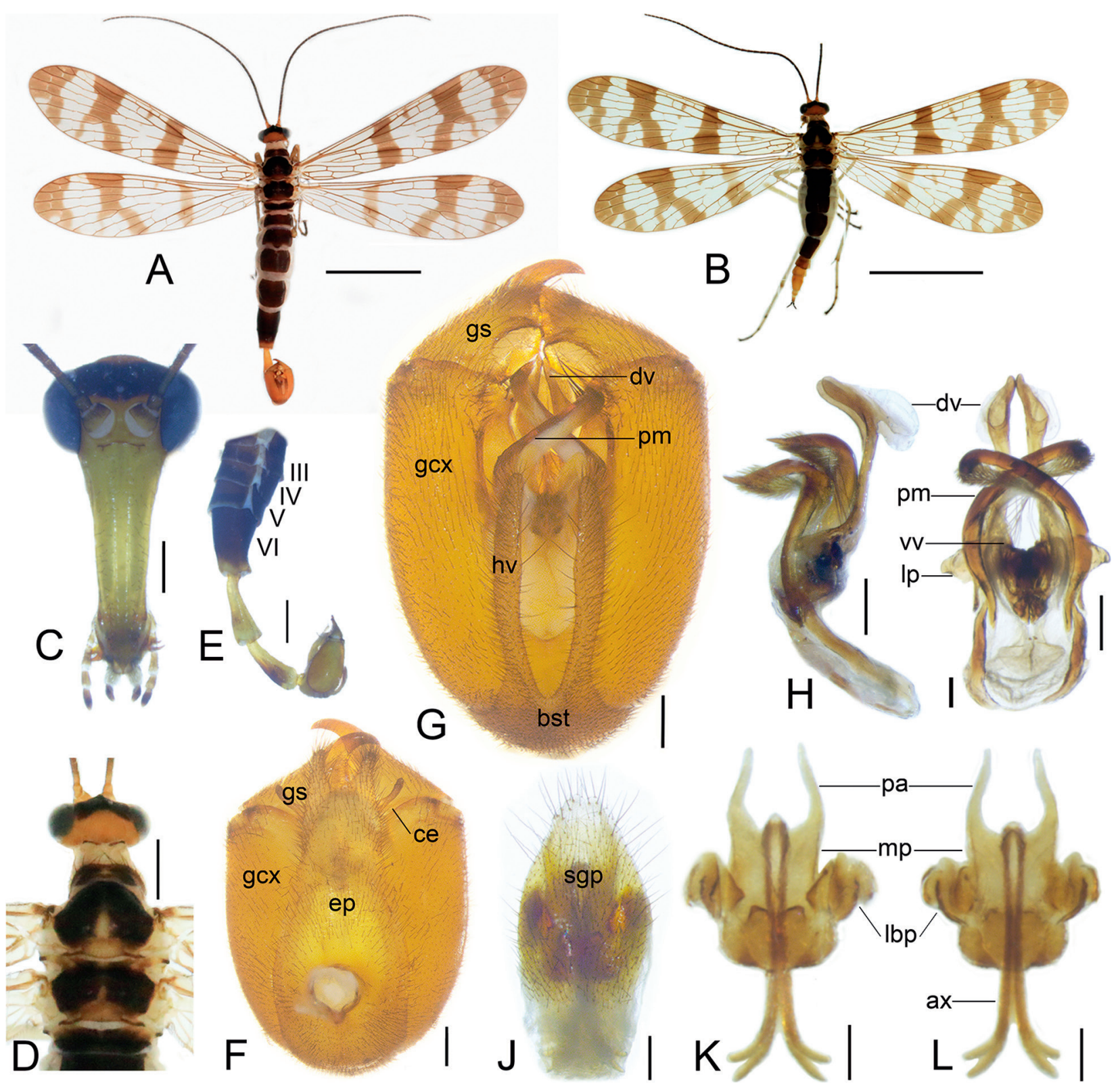

Figure 16. Panorpa huayuani sp. nov. from Ankang, Shaanxi. A, C-I. Male. A. Habitus, dorsal view. C. Head, frontal view. D. Dorsum, dorsal view. E. Abdomen, lateral view. F-G. Genital bulb, dorsal and ventral views. H-I. Aedeagal complex, lateral and ventral views. B, J-L. Female. B. Habitus, dorsal view. J. Subgenital plate, ventral view. K-L. Medigynium, ventral and dorsal views. Scale bars: $\mathrm{A}-\mathrm{B}=5 \mathrm{~mm} ; \mathrm{C}=0.5 \mathrm{~mm}$; D-E $=1 \mathrm{~mm} ; \mathrm{F}-\mathrm{L}=0.2 \mathrm{~mm}$.

16J-L): Subgenital plate broad subbasally, narrowed towards apex, with V-shaped terminal emargination, bearing long setae on distal third laterally. Medigynium with well-developed main plate, twice as long as wide; middle part bearing pair of lateral basal plates; posterior arms slender, half length of main plate, forming large, deep U-shaped emargination; axis elongated, bifurcated anteriorly, extended beyond main plate for half of its length, with posterior distinctly extruded.

Distribution. China: Chongqing, Hubei, Shaanxi.

Remarks. This new species resembles $P$. sexspinosa in appearance, but can be readily differentiated from the latter by: (1) meso- and metanotum unevenly black, bearing an indistinct narrow (cf. distinct) yellow mesal stripe;
(2) basal spot greatly reduced (cf. absent); (3) hypovalve extremely slender (cf. broad); separated (cf. dense) long setae on inner margin; (4) middle (cf. basal) region of medigynium bearing a pair of lateral basal plates.

\section{Panorpa jinchuana Hua, Sun \& Li, 2001}

Fig. 17

Panorpa jinchuana Hua, Sun \& Li, 2001: 121, fig. 1A-B. Type locality: Jinchuan, Sichuan, China; Wang \& Hua, 2018: 355, figs 5-129-1-5129-2.

Diagnosis. This species can be readily recognized by the following characters: (1) wing markings well-devel- 


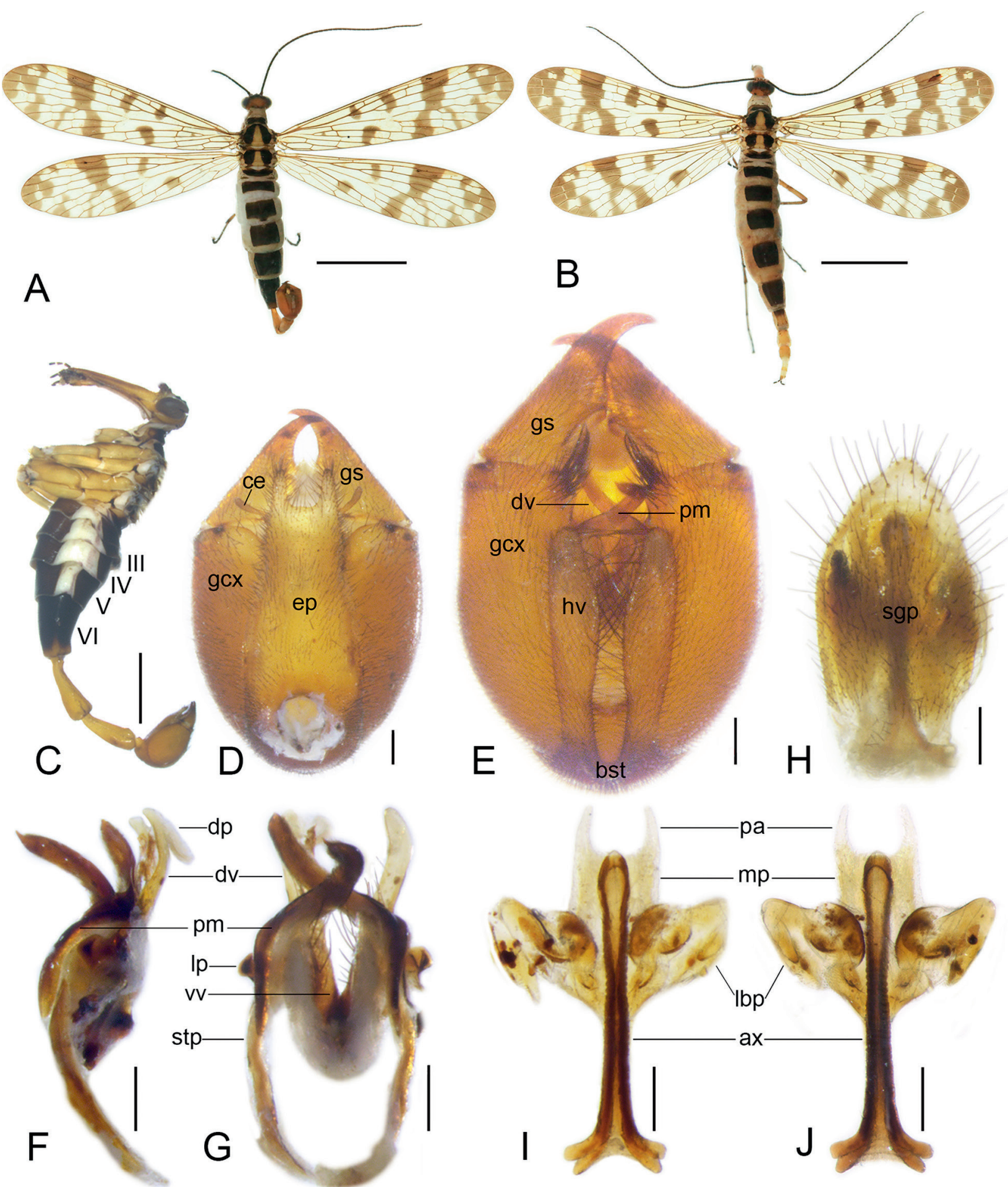

Figure 17. Panorpa jinchuana Hua, Sun \& Li, 2001 from Danba, Sichuan. A, C-G. Male. A. Habitus, dorsal view. C. Habitus, lateral view. D-E. Genital bulb, dorsal and ventral views. F-G. Aedeagal complex, lateral and ventral views. B, H-J. Female. B. Habitus, dorsal view. H. Subgenital plate, ventral view. I-J. Medigynium, ventral and dorsal views. Scale bars: A-B = $5 \mathrm{~mm}$; C = $2 \mathrm{~mm}$; D-J $=0.2 \mathrm{~mm}$.

oped, forewing apical band with two inner hyaline spots; pterostigmal band complete, with broad basal branch and thinly connected or detached apical branch; marginal spot large; basal band split into two spots; basal spot greatly reduced (Fig. 17A-B); (2) meso- and metanotum black, with broad pale mesal stripe (Fig. 17A-B); in males, (3) gonocoxites with cluster of long setae along slightly oblique inner apex ventrally (Fig. 17E); (4) parameres crossed mesally, twisted in S-shape (Fig. 17G); in females, (5) main plate of medigynium three times as long as posterior arms; axis extended beyond main plate for half of its length anteriorly (Fig. 17I-J).

Material examined. CHINA - Sichuan Prov. $\bullet 1 \hat{\jmath}$ (Holotype); Jinchuan; 10 Sep. 1963; Sheng-Li Liu leg. 10 (Paratype); Jinchuan; 8 Sep.

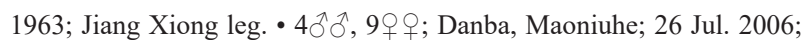


Xiao-Yan Hou et al. leg. ・1 ${ }^{\lambda}$, 1 우 $Z$ Zhonglu; 30 $53^{\prime} 46^{\prime \prime} \mathrm{N}, 101^{\circ} 55^{\prime} 50^{\prime \prime} \mathrm{E}$; $2230 \mathrm{~m}$ a.s.1.; 7 Jul. 2019; Ning Li \& Lu Liu leg. $111 \widehat{\jmath}$, 13우; Donggu; $30^{\circ} 46^{\prime} 37^{\prime \prime} \mathrm{N}, 101^{\circ} 43^{\prime} 48^{\prime \prime} \mathrm{E}$; 2230 m a.s.1.; 8 Jul. 2019; Ning Li \& Lu Liu leg.

Measurements. Male: $\mathrm{FL}=11.8-13.0 \mathrm{~mm}, \mathrm{FW}=3.0-3.2$ $\mathrm{mm} ; \mathrm{HL}=10.9-12.0 \mathrm{~mm}, \mathrm{HW}=2.8-3.1 \mathrm{~mm}$. Female: $\mathrm{FL}=12.2-14.0 \mathrm{~mm}, \mathrm{FW}=3.0-3.4 \mathrm{~mm} ; \mathrm{HL}=11.0-13.0$ $\mathrm{mm}, \mathrm{HW}=2.9-3.3 \mathrm{~mm}$.

Description. Female: Head (Fig. 17B): Frons, vertex and occiput yellowish brown. Black transverse band passing through ocellar triangle, extending to inner margins of compound eyes. Rostrum yellow, slender, with labrum dark brown. Maxillary and labial palps mostly pale brown, with distal segments dark brown. Antennal scape yellowish brown; pedicel dark yellowish brown; flagellum blackish brown, filiform. Thorax (Fig. 17B): Pronotum black, with 12-16 stout setae along anterior margin. Meso- and metanotum black, with prominent pale yellow mesal stripe; scutella totally pale yellow. Pleura yellowish; legs yellowish brown, with distal tarsomere blackish. Wings (Fig. 17B): Membrane hyaline, with black brown markings. Forewing apical band with two hyaline spots inside; pterostigmal band complete, with broad basal branch and thinly connected or detached apical branch; marginal spot large; basal band split into two spots; basal spot greatly reduced between veins $\mathrm{CuA}$ and $\mathrm{CuP}$. Abdomen (Fig. 17B): T2-T6 black. A7-A10 uniformly yellowish brown. Genitalia (Fig. 17H-J): Subgenital plate ligulate, bearing long setae on distal quarter. Medigynium with main plate oblong, broad; three times as long as posterior arms; pair of large wing-like lateral basal plates on basal half; axis slightly extruded posteriorly, extended beyond main plate for half of its length anteriorly.

Distribution. China: Sichuan.

Remarks. Panorpa jinchuana was described from two males from Jinchuan, Sichuan. The male and female specimens obtained from Danba, Sichuan match the characters of this species. Here, the female is described and illustrated for the first time.

\section{Panorpa neospinosa Chou \& Wang, 1981}

Panorpa neospinosa Chou \& Wang in Chou et al., 1981: 7, figs 19-23. Type locality: Qinling Railway Station, Shaanxi, China; Wang \& Hua, 2018: 374, figs 5-138-1-5-138-2.

Diagnosis. This species can be readily recognized by the following characters: (1) wing markings well-developed, forewing apical band broad with one or two large inner hyaline spots; pterostigmal band with broad basal branch and thin apical branch; marginal spot large; broad basal band complete; basal spots large; (2) meso- and metanotum blackish brown, with prominent pale yellow mesal stripe; in males, (3) gonocoxites bearing 4-7 (usually 6) long setae along beveled inner apex ventrally; (4) param- eres crossed mesally, twisted in S-shape, extended beyond gonocoxites; in females, (5) medigynium with main plate long, broad; a pair of lateral basal plates reaching two-thirds of main plate; axis extended beyond main plate for one-third of its length anteriorly.

Material examined. CHINA - Shaanxi Prov. • $1 \circlearrowleft$ (Holotype); Fengxian, Qinling Railway Station; 1600-2000 m a.s.1.; 18 Aug. 1965; Io

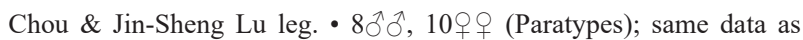
holotype $・ 1$ ㅇ (Paratype); Zhouzhi, Tianyu; 18-19 Aug. 1951; Io Chou leg.

Measurements. Male: $\mathrm{FL}=10.0-11.1 \mathrm{~mm}, \mathrm{FW}=3.0-3.2$ $\mathrm{mm} ; \mathrm{HL}=9.1-10.0 \mathrm{~mm}, \mathrm{HW}=2.9-3.1 \mathrm{~mm}$. Female: $\mathrm{FL}$ $=10.5-11.5 \mathrm{~mm}, \mathrm{FW}=3.0-3.3 \mathrm{~mm} ; \mathrm{HL}=9.6-10.5 \mathrm{~mm}$, $\mathrm{HW}=2.9-3.2 \mathrm{~mm}$.

\section{Distribution. China: Shaanxi.}

Remarks. Panorpa neospinosa resembles $P$. sexspinosa, but differs from the latter in the conspicuous (cf. absent) basal spot.

\section{Panorpa qinlingensis Chou \& Ran, 1981}

Panorpa qinliengensis Chou \& Ran in Chou et al., 1981: 9, figs 30-33. Type locality: Qinling, Shaanxi, China; Wang \& Hua, 2018: 388, figs 5-145-1-5-145-2

Diagnosis. This species can be readily recognized by the following characters: (1) forewing with apical band broad, bearing large hyaline spot posteriorly; pterostigmal band complete, with broad basal branch and thin apical branch; marginal spot long and narrow or inconspicuous; basal band broad; basal spot extremely reduced or absent; (2) meso- and metanotum blackish brown with conspicuous yellowish mesal stripe; in males, (3) gonocoxites with triangular process on inner apex ventrally, bearing 1 or 2 long setae on inner margin subapically; (4) parameres crossed mesally, twisted in S-shape; in males, (5) medigynium with main plate almost oblong in shape, twice as long as wide; a pair of large basal plates reaching the middle of main plate; axis extended beyond main plate for two-fifths of its length anteriorly.

Material examined. CHINA - Shaanxi Prov. • $1 \lesssim$ (Holotype); Qin-

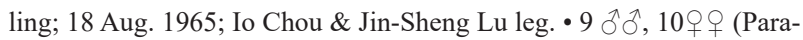
types); same data as holotype ・ $7 \hat{\jmath} \hat{\jmath}, 5$ 우; Nanzheng, Liping Village; 1650 m a.s.1.; 9 Aug. 2011; Shuang Xue leg. • 9ð̋̋, 3우; Liping National Forest Park, Qixingge; 1500 m a.s.1.; 30 Jun. 2018; Zheng Wei

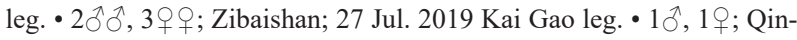
ling Railway Station; $34^{\circ} 14^{\prime} 13^{\prime \prime} \mathrm{N}, 106^{\circ} 55^{\prime} 08^{\prime \prime} \mathrm{E}$; $1440 \mathrm{~m}$ a.s.1.; 18 Aug. 2019; Ning Li leg. - Sichuan Prov. • 3 $\widehat{\jmath}, 2$, $\circ$; Wanyuan, Huaeshan; 1200 m a.s.1.; 16 Jun. 2018; Kai Gao \& Yu-Ru Yang leg.

Measurements. Male: $\mathrm{FL}=10.2-12.2 \mathrm{~mm}, \mathrm{FW}=2.8-3.1$ $\mathrm{mm}$; HL $=9.0-11.4 \mathrm{~mm}, \mathrm{HW}=2.7-3.0 \mathrm{~mm}$. Female: FL $=10.4-12.7 \mathrm{~mm}, \mathrm{FW}=2.9-3.2 \mathrm{~mm} ; \mathrm{HL}=9.4-11.6 \mathrm{~mm}$, $\mathrm{HW}=2.8-3.1 \mathrm{~mm}$. 

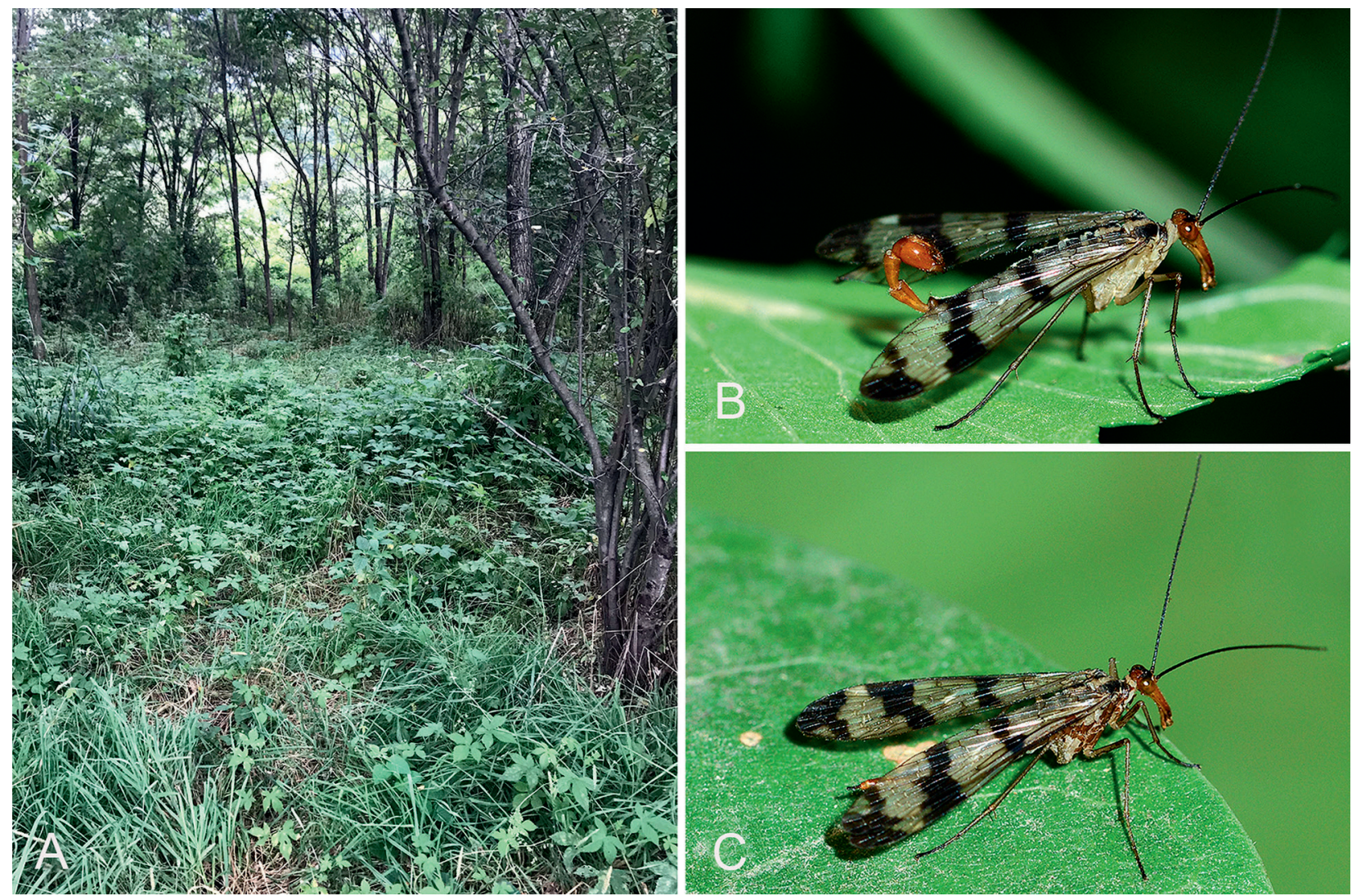

Figure 18. Live adult habitus and habitat of Panorpa sexspinosa Cheng, 1949. A. Habitat in Tiantaishan Forest Park, Baoji, Shaanxi. B. Male, dorso-lateral view. C. Female, dorso-lateral view. Photos by Ning Li (A) and by Xin Tong (B-C).

Distribution. China: Shaanxi, Sichuan.

Remarks. This species is bivoltine, overwintering in the prepupal stage in the soil. Adults emerge from mid-May to early June and from late July to mid-August in Liping, Shaanxi (Cai \& Hua 2009).

\section{Panorpa sexspinosa Cheng, 1949}

Figs 18-19

Panorpa sexspinosa Cheng, 1949: 145, figs 4, 8, 9, 15 \& 16. Type locality: "Taipaishan, Shensi" [now Taibaishan, Shaanxi], China; Cheng, 1957: 49, figs 81, 87, 89, 123, 124 \& 278; Chou et al. 1981: 5, figs 14-18; Wang \& Hua, 2018: 396, figs 5-149-1-5-149-3.

Panorpa sexspinosa zhongnanensis Chou \& Ran in Chou et al., 1981: 6. Type locality: Zhongnanshan, Shaanxi, China, syn. nov.

Panorpa shanyangensis Chou \& Wang in Chou et al., 1981: 8, figs 2829. Type locality: Cuipingshan, Shanyang, Shaanxi, China; Wang \& Hua, 2018: 400, figs 5-151-1, syn. nov.

Diagnosis. This species can be readily recognized by the following characters: (1) wing markings well-developed, forewing apical band broad with large hyaline spot posteriorly; pterostigmal band with broad basal branch, and thin or no apical branch; marginal spot slender or absent; basal band broad; basal spot absent (Figs 18B-C, 19AB); (2) meso- and metanotum blackish brown to black, with broad pale yellow mesal stripe (Fig. 19A-B); in males, (3) gonocoxites bearing 4-8 (usually 6) long setae along beveled inner apex ventrally (Fig. 19E-F); (4) parameres crossed mesally, twisted in S-shape, extending beyond gonocoxites (Fig. 19E, G); in females, (5) medigynium with main plate broad, pair of lateral basal plates reaching two-thirds length of main plate, each basal plate formed by three sclerotized structures connected by membrane; axis extended beyond main plate for onethird of its length anteriorly (Fig. 19J-K).

Material examined. CHINA - Shaanxi Prov. 10 (Holotype of $P$. sexspinosa); Taibaishan; Jul. 1942; Io Chou leg. $・ 1$ ㅇ (Holotype of $P$. shanyangensis); Shanyang, Cuipingshan; 14 Aug. 1973; Chou Tian, Tian-Yin Zeng \& Man-Sheng Ruan leg. • $1{ }^{\Uparrow}$ (Holotype of P. sexspinosa zhongnanensis); Nanwutai; 28 Aug. 1980; Su-Mei Wang leg. 15 우우 (Paratypes of P. sexspinosa zhongnanensis); same data as previous; Su-Mei Wang et al. leg. $・ 2 \widehat{\jmath}, 2$ 우 (Paratypes of $P$. sexspinosa zhongnanensis); Nanwutai; 8 Jul. 1979; Chou Tian \& Tong Chen leg. $・ 1$ र, 2우; Taibaishan; 5 Jul. 2020; Bao-Zhen Hua \& Xiao-Yan Wang leg. • 13\%; Qinling Railway Station; 18 Aug. 1965; Io Chou \& Jin-Sheng Lu

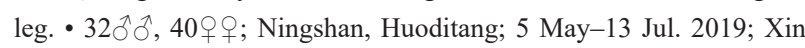
Tong \& Peng-Yang Wang leg. $・ 35 \hat{\jmath} \hat{\partial}, 42$ 우; Zhuque National Forest Park; 3 Sep. 2009; Yan-Kai Li \& Jie Meng leg. ・1 1 , 2 우; same data as previous; 8 Aug. 2020; Wan-Ruo Ma leg. $・ 3 \hat{\jmath} \widehat{\partial}, 1$; ; Tiantaishan Forest Park; 1500 m a.s.l.; 17 Jul. 2012; Qiong-Hua Gao \& Yan-Yan Feng leg. 3 3 + ; Niubeiliang National Forest Park; 2200 m a.s.1.; 29

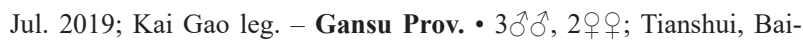
hua Forest Farm; 7 Aug. 2011; Na Ma leg. • 1 $\delta^{\lambda}$; Pingliang, Kongtongshan, Xiangshanding; 2090 m a.s.l.; 19 Jul. 2019; Yan-Na Zhang leg. - Henan Prov. • 1ô; Pingdingshan, Lushan, Yaoshan; 1200-1400 m 


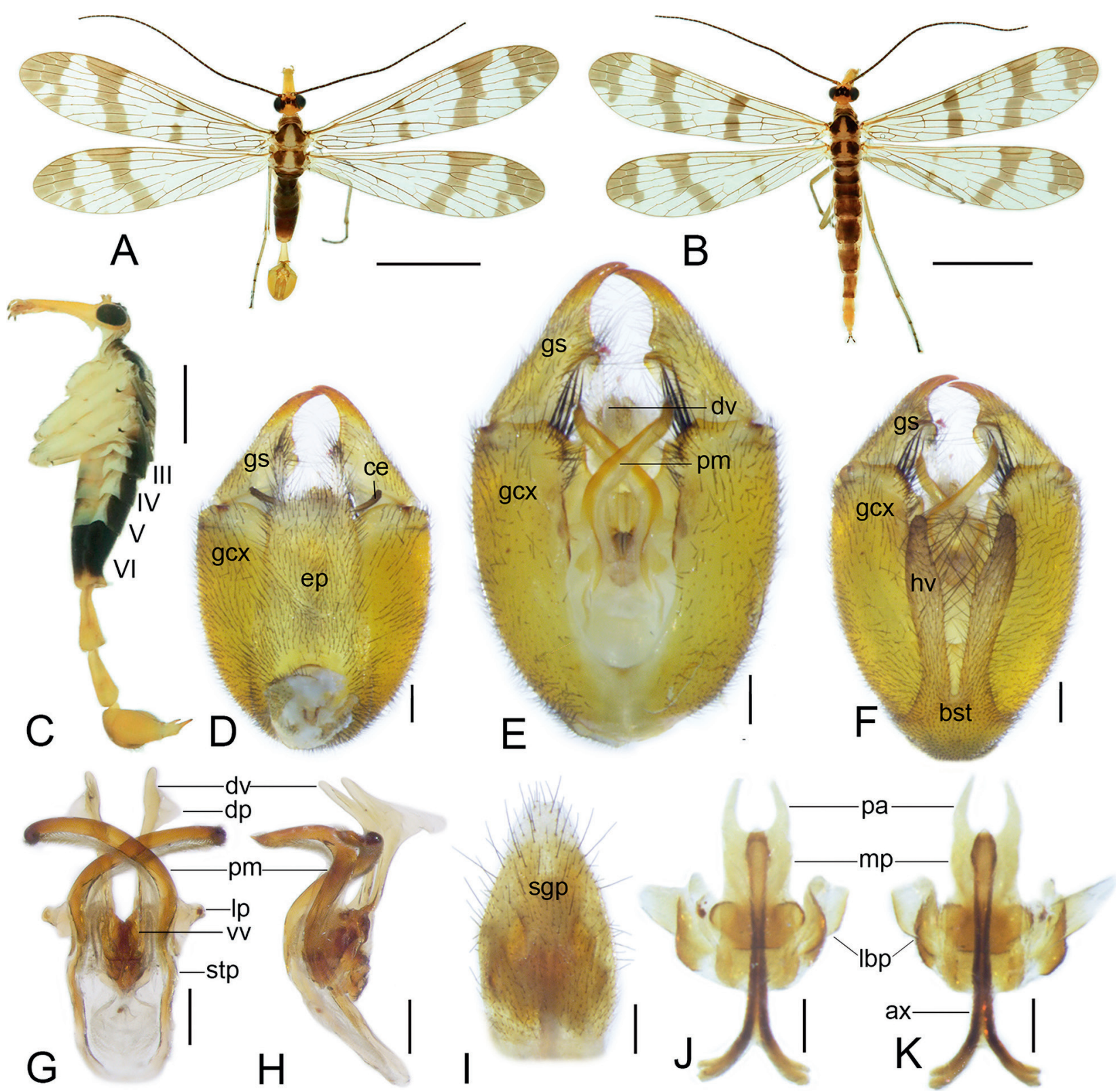

Figure 19. Panorpa sexspinosa Cheng, 1949 from Ningshan, Shaanxi. A, C-H. Male. A. Habitus, dorsal view. C. Habitus, lateral view. D-F. Genital bulb, dorsal, ventral (removing hypandrium), and ventral views. G-H. Aedeagal complex, ventral and lateral views. B, I-K. Female. B. Habitus, dorsal view. I. Subgenital plate, ventral view. J-K. Medigynium, dorsal and ventral views. Scale bars: $\mathrm{A}-\mathrm{B}=5 \mathrm{~mm}$; $\mathrm{C}=2 \mathrm{~mm}$; $\mathrm{D}-\mathrm{K}=0.2 \mathrm{~mm}$.

a.s.1.; 20 Jul. 2012; Bao-Zhen Hua leg. - Hubei Prov. •1乃; Shennongjia, Badong, Tiansanping.

Measurements. Male: $\mathrm{FL}=11.3-14.3 \mathrm{~mm}, \mathrm{FW}=3.0-3.5$ $\mathrm{mm}$; HL $=10.4-13.2 \mathrm{~mm}, \mathrm{HW}=2.8-3.3 \mathrm{~mm}$. Female: $\mathrm{FL}=11.6-14.7 \mathrm{~mm}, \mathrm{FW}=3.1-3.6 \mathrm{~mm} ; \mathrm{HL}=10.5-13.6$ $\mathrm{mm}, \mathrm{HW}=2.9-3.4 \mathrm{~mm}$.

Distribution. China: Gansu, Henan, Hubei, Shaanxi.

Remarks. Panorpa sexspinosa zhongnanensis was described from Nanwutai, Shaanxi. Based on our observations, no significant differences from the nominotypical subspecies have been found in morphological characters, including body colour, wing markings, and male and female genitalia. Therefore, P. sexspinosa zhong- nanensis is here treated as a junior synonym of $P$. sexspinosa.

Panorpa shanyangensis was described from a single female specimen from Cuipingshan, Shanyang, Shaanxi. It resembles $P$. sexspinosa in gross morphology, although it can be distinguished from the latter by three pairs (cf. a pair) of lateral basal plates, three spots, and incomplete apical band with three separated small spots near the inner margin (cf. apical band broad with a large hyaline spot posteriorly). After dissecting series of female specimens of $P$. sexspinosa from the type locality and other localities, we found that each complete basal plate is formed by three sclerotized structures connected by membrane. After comparing the female genitalia of $P$. shanyangensis and $P$. sexspinosa, we found these two nominal species share highly similar lateral basal plates and outline of 

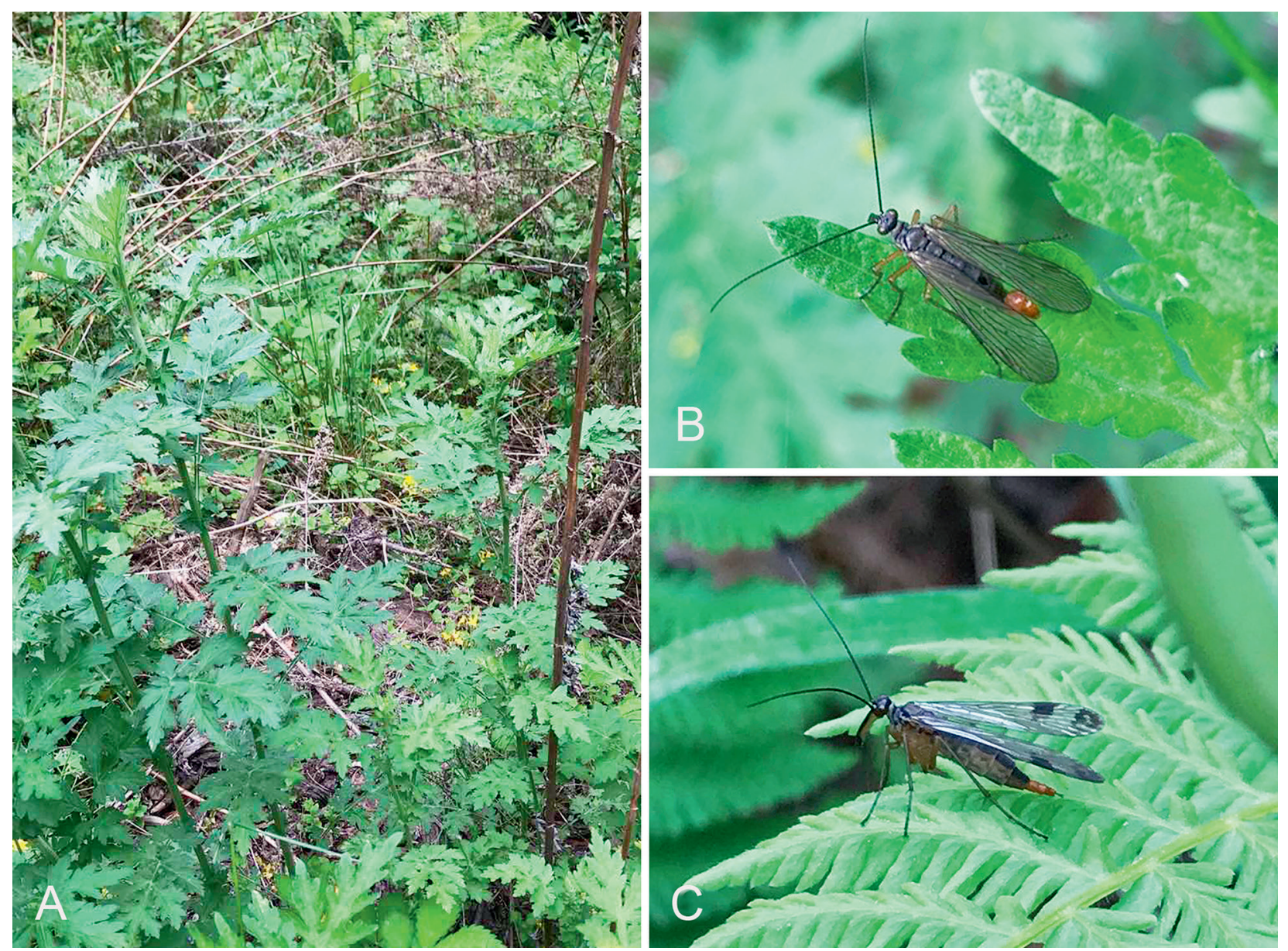

Figure 20. Live adult habitus and habitat of Panorpa stigmosa Zhou, 2006. A. Habitat in Pantiange, Weixi, Yunnan. B. Male, dorsal view. C. Female, dorso-lateral view. Photos by Ning Li.

the main plate. It is reasonable to consider that the apical band with three separated small spots near the inner margin in $P$. shanyangensis is variation of wing markings, thus $P$. shanyangensis and $P$. sexspinosa are very likely conspecific. Consequently, $P$. shanyangensis is treated as a junior subjective synonym of $P$. sexspinosa. In addition, according to the collection records, Panorpa sexspinosa is very likely a bivoltine insect in Shaanxi.

\section{Panorpa stigmosa Zhou, 2006}

Figs 20-21

Panorpa stigmosa Zhou, 2006: 274. Type Locality: Chishui Suoluo National Nature Reserve, Guizhou, China. Wang \& Hua, 2018: 420, figs 5-154-1-5-154-2.

Diagnosis. This species can be recognized by the following features: (1) frons, vertex, occiput and ocellar triangle black brown to black (Figs 20B-C, 21B-D); (2) wing membrane hyaline, with markings scattered into series of spots or only with pterostigma black brown in some males (Fig 21A-C); (3) pro-, meso- and metanotum blackish brown (Fig 20B-C); in males, (4) ventral termination of gonocoxites bearing 3-5 long setae and acute protuberance on inner apex (Fig. 21G); (5) param- eres crossed mesally, twisted in S-shape (Fig. 21G, I); in females, (6) main plate of medigynium broad, long, basal half narrow, distal half broad; small lateral basal plates on basal half not extended to the base; axis extended beyond main plate quarter of its length anteriorly, not extruded posteriorly (Fig. $21 \mathrm{~K}-\mathrm{L}$ ).

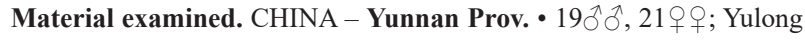
Snow Mountain; 6 Jun. 2009; Jiang-Li Tan leg. • 23 $\partial^{\lambda}$, 31우; Weixi, Pantiange; 2600 m a.s.1.; 13 Jun. 2016; Gui-Lin Hu \& Wei Du leg. •

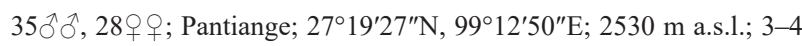
Jun. 2019; Ning Li \& Lu Liu leg.

Measurements. Male: $\mathrm{FL}=11.0-11.7 \mathrm{~mm}, \mathrm{FW}=2.4-2.7$ $\mathrm{mm} ; \mathrm{HL}=10.0-10.7 \mathrm{~mm}, \mathrm{HW}=2.3-2.6 \mathrm{~mm}$. Female: $\mathrm{FL}=11.2-12.1 \mathrm{~mm}, \mathrm{FW}=2.5-2.8 \mathrm{~mm} ; \mathrm{HL}=10.4-11.1$ $\mathrm{mm}, \mathrm{HW}=2.4-2.7 \mathrm{~mm}$.

Description. Male: Head (Figs 20B, 21B, D): Frons, vertex, occiput and ocellar triangle blackish brown; rostrum dark brown, with labrum blackish brown. Maxillary and labial palps dark brown, with distal segments darker. Antenna blackish brown. Thorax (Figs 20B, 21B, D): Pronotum black, with 10-16 stout setae along anterior margin. Meso- and metanotum black, without pale mesal stripe; scutella blackish brown. Pleura yellow. Legs pale yellowish brown with distal tarsomere black. Wings 


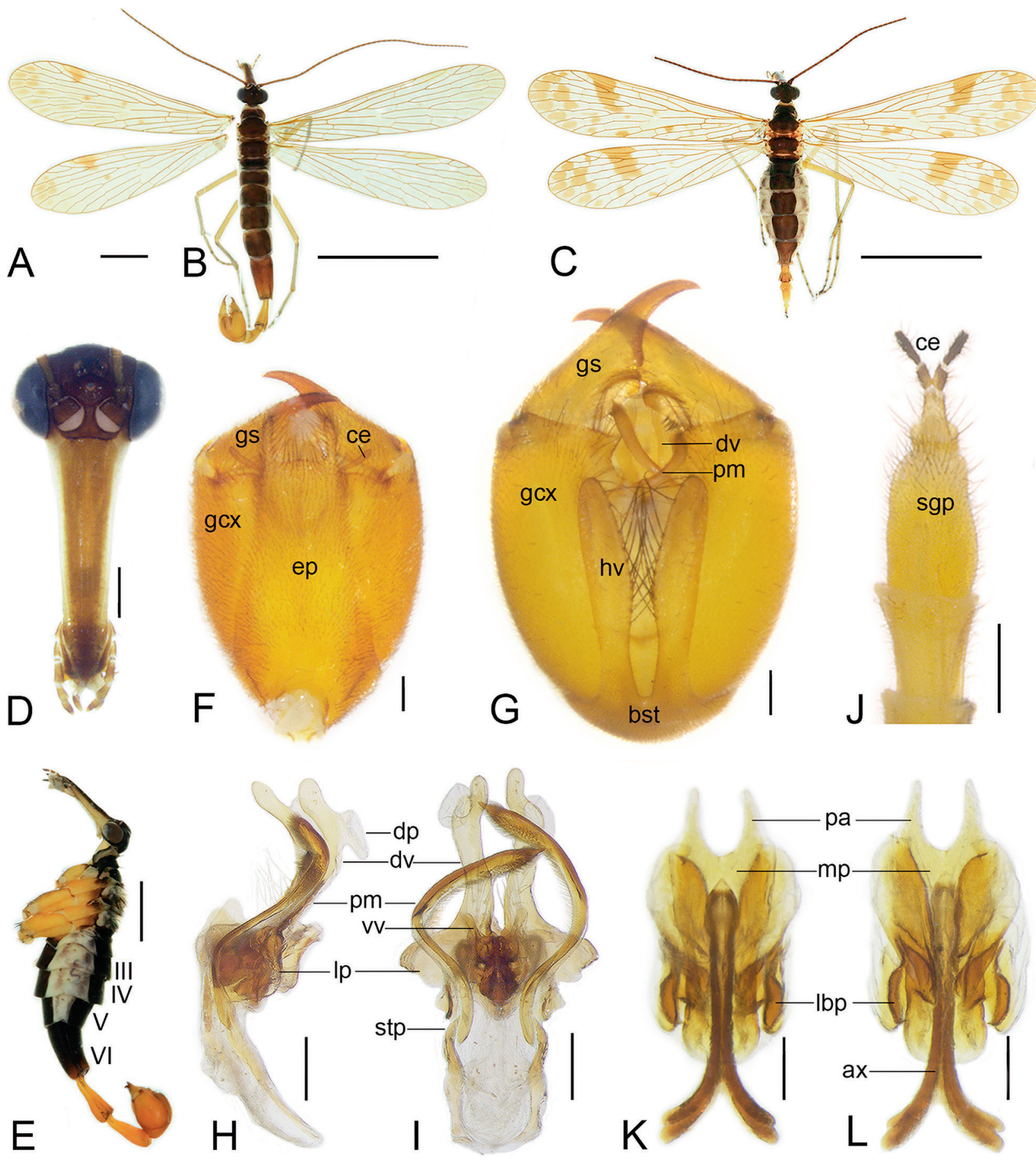

Figure 21. Panorpa stigmosa Zhou, 2006 from Yulong Snow Mountain (A) and Weixi (B-L), Yunnan. A-B, D-I. Male. A. Left forewing. B. Habitus, dorsal view (removing left forewing). D. Head, frontal view. E. Habitus, lateral view. F-G. Genital bulb, dorsal and ventral views. H-I. Aedeagal complex, lateral and ventral views. C, J-L. Female. C. Habitus, dorsal view. J. Terminalia, ventral view. $\mathbf{K}-\mathbf{L}$. Medigynium, ventral and dorsal views. Scale bars: $\mathbf{B}-\mathbf{C}=5 \mathrm{~mm} ; \mathbf{D}=0.5 \mathrm{~mm} ; \mathbf{A}, \mathbf{E}=2 \mathrm{~mm} ; \mathbf{F}-\mathbf{L}=0.2 \mathrm{~mm}$.

(Figs 20B, 21A-B): Membrane hyaline, with markings dark brown to black brown. Wing markings variable: only with pterostigma in some males; scattered into series of spots in most individuals. Forewing apical band broad, split into series of spots arranged in two rows; pterostigmal band broad, complete anteriorly, scattered into series of small spots posteriorly; marginal spot represented by small rounded spot between $\mathrm{R}$ and $\mathrm{M}$; basal band incomplete, reduced to irregular spot usually between $\mathrm{CuA}$ and CuP; basal spot usually faint or absent. Abdomen (Figs
20B, 21B, E): T2-T5 black. Notal organ of T3 covering acute postnotal organ of T4. A6 cylindrical with basal two-thirds black and distal one-third reddish brown. A7 and $\mathrm{A} 8$ yellowish brown, constricted basally. Genitalia (Fig.21E-I): Genital bulb oval, yellowish brown. Epandrium long, broad, slightly tapered towards deep square terminal emargination, bearing numerous long dense setae. Hypandrium with shortened basal stalk and pair of hypovalves; hypovalves broadened from middle, extending to four-fifths length of gonocoxites, bearing row 
of long black bristles along inner margin of distal half. Gonocoxite bearing 3-5 long setae on inner apex ventrally, inner margin bearing acute protuberance. Gonostylus with obtuse triangular median tooth and large basal cup on inner margin. Parameres crossed, reaching apex of gonocoxites. Dorsal valves of aedeagus with enlarged dorsal process on subapical portion dorsally. Ventral valves greatly shortened. Lateral processes distinct, triangular.

\section{Distribution. China: Guizhou; Yunnan.}

Remarks. This species was described from a single female specimen from Chishui, Guizhou with promient scattered wing markings. The specimens obtained from Yunnan match the characters of $P$. stigmosa. Here, the male of this species is described for the first time.

\section{Panorpa typicoides Cheng, 1949}

Panorpa typicoides Cheng, 1949: 143, figs 3, 13, 14, 28 \& 31. Type locality: "Tachielu, Sikang” [now Kangding, Sichuan], China; Cheng, 1957: 40, figs 26, 36, 39, 66, 67, \& 276; Wang \& Hua, 2018: 416, figs 5-159-1-5-159-2

Diagnosis. This species can be readily recognized by the following characters: (1) wing markings well-developed, forewing apical band with two hyaline spots inside; pterostigmal band complete, with broad basal branch and connected or detached thin apical branch; marginal spot large; basal band split into two spots; basal spot prominent; (2) meso- and metanotum black, with broad pale mesal stripe; in males, (3) gonocoxites with cluster of long setae along oblique inner apex ventrally; (4) parameres crossed mesally, twisted in S-shape; in females, (5) main plate of medigynium twice as long as posterior arms; axis extended beyond main plate for half of its length anteriorly.

\footnotetext{
Material examined. CHINA - Sichuan Prov. - 1今 (Holotype); "Tachielu" [now Kangding]; 5000-8500 ft; 27 Aug. 1939; Fung Ying Cheng, Io Chou \& Tein Ho Hei leg. • 1 + (Paratype); same data as holotype •1; Kangding; 2500 m a.s.1.; 28 May 1983; Yuan-Qing Chen leg. •1ð̂, 1; Kangding; 2650 m a.s.1.; 29 May 1983; Shu-Yong Wang leg. • 1\%; Kangding; $2600 \mathrm{~m}$ a.s.1.; 4 Jun. 1983; Yuan-Qing Chen leg. • 4 9 ; Kangding, Paomashan; $30^{\circ} 02^{\prime} 41^{\prime \prime} \mathrm{N}, 101^{\circ} 57^{\prime} 40^{\prime \prime} \mathrm{E} ; 2600 \mathrm{~m}$ a.s.1.; 27

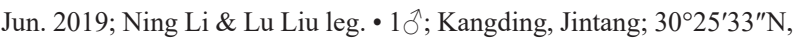
$102^{\circ} 17^{\prime} 03^{\prime \prime E}$; 2200 m a.s.1.; 5 Jul. 2019; Ning Li leg.
}

Measurements. Male: $\mathrm{FL}=12.1-13.1 \mathrm{~mm}, \mathrm{FW}=2.9-3.2$ $\mathrm{mm} ; \mathrm{HL}=11.1-12.2 \mathrm{~mm}, \mathrm{HW}=2.8-3.0 \mathrm{~mm}$. Female: $\mathrm{FL}=12.3-13.9 \mathrm{~mm}, \mathrm{FW}=3.0-3.3 \mathrm{~mm} ; \mathrm{HL}=11.3-13.1$ $\mathrm{mm}, \mathrm{HW}=2.8-3.2 \mathrm{~mm}$.

Distribution. China: Sichuan.

Remarks. This species resembles $P$. jinchuana, but is different from the latter by the posterior arms half (cf. onethird) length of the main plate.

\section{Panorpa uncinata sp. nov.}

Fig. 22

Diagnosis. The new species can be recognized by the following features: (1) forewing with broad apical band occasionally bearing two inner hyaline spots; pterostigmal band with broad basal branch and thin apical branch; marginal spot narrow or reduced; basal band broad; basal spots extremely reduced and faint (Fig. 22A-B); (2) meso- and metanotum black, with narrow yellow brown mesal stripe (Fig. 22A-B); (3) gonocoxites with approximately four stout setae on inner apex ventrally (Fig. 22F); (4) paramere intensively curved, hook-like on apical half, reaching two-thirds of gonocoxite (Fig. 22G); (5) main plate of medigynium broad; a pair of lateral basal plates extended from base to middle of main plate; extended beyond main plate for half of its length anteriorly (Fig. $22 \mathrm{~K}-\mathrm{L}$ ).

Etymology. The specific name is derived from the Latin uncinata (hooked), referring to the hooked parameres.

Material examined. Holotype: CHINA - Shanxi Prov. • $\delta$; Yuncheng, Shunwangping; 2000 m a.s.1.; 30 Jun. 2019; Kai Gao leg. Paratypes: CHINA - Shanxi Prov. • $1 q$; same data as for holotype. $・ 1 \hat{\jmath}, 2 q \circ$; Linfen, Anziping Forest Farm; 1800 m a.s.1.; 1 Jul. 2019; Kai Gao leg.

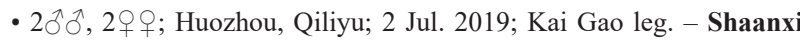
Prov. • 19; Ankang, Zhenping; 18 Aug. 2018; Lin Lyu leg. - Henan Prov. $\cdot 2 \hat{\jmath}$; Jiyuan, Wangwushan; $1700 \mathrm{~m}$ a.s.1.; 29 May 2019; Kai Gao leg. - Hubei Prov. • 1ð̋; Shennongjia, Yemahe; $1600 \mathrm{~m}$ a.s.1.; 29 Jul. 2016; Ji-Shen Wang leg. • 1ð̊; Badong, Tiechanghuang; 8 Jun. 2016; Ji-Shen Wang leg.

Measurements. Male: $\mathrm{FL}=12.1-12.9 \mathrm{~mm}, \mathrm{FW}=3.2-3.4$ $\mathrm{mm} ; \mathrm{HL}=10.9-11.5 \mathrm{~mm}, \mathrm{HW}=3.1-3.3 \mathrm{~mm}$. Female: $\mathrm{FL}=12.1-13.6 \mathrm{~mm}, \mathrm{FW}=3.1-3.4 \mathrm{~mm} ; \mathrm{HL}=11.0-12.3$ $\mathrm{mm}, \mathrm{HW}=2.9-3.2 \mathrm{~mm}$.

Description. Male: Head (Fig. 22A, C): Frons, vertex and occiput yellowish brown. Black band through ocellar triangle not extending to compound eyes. Rostrum yellow, with labrum dark brown. Maxillary and labial palps mostly brown, with distal segments dark brown. Antennal scape yellowish brown basally and dark brown apically; flagellum dark brown, filiform, with 33-38 flagellomeres. Thorax (Fig. 22A, D): Pronotum black, with 10-12 stout setae along anterior margin. Meso- and metanotum black, with narrower yellow brown mesal stripe; scutella yellow brown. Pleura pale yellow. Legs light yellowish brown, with distal tarsomere blackish. Wings (Fig. 22A): Membrane hyaline, with markings dark brown. Forewing with apical band broad, bearing one or two hyaline spots, smaller one between $\mathrm{R}_{2 \mathrm{~b}}$ and $\mathrm{R}_{3}$, and larger one between $\mathrm{R}_{5}$ and $\mathrm{M}_{2}$; pterostigmal band complete, with basal branch approximately twice as wide as apical branch; marginal spot variable: slender; split into two spots, not extended to $\mathrm{M}$; or greatly reduced in some individuals; basal band broad; basal spots greatly reduced. Hindwing similar to forewing in coloration and pattern, but with 


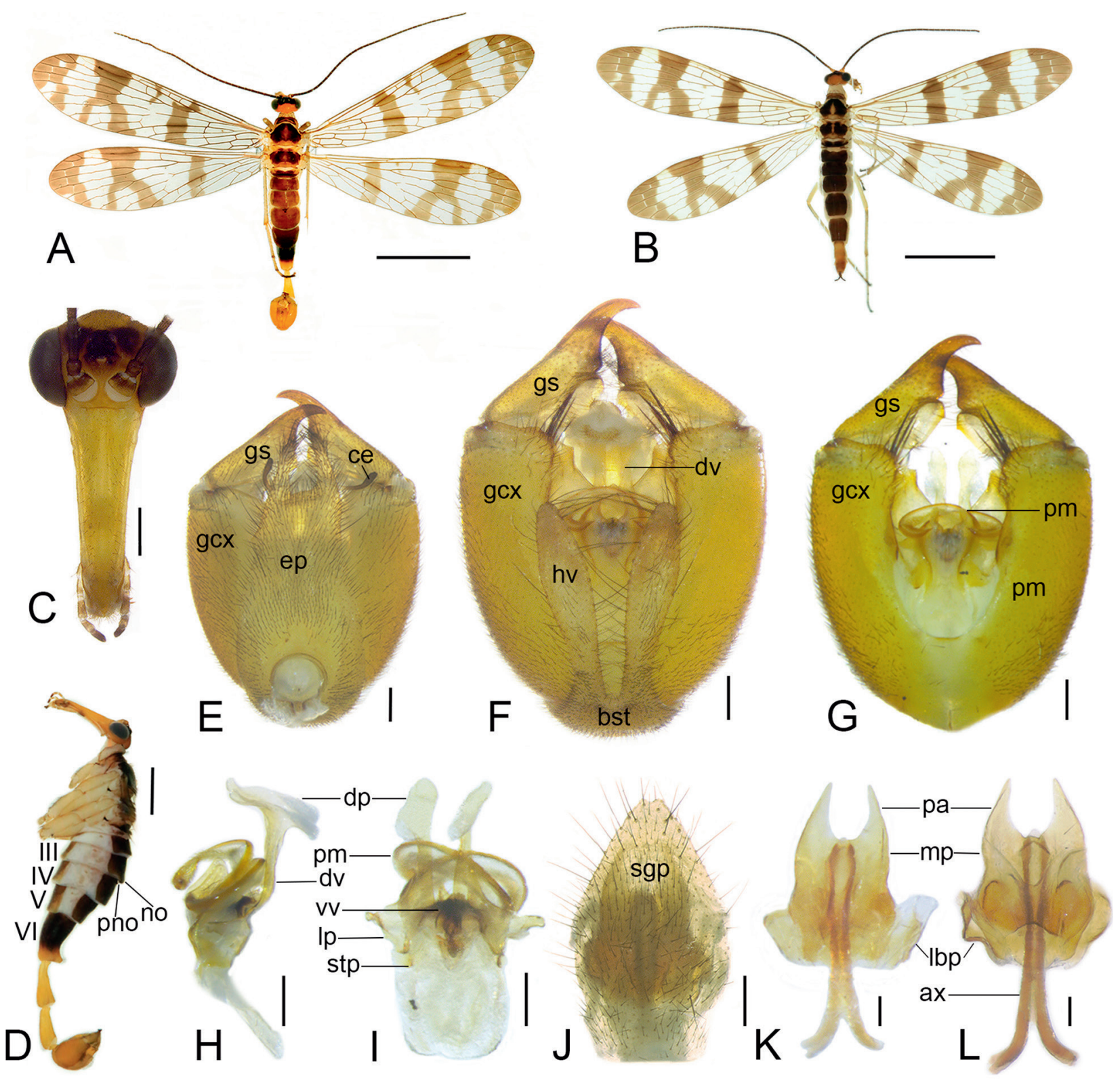

Figure 22. Panorpa uncinata sp. nov. from Yuncheng (A) and Huozhou (B-L), Shanxi. A, C-I. Male. A. Habitus, dorsal view. C. Head, frontal view. D. Habitus, lateral view. E-G. Genital bulb, dorsal, ventral, and ventral (removing hypandrium) views. H-I. Aedeagal complex, lateral and ventral views. B, J-L. Female. B. Habitus, dorsal view. J. Subgenital plate, ventral view. K-L. Medigynium, ventral and dorsal views. Scale bars: $A-B=5 \mathrm{~mm} ; C=0.5 \mathrm{~mm} ; \mathrm{D}=2 \mathrm{~mm}$; $\mathrm{E}-\mathrm{L}=0.2 \mathrm{~mm}$.

marginal and basal spots much reduced, apical band usually bearing one hyaline spot in posterior portion. Abdomen (Fig. 22A, D): T2-T5 black brown to black. Notal organ of T3 flat triangular, covering acute postnotal organ on T4. A6 with basal two-thirds black, distal third yellow, projected and setose on dorsal apex. A7 and A8 uniformly yellow, slightly constricted basally. Genitalia (Fig. 22E-I): Genital bulb elliptical, yellow. Epandrium broad, with deep terminal emargination, bearing numerous setae. Cercus clavate, yellow brown basally and dark brown distally. Hypandrium with shortened basal stalk and pair of hypovalves; hypovalves broad, with basal half narrower, extending to three-quarters length of gonocoxites, bearing row of long bristles along inner margin. Gonocoxite mostly with four stout setae on inner apex ventrally. Gonostylus with obtuse triangular median tooth and large basal cup. Parameres slender, crossed mesally, intensively curved, hook-like, reaching two-thirds length of gonocoxites. Dorsal valves of aedeagus elongate, each with enlarged dorsal process on subapical portion dorsally. Ventral valves shortened. Lateral processes distinct, triangular. - Female: Similar to male in wing markings (Fig. 22B). Genitalia (Fig. 22J-L): Subgenital plate ligulate, narrow basally, broadest medially, and narrowed towards apex, with shallow V-shaped terminal emargination, bearing long setae on caudal and lateral margins. Medigynium with well-developed broad main plate. Pair of lateral basal plates extended from base to middle of main plate. Posterior arm one-third length of main plate, forming broad U-shaped emargination. Axis bifurcated, elongated, extended anteriorly beyond main plate for half of its length, with posterior slightly extruded. 
Distribution. China: Henan, Hubei, Shaanxi, Shanxi.

Remarks. This new species resembles $P$. yangi, especially in the intensively curved, hook-like parameres, but can be readily differentiated from the latter by: (1) meso- and metanotum black, bearing a narrow (cf. very broad) yellow mesal stripe; (2) basal spots extremely reduced and faint (cf. large and distinct).

\section{Panorpa yangi Chou, 1981}

Panorpa yangi Chou in Chou et al., 1981: 8, figs 24-27. Type locality: Qingquangou, Ganquan, Shaanxi, China; Wang \& Hua, 2018: 420, figs 5-161-1-5-161-2.

Diagnosis. This species can be recognized from by the following features: (1) forewing with broad apical band bearing one hyaline spot posteriorly; pterostigmal and basal bands complete, broad; marginal and basal spots large, conspicuous (2) meso- and metanotum mostly yellowish brown and anterior margin blackish brown laterally; in males, (3) ventral termination of gonocoxites wavy, bearing 3-6 long setae on inner portion; (4) parameres very slender, intensively curved, hook-like on apical halves, reaching two-thirds length of gonocoxites; in females, (5) main plate of medigynium approximately rectangular, twice as long as wide; a pair of simple lateral basal plates extending from base to middle of main plate; axis extended beyond main plate for two-thirds of its length anteriorly.

Material examined. CHINA - Shaanxi Prov. • $1 ð$ (Holotype); Ganquan, Qingquangou;13 Aug. 1971; Chi-Kun Yang leg.; • $2 \hat{\jmath} \widehat{o}$ (Paratypes); same data as holotype $-5 \hat{\jmath} \hat{\jmath}, 2+q$; Shibao Forest Farm, Dayuangou; 1433 m a.s.1.; 5 Aug. 2016; Kai Gao \& Shi-Xiang Jiang leg. • 19; Qigan Temple; 3544'59"N, 109 53'33"E; 1622 m a.s.1.; 4

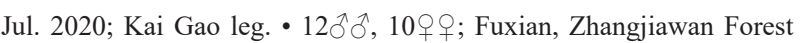
Farm; 36³'36"N, 108 51'25"E; 1027 m a.s.1.; 28 Jul. 2016; Kai Gao \& Shi-Xiang Jiang leg. $\bullet 4 \hat{\jmath} \widehat{\jmath}, 11$ 우; Niuwu Forest Farm, Shaowan Reservoir; 36 5'17"N, 109 30'02"E; 1042-1078 m a.s.1.; 1 Aug 2016; Kai Gao \& Shi-Xiang Jiang leg. • 1 $\jmath^{\Uparrow}$; Xunyi, Shimen, Liangjiawan; 35॰3'43"N, 108 32'16"E; 1520 m a.s.1.; 3 Jul. 2019; Meng-Di Li leg. • $3 \widehat{\jmath} \widehat{\jmath}, 4$ 우; Ziwuling; 1-4 Jul. 2019; Jian Shen leg.

Measurements. Male: $\mathrm{FL}=9.4-10.6 \mathrm{~mm}, \mathrm{FW}=2.4-2.6$ $\mathrm{mm}$; HL $=8.4-9.5 \mathrm{~mm}, \mathrm{HW}=2.3-2.5 \mathrm{~mm}$. Female: FL $=9.6-11.5 \mathrm{~mm}, \mathrm{FW}=2.5-2.8 \mathrm{~mm} ; \mathrm{HL}=8.7-10.5 \mathrm{~mm}$, $\mathrm{HW}=2.4-2.7 \mathrm{~mm}$.

\section{Distribution. China: Shaanxi.}

Remarks. This species resembles $P$. neospinosa in wing markings, but can be differentiated from the latter by meso- and metanotum mostly yellowish brown (cf. blackish brown with pale yellow mesal stripe) and hook-like (cf. S-shaped) parameres.

\section{Panorpa yaoluopingensis sp. nov.}

Fig. 23

Diagnosis. This species can be readily recognized by the following characters: (1) forewing with apical band broad, bearing large hyaline spot on posterior margin; pterostigmal band with basal branch broad, and apical branch greatly reduced; basal band reduced into large spot near anal margin; marginal spot absent or as 1-3 small spots (Fig. 23A-B); (2) meso- and metanotum blackish brown, with prominent pale yellow mesal stripe (Fig. 23A-B); in males, (3) inner apex of gonocoxites oblique, with 6-8 dark brown setae (Fig. 23E); (4) parameres twisted in S-shape, crossed mesally (Fig. 23E-F); in females, (5) medigynium with broad main plate and pair of lateral basal plates on middle portion; posterior arms one-third as long as main plate, axis extended beyond main plate for half of its length, with posterior slightly extruded (Fig. 23J-K).

Etymology. The specific name refers to the type locality, Yaoluoping, Yuexi, Anhui.

Material examined. Holotype: CHINA - Anhui Prov. • §’; Yuexi, Yaoluoping National Nature Reserve; 18 Aug. 2013; Qiu-Lei Men leg. Paratypes: CHINA - Anhui Prov. $\bullet 3 \hat{\partial} \hat{\jmath}, 5 \circ \propto+$; same data as holotype.

Measurements. Male: $\mathrm{FL}=11.4-12.0 \mathrm{~mm}, \mathrm{FW}=2.9-3.1$ $\mathrm{mm} ; \mathrm{HL}=10.3-11.2 \mathrm{~mm}, \mathrm{HW}=2.8-3.0 \mathrm{~mm}$. Female: $\mathrm{FL}=11.3-12.1 \mathrm{~mm}, \mathrm{FW}=3.1-3.2 \mathrm{~mm} ; \mathrm{HL}=10.1-11.1$ $\mathrm{mm}, \mathrm{HW}=3.0-3.1 \mathrm{~mm}$.

Description. Male: Head (Fig. 23A, C): Frons, ocellar triangle, vertex and occiput dark blown. Rostrum yellowish; labrum yellowish brown. Labial and maxillary palps yellowish basally, gradually darkening toward apex, with apical segment dark brown. Antennal scape yellowish brown; flagellum brownish black, filiform with 39-42 flagellomeres. Thorax (Fig. 23A, D): Pronotum dark brown, with 10-14 black setae along anterior margin; meso- and metanotum dark brown, with pale yellow fusiform mesal stripe; scutella pale yellow. Pleura yellow. Legs yellowish brown, with distal tarsomere dark brown. Wings (Fig. 23A): Membrane hyaline, with brown markings. Forewing with apical band broad, bearing large hyaline spot on posterior margin; pterostigmal band with basal branch broad and apical branch greatly reduced; marginal spot absent or divided into 1-3 small spots; basal band reduced into large spot from $M$ to anal margin; basal spot absent. Hindwing similar to forewing, but with relatively reduced markings. Marginal spot absent or faint; basal band smaller, usually not reaching anal margin. Abdomen (Fig. 23A, D): T2-T5 dark to black brown. Notal organ of T3 flat, covering acute postnotal organ on T4. A6 dark brown on basal two-thirds and yellow distally, projected on dorsal apex, with sparse long yellow setae. A7 and A8 elongate, uniformly yellow, constricted basally. Genitalia (Fig. 23E-G): Genital bulb oval, yellow. Epandrium broad basally, with square, 


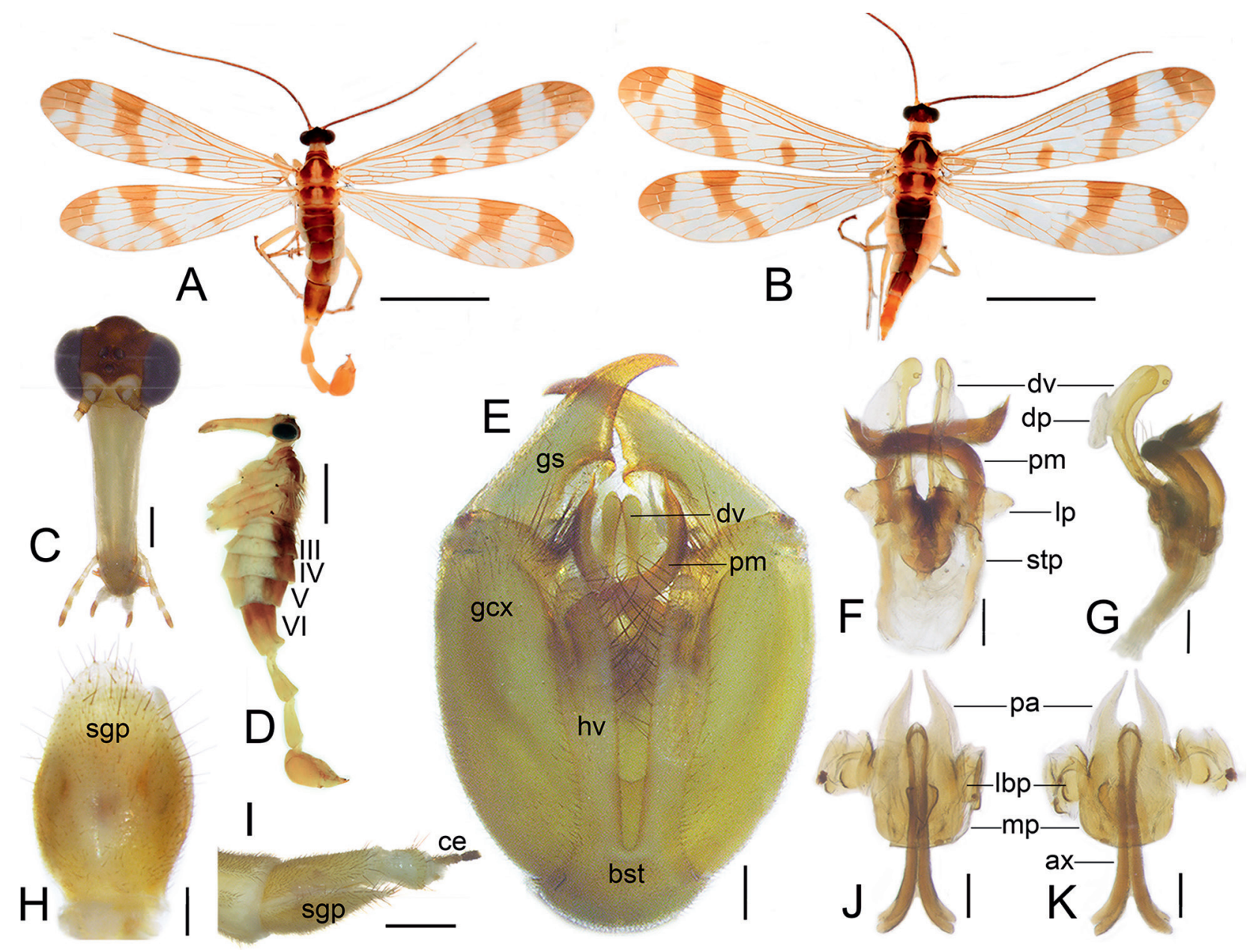

Figure 23. Panorpa yaoluopingensis sp. nov. from Yuexi, Anhui. A, C-G. Male. A. Habitus, dorsal view. C. Head, frontal view. D. Habitus, lateral view. E. Genital bulb, ventral views. F-G. Aedeagal complex, dorsal and lateral views. B, H-K. Female. B. Habitus, dorsal view. H-I. Subgenital plate, ventral and lateral views. J-K. Medigynium, ventral and dorsal views. Scale bars: A-B = $5 \mathrm{~mm}$; $\mathrm{C}, \mathrm{I}=0.5 \mathrm{~mm} ; \mathrm{D}=2 \mathrm{~mm}$; E-H, J-K = $0.2 \mathrm{~mm}$.

deep terminal emargination, bearing dense setae distally. Cercus long clavate, slightly expanded towards apex. Hypandrium with shortened basal stalk, with pair of long strip-like hypovalves; each hypovalve rounded at apex, bearing long bristles along apical half on inner margin, not reaching apex of gonocoxites. Inner margin of gonocoxite oblique apically, with 6-8 stout setae. Gonostylus with large basal cup and obtuse triangular median tooth on inner margin. Parameres twisted in S-shape, crossed mesally, bearing dense short spines on inner margin and whole distal portion, with apex pointed. Aedeagus with ventral valves greatly shortened; dorsal valves greatly elongated, strongly curved dorsally, constricted basally and expanded towards rounded apex; bearing bundle of long hairs ventrally on basal third and enlarged dorsal process near middle. Lateral process distinctly triangular. - Female: Similar to male in wing patterns (Fig. 23B). Genitalia (Fig. 23H-K): Subgenital plate broad subbasally, narrowed towards apex, bearing long setae on caudal and lateral margins. Medigynium with broad main plate, pair of lateral basal plates on middle portion; posterior arms one-third as long as length of main plate, forming "water drop"-shaped emargination; axis with pair of small sclerotized structures near central position of main plate, extended beyond main plate for approximately half of its length, with posterior slightly extruded.

\section{Distribution. China: Anhui.}

Remarks. This new species resembles $P$. huayuani and $P$. sexspinosa in general appearance, but can be readily differentiated from the latter two species by the following characters: (1) wing markings with basal band reduced into a large spot extending from $\mathrm{M}$ to anal margin in forewing (cf. complete); (2) occiput dark brown (cf. yellowish brown).

\section{Phylogenetic analyses}

Maximum parsimony analysis yielded eight most parsimonious trees, with tree length of 128 , consistency index (CI) of 0.70 and retention index (RI) of 0.88 . The strict consensus tree is shown in Figure 24 with bootstrap values and characters annotated. The monophyly of the newly defined $P$. davidi group is well supported (MPBS 


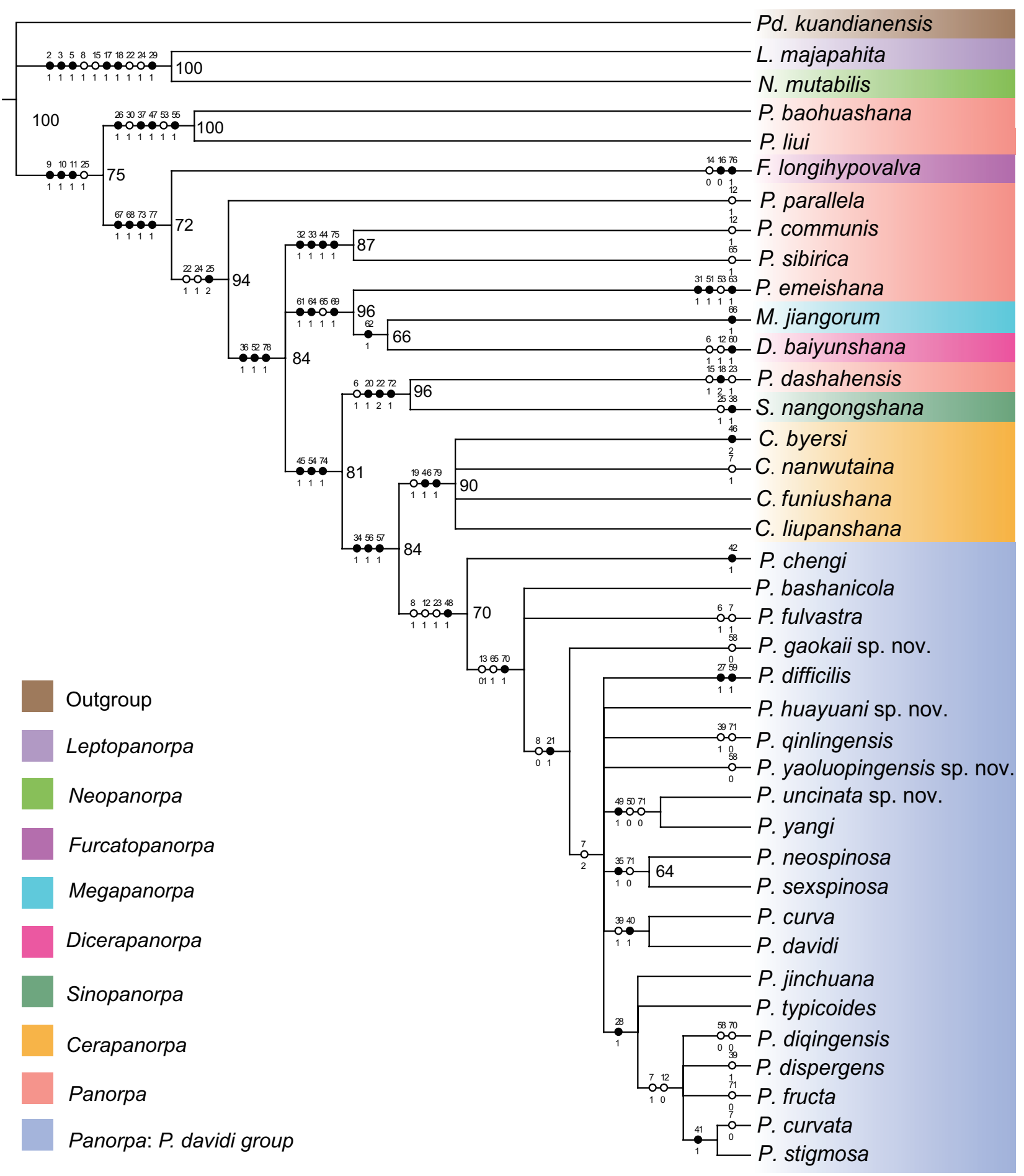

Figure 24. Strict consensus tree obtained from most parsimony (MP) analysis. MP bootstrap values (MPBS $>50)$ are indicated at internal nodes.

$=70$ ) by three homoplasies (characters: 8:1, 12:1, 23:1) and one synapomorphy (char. 48:1) (Fig. 24). The sister group relationship between the $P$. davidi group and Cerapanorpa is well supported (MPBS $=84$ ) by three synapomorphies (characters: $34: 1,56: 1$, and 57:1). The relationships among species of the $P$. davidi group are usually weakly supported (MPBS $<50$ ) in the MP analysis. Panorpa chengi is the sister taxon to other species of the $P$. davidi group. Panorpa fulvastra and $P$. bashanicola occupy the more basal lineages. One monophyletic clade consists of all four species from Yunnan and Guizhou, $P$. diqingensis, $P$. dispergens, $P$. stigmosa, $P$. curvata; and three species from Sichuan, P. fructa, P. typicoide, and $P$. jinchuana (Fig. 24).

The phylogenetic trees are similar in topology between the MP and ML analyses, although the ML tree (Fig. 25) has higher support values than the strict consensus tree of the MP trees. The ML tree shows that the P. davidi group is a well-supported monophyletic group (MLBS =94) and is sister to Cerapanorpa (MLBS = 95). The incongruence between the analyses is restricted to the relationship of some species of the $P$. davidi group. 


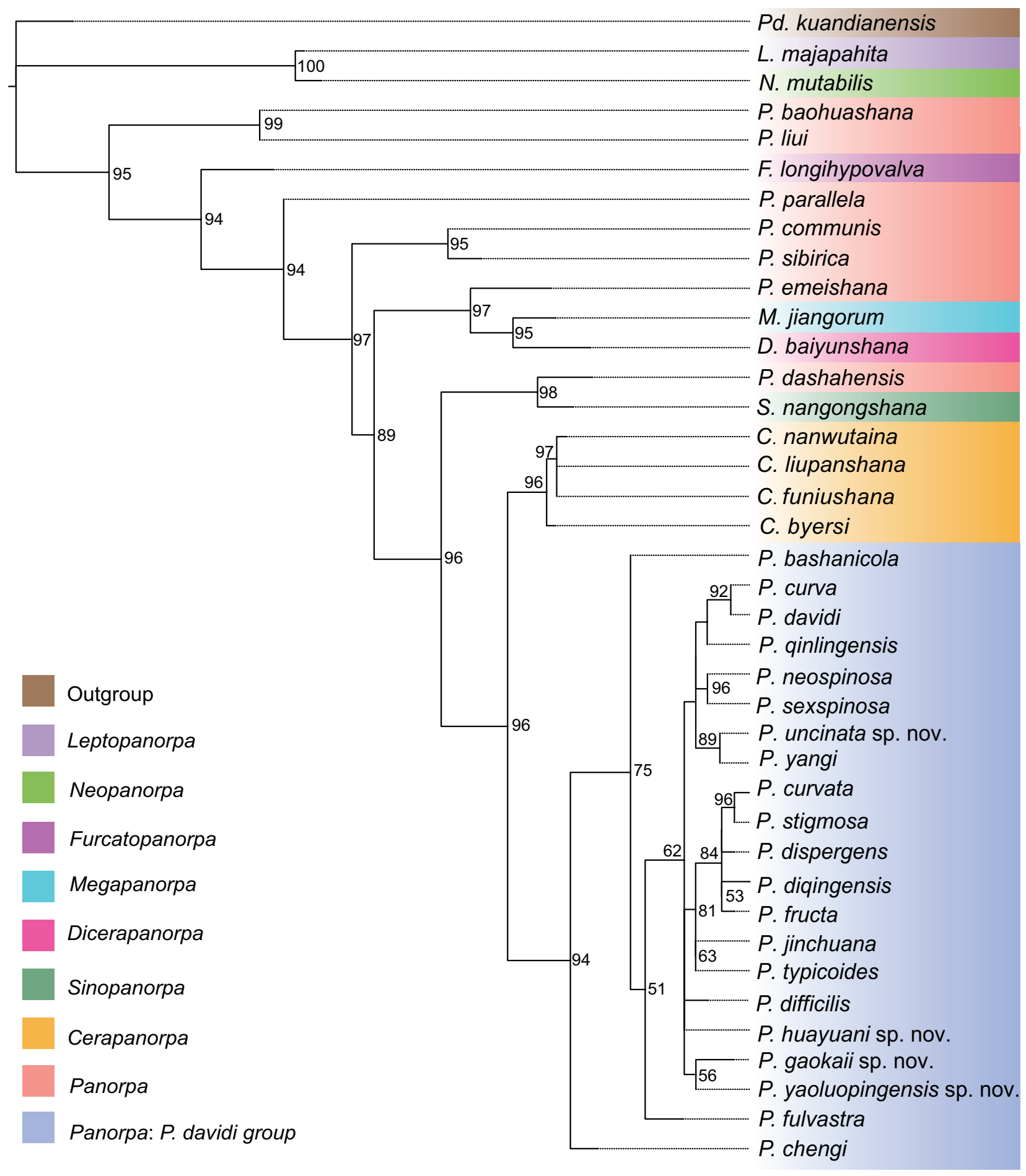

Figure 25. Phylogenetic tree obtained from maximum likelihood (ML) analysis. ML bootstrap values (MLBS $>50)$ are indicated at internal nodes.

Based on the cladograms, Sinopanorpa Cai \& Hua, Furcatopanorpa Ma \& Hua, Dicerapanorpa Zhong \& Hua, Cerapanorpa Gao, Ma \& Hua, and Megapanorpa Wang \& Hua are all nested within Panorpa Linneaus (Figs 24-25). The Chinese species of Panorpa without anal horn in males were previously treated as the $P$. davidi group, which is here reconfirmed to be paraphyletic, since they are scattered on the phylogenetic tree of the Panorpidae (Figs 24-25). Panorpa sibirica and $P$. communis are well-supported sister taxa, distant from the newly defined P. davidi group.

\section{Discussion}

In the present study, phylogenetic reconstruction was conducted for all the eight genera of Panorpidae based on 79 morphological characters. The $P$. davidi group sensu Carpenter $(1938)$ and Cheng $(1949,1957)$ is reconfirmed to be a paraphyletic group. Panorpa davidi and 20 species are clustered into a well-supported monophyletic clade, sister group to Cerapanorpa. In the present study we newly defined the $P$. davidi group based on morphol- 
ogy and phylogeny. Four new species are described and two synonyms are proposed. Consequently, 21 species are currently recognized in the $P$. davidi group.

In a morphological phylogenetic analysis, Ma et al. (2012) found that three species of the $P$. davidi group ( $P$. chengi, $P$. fulvastra, and $P$. sexspinosa) did not form a monophyletic group, possibly owing to insufficient characters encoded. In contrast molecular phylogenetic analyses by $\mathrm{Hu}$ et al. (2015) and Miao et al. (2019) found six species of this group formed a monophyletic group. Based on our present phylogenetic study, the monophyly of the newly defined $P$. davidi group is confirmed.

Previously, the $P$. davidi group sensu Carpenter (1938) and Cheng $(1949,1957)$ consisted of the Chinese species that lack the anal horn in males. Herein, however, we assign only 21 species to the $P$. davidi group. These species share a similar morphology, especially the male and female genitalia. According to recent phylogenetic analyses (Hu et al. 2015; Miao et al. 2017, 2019; Jiang et al. 2019; Wang and Hua 2020), this new definition of the $P$. davidi group constitutes a well-supported monophyletic group, sister to Cerapanorpa.

The species of the $P$. davidi group are normally found in the groundcover of moist forests in mountainous regions, with a broad spectrum of elevations. Panorpa difficilis inhabits ranges from 230 to $2050 \mathrm{~m}$ in elevation, whereas $P$. fructa is found only at high-altitude from 3300 to $4000 \mathrm{~m}$ in the Hengduan Mountains, exhibiting strong cold-adaptation. The $P$. davidi group not only exhibits a discrete distribution in the Taihang and Dabie Mountains, but also displays a circular distribution pattern around the Sichuan Basin, similar to that of Dicerapanorpa (Hu and Hua 2020). It would be a fascinating issue to explore the distribution pattern and mechanism in future research.

\section{Acknowledgements}

We are grateful to Kai Gao for comments on the early draft of the manuscript; Kai Gao, Xin Tong, Lu Liu, Lu-Yao Yang, and Le-Le He for providing pictures of live adult habitus and habitats. We also thank Jian-Yue Qiu, Hao Xu, Qiu-Lei Men, and Jian Shen for donating specimens. We also thank the two anonymous reviewers for valuable comments and suggestions to the revision of the manuscript. This research was supported by the National Natural Science Foundation of China (Grant number 31172125).

\section{References}

Bremer K (1994) Branch support and tree stability. Cladistics 10: 295304. https://doi.org/10.1006/clad.1994.1019

Byers GW (1993) Autumnal Mecoptera of southeastern United States. University of Kansas Science Bulletin 55: 57-96.

Byers GW, Thornhill R (1983) Biology of the Mecoptera. Annual Review of Entomology 28: 203-228. https://doi.org/10.1146/annurev. en.28.010183.001223

Cai LJ, Hua BZ (2009) Morphology of the immature stages of Panorpa qinlingensis (Mecoptera: Panorpidae) with notes on its biology. Entomologica Fennica 20: 215-224. https://doi.org/10.33338/ef.84480
Cai LJ, Huang PY, Hua BZ (2008) Sinopanorpa, a new genus of Panorpidae (Mecoptera) from the Oriental China with descriptions of two new species. Zootaxa 1941: 43-54. https://doi.org/10.11646/zootaxa.1941.1.4

Carpenter FM (1931) Revision of the Nearctic Mecoptera. Bulletin of the Museum of Comparative Zoology 72: 205-277.

Carpenter FM (1938) Mecoptera from China, with descriptions of new species. Proceedings of the Entomological Society of Washington 40: $267-281$.

Cheng FY (1949) New species of Mecoptera from northwest China. Psyche 56: 139-173.

Cheng FY (1957) Revision of the Chinese Mecoptera. Bulletin of the Museum of Comparative Zoology 116: 1-117.

Chou I, Ran RB, Wang SM (1981) Studies on the classification of Chinese Mecoptera (I, II). Entomotaxonomia 3: 1-18.

Esben-Petersen P (1921) Mecoptera. Monographic revision: Collections zoologiques du Baron Edm. de Selys Longchamps. Catalogue systematique et descriptif 5: 1-172.

Felsenstein J (1985) Phylogenies and the comparative method. The American Naturalist 125: 1-15. https://doi.org/10.1086/284325

Gao K, Hua BZ (2019) Revision of the genus Cerapanorpa (Mecoptera: Panorpidae) with descriptions of four new species. European Journal of Taxonomy 537: 1-23. https://doi.org/10.5852/ejt.2019.537

Gao C, Ma N, Hua BZ (2016) Cerapanorpa, a new genus of Panorpidae (Insecta: Mecoptera) with descriptions of three new species. Zootaxa 4158: 93-104.

Goloboff PA, Farris JS, Nixon KC (2008) TNT, a free program for phylogenetic analysis. Cladistics 24: 774-786. https://doi.org/10.1111/ j.1096-0031.2008.00217.x

Hu GL, Hua BZ (2020) Review of the scorpionfly genus Dicerapanorpa Zhong \& Hua (Mecoptera: Panorpidae), with descriptions of two new species. European Journal of Taxonomy 711: 1-13. https://doi. org/10.5852/ejt.2020.711

Hu GL, Yan G, Xu H, Hua BZ (2015) Molecular phylogeny of Panorpidae (Insecta: Mecoptera) based on mitochondrial and nuclear genes. Molecular Phylogenetics and Evolution 85: 22-31. https:// doi.org/10.1016/j.ympev.2015.01.009

Hua BZ, Sun GH, Li ML (2001) Sichuan Panorpidae (Mecoptera) kept in the Tianjin Natural History Museum. Entomotaxonomia 23: 120-123.

Hua Y, Tao SH, Hua BZ (2018) An enigmatic new species of Panorpa Linneaus from the Bashan Mountains (Mecoptera, Panorpidae). ZooKeys 777: 109-118. https://doi.org/10.3897/zookeys.777.26056

Issiki S (1933) Morphological studies on the Panorpidae of Japan and adjoining countries and comparison with American and European forms. Japanese Journal of Zoology 4: 315-416.

Jiang L, Hua BZ (2013) Morphology and chaetotaxy of the immature stages of the scorpionfly Panorpa liui Hua (Mecoptera: Panorpidae) with notes on its biology. Journal of Natural History 47: 41-42. https://doi.org/10.1080/00222933.2013.791885

Jiang L, Hua BZ (2016) Morphology of the immature stages of Panorpa macrostyla Hua (Mecoptera: Panorpidae) with notes on its biology. Acta Entomologica Sinica 59: 1004-1012. https://doi.org/ 10.16380/j.kcxb.2016.09.011

Jiang L, Hua Y, Hu GL, Hua BZ (2019) Habitat divergence shapes the morphological diversity of larval insects: insights from scorpionflies. Scientific Reports 9: 12708. https://doi.org/10.1038/s41598019-49211-z

Li N, Hua BZ (2020) Two new species of Panorpa (Mecoptera, Panorpidae) from the Hengduan Mountains in Yunnan, China. Journal of 
Asia-Pacific Entomology 23: 138-145. https://doi.org/10.1016/j. aspen.2019.12.005

Linnaeus C (1758) Systema Naturae. Per regna tria naturae, secundum classes, ordines, genera, species, cum characteribus, differentiis, synonymis, locis. Tomus I. Editio decima, reformata. Holmiæ, Laurentius Salvius, pp. 1-824. https://doi.org/10.5962/bhl.title.542

Ma N, Cai LJ, Hua BZ (2009) Comparative morphology of the eggs in some Panorpidae (Mecoptera) and their systematic implication. Systematics and Biodiversity 7: 403-417. https://doi.org/10.1017/ S1477200009990107

Ma N, Liu SY, Hua BZ (2011) Morphological diversity of male salivary glands in Panorpidae (Mecoptera). European Journal of Entomology 108: 493-499. https://doi.org/10.14411/eje.2011.064

Ma N, Zhong W, Gao QH, Hua BZ, (2012) Female genital plate diversity and phylogenetic analyses of East Asian Panorpidae (Mecoptera). Systematics and Biodiversity 10: 159-178. https://doi.org/10.1080/ 14772000.2012 .683459

Maddison WP, Maddison DR (2016). Mesquite: a modular system for evolutionary analysis. Version 3.61. http://www.mesquiteproject. org/

Martynova OM (1957) Skorpionnitzy (Mecoptera) fauny SSSR II. Semejstvo Panorpidae. Entomologischeskoe Obozreni 36: 721-747.

Miao Y, Ma N, Hua BZ (2017) Cytotaxonomy and molecular phylogeny of the genus Cerapanorpa Gao, Ma \& Hua, 2016 (Mecoptera: Panorpidae). Scientific Reports 7: 4493. https://doi.org/10.1038/ s41598-017-04926-9

Miao Y, Wang JS, Hua BZ (2019) Molecular phylogeny of the scorpionflies Panorpidae (Insecta: Mecoptera) and chromosomal evolution. Cladistics 35: 385-400. https://doi.org/10.1111/cla. 12357

Navás L (1908) Neurópteros nuevos. Memorias de la Real Academia de Ciencias y Artes de Barcelona 6: 401-423.

\section{Supplementary material}

\section{File 1}

\section{Authors: Li N, Wang JS and Hua BZ (2021)}

Data type: .doc

Explanation note: Seventy-nine morphological characters of adults were encoded.

Copyright notice: This dataset is made available under the Open Database License (http://opendatacommons.org/licenses/odbl/1.0). The Open Database License $(\mathrm{ODbL})$ is a license agreement intended to allow users to freely share, modify, and use this Dataset while maintaining this same freedom for others, provided that the original source and author(s) are credited.

Link: https://doi.org/10.3897/asp.79.e65179.suppl1
Navás L (1931) Decadas de insectos nuevos. Revista de la Real Academia de Ciencias Exactas, Fisicas y Naturales de Madrid 26: 60-86.

Nixon KC (2002) WinClada ver. 1.0000. Published by the Author, Ithaca, New York.

Wang JS, Hua BZ (2018) A color atlas of the Chinese Mecoptera. Henan Science and Technology Press, Zhengzhou, pp. 315-420.

Wang JS, Hua BZ (2020) Taxonomic revision and phylogenetic analysis of the enigmatic scorpionfly genus Leptopanorpa MacLachlan (Mecoptera: Panorpidae). Journal of Zoological Systematics and Evolutionary Research 58: 900-928. https://doi.org/10.1111/jzs.12363

Wang JS, Gao XT, Hua BZ (2019) Two new species of the genus Panorpa (Mecoptera, Panorpidae) from eastern China and a new synonym. ZooKeys 874: 149-164. https://doi.org/10.3897/zookeys.874.36314

Whiting MF (2002) Mecoptera is paraphyletic: multiple genes and phylogeny of Mecoptera and Siphonaptera. Zoologica Scripta 31: 93-104. https://doi.org/10.1046/j.0300-3256.2001.00095.x

Willmann R (1977) Zur Phylogenie der Panorpiden Europas (Insecta, Mecoptera). Zeitschrift für Zoologische Systematik und Evolutionsforschung 15: 208-231.

Willmann R (1989) Evolution und phylogenetisches System der Mecoptera (Insecta: Holometabola). Abhandlungen der Senckenbergischen Naturforschenden Gesellschaft 554: 1-153.

Zhong W, Hua BZ (2013) Dicerapanorpa, a new genus of East Asian Panorpidae (Insecta: Mecoptera: Penorpidae) with descriptions of two new species. Journal of Natural History 47: 1019-1046. https:// doi.org/10.1080/00222933.2012.752540

Zhou WB (2006) Mecoptera. In: Jin DC, Li ZZ (Eds) Insects from Chishui Suoluo Landscape. Guizhou Science and Technology Publishing House, Guiyang, pp. 273-375.

\section{File 2}

Authors: Li N, Wang JS and Hua BZ (2021)

Data type: .doc

Explanation note: Data matrix of morphological characters.

Copyright notice: This dataset is made available under the Open Database License (http://opendatacommons.org/licenses/odbl/1.0). The Open Database License $(\mathrm{ODbL})$ is a license agreement intended to allow users to freely share, modify, and use this Dataset while maintaining this same freedom for others, provided that the original source and author(s) are credited.

Link: https://doi.org/10.3897/asp.79.e65179.suppl2 